\title{
مستقبل الواجهات التكيفية : المفاهيم والتقنيات والأداء
}

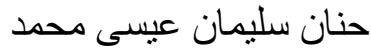 \\ مدرس بقسم الهندسة المعمارية، كلية الهندسة بالمطرية، جامعة حلوان
}

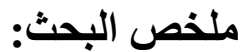

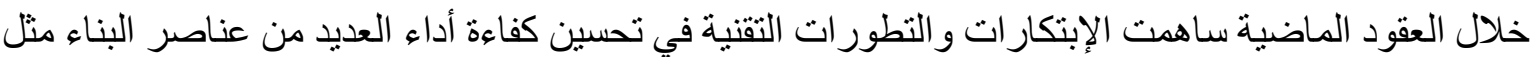

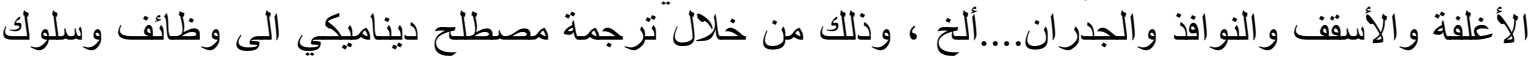

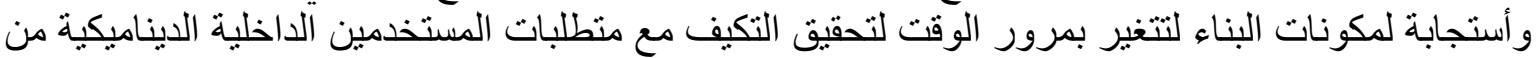

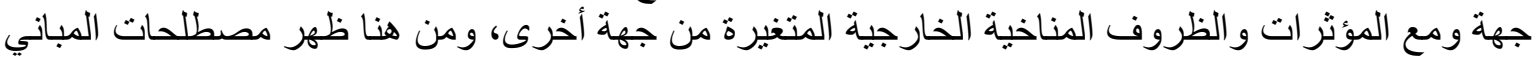
التكيفية والمستجيبة و الحركية، وتوفر واجهات المباني التكيفية تحسينات كبيرة في كفاءة إستخدام الطاقة ور احة

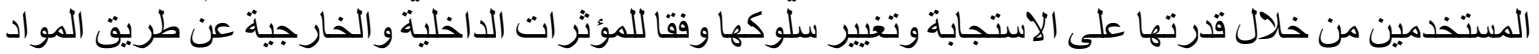

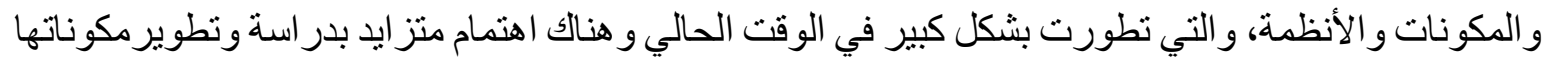

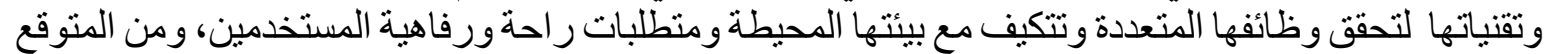
زيادة الحلول المبتكرة لها في المستقبل القريب، بالر غم من ذلك هناك فجوة معرفية ونقص في الدر اسات البحنية

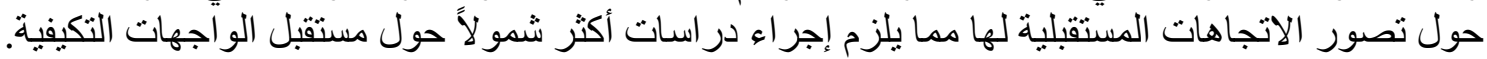
و وتقوم الدراسة بالتحقق من المفاهيم الرئيسة والإتجاهات الحالية للواجهات التكيفية ودر اسة المواد التها و المكونات

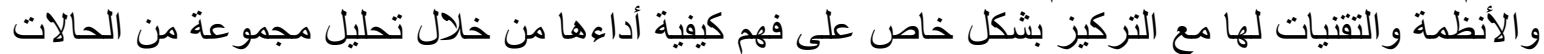

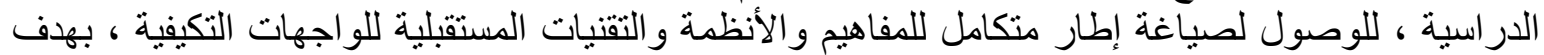
المساهمة في التطور ات المستقبلية لها وتحسين أداءها وأن تحقق كامل إمكاناتها في التكيف مع مؤثرات التهات البيئة المحيطة وتوفير الطاقة وتحسين رضات المبات المستخدمين.

الكلمات الدالة: التكيف ، الواجهات التكيفية ، المكونات ، الأداء ، أنظمة التحكم.

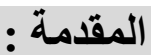

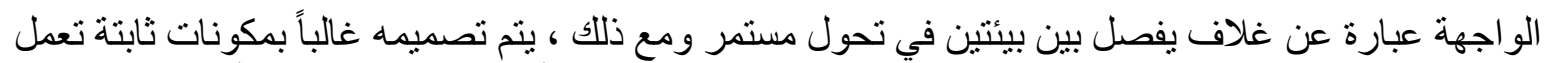

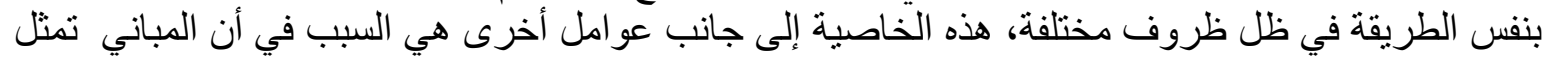

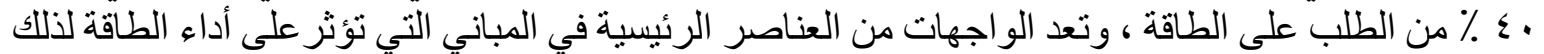

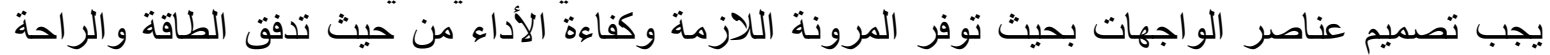

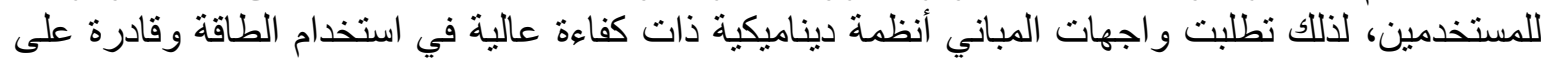

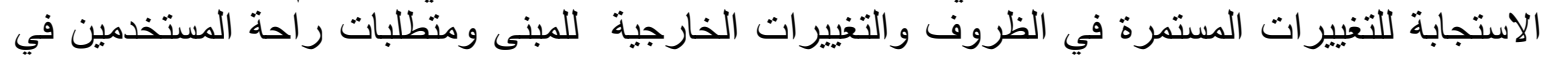

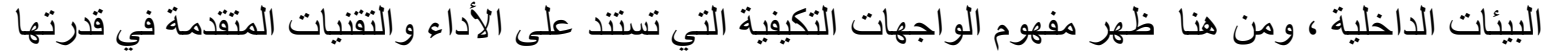
على التكيف والاستجابة الديناميكية.

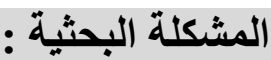

تطورت الو اجهات التكيفية بشكل كبير في الوقت الحالي و هناك اهتمام متز ايد بدر اسة وتطوير مكوناتها وتقنياتها

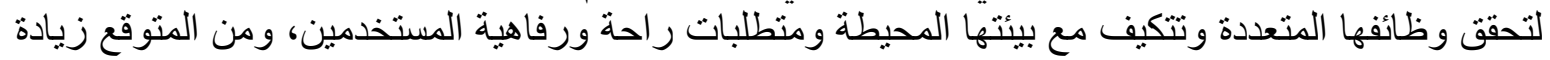

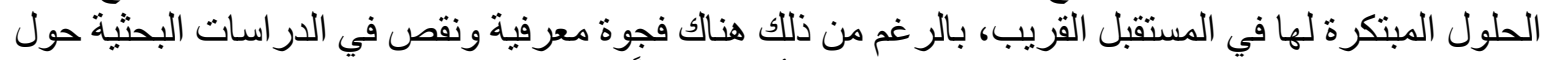

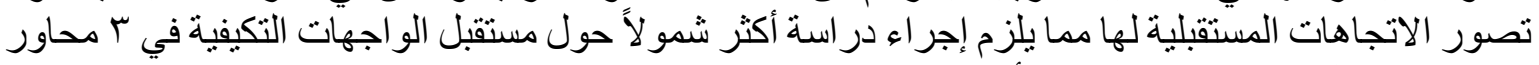
رئيسية هي (المفاهيم - التقنيات - الأداء) . 


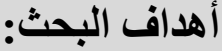

الهدف من هذه الدراسة هو التحقق من المفاهيم الرئيسة والتقنيات الحالية للواجهات التكيفية (مواد ومكونات

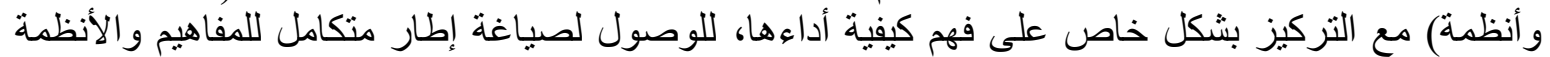
و التقنيات المستقبلية للواجهات التكيفية بهدف المساهمة في التطورات المستقبلية لها وتحسية التهين أداءها وأن أن تحقق كامل إمكاناتها في التكيف مع مؤثرات البيئة المحيطة وتوفير الطاقة وتحسين رضات الميات المستخدمين. منهجية البحث: البحة تقوم الدر اسة على ب مر احل أساسية يتم فيها استخدام المناهج التالية :

المنهج الوصفي التحليلي في التعرف على مجموعة من المفاهيم التي تتعلق بالواجهات التكيفية

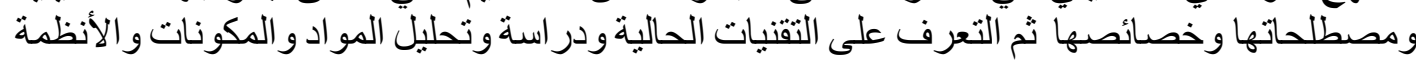

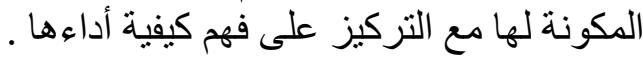

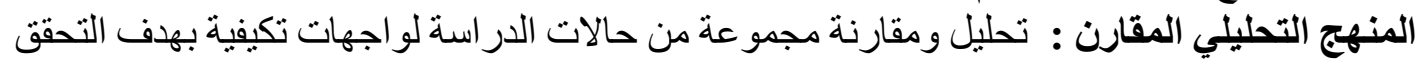

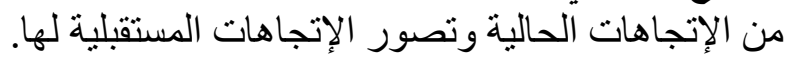
المنهج الاستنباطي: في الوصول لصياغة إطار متكامل للمفاهيم والأنظمة والتقنيات المستقبلية ل اللواجهات التكيفية.

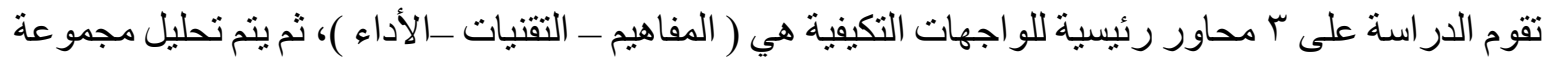
من الحالات الدر اسية لو اجهات تكيفية حديثة حالية ، للوصول لصياغة الصاتة إطار متكامل للمفاهيم و الأنظمة و التقنيات

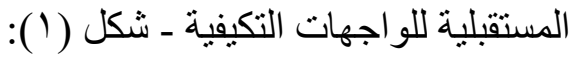

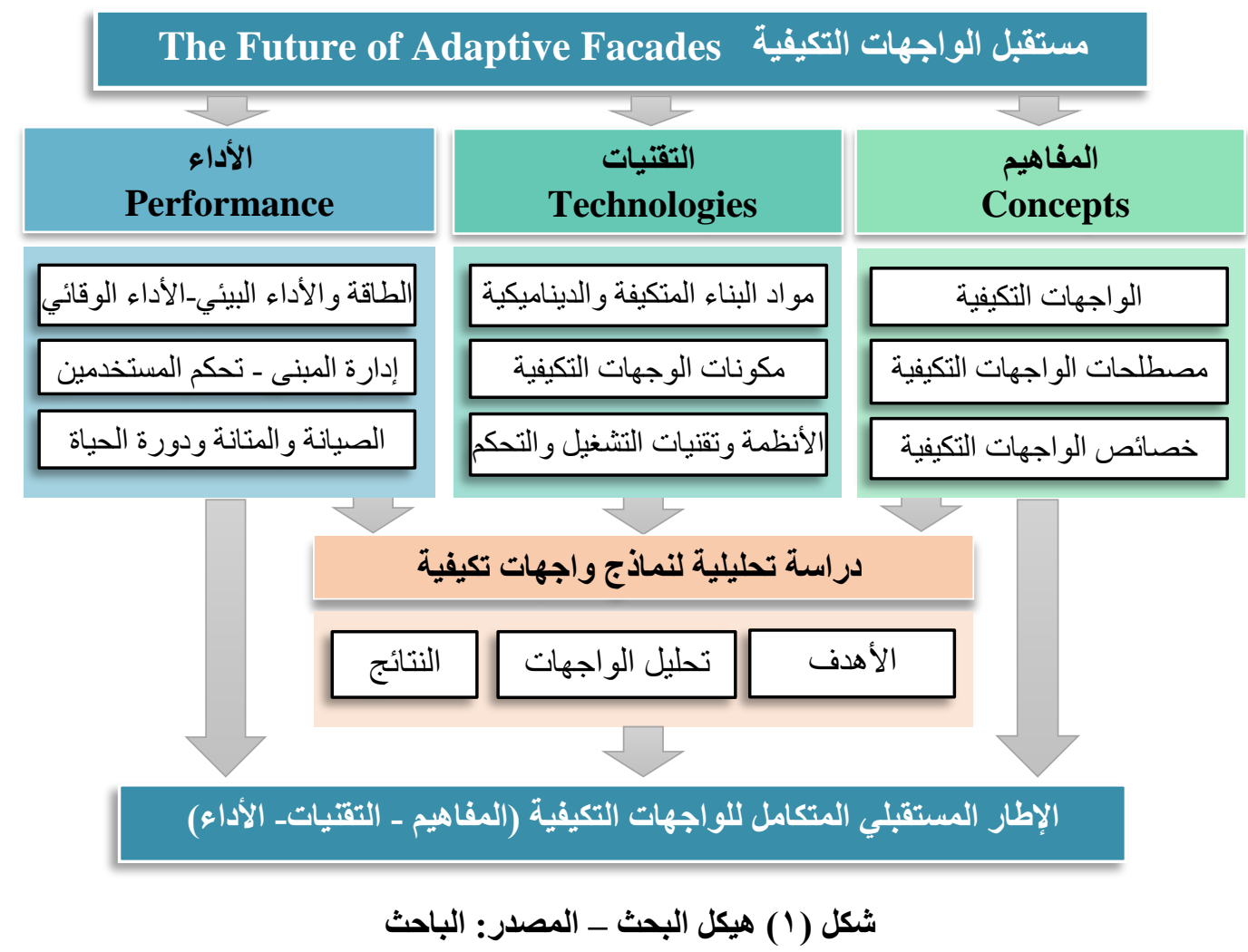




\section{1. مفاهيم المباني والواجهات التكيفية.}

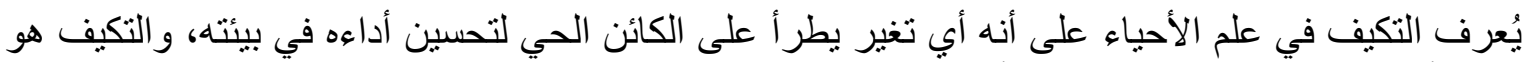

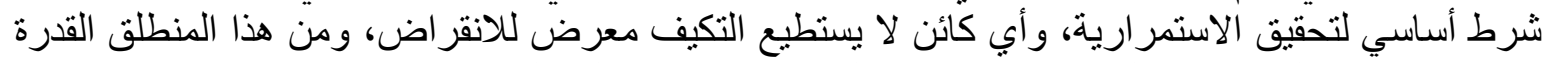

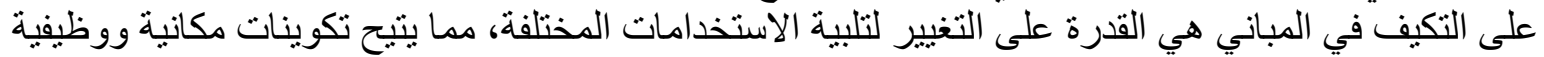
مختلفة وتحديث التقنيات دون الحاجة إلى تعطل كبير في المبنى والأنشطة الجارية والبيئة، و على هذا الأساس

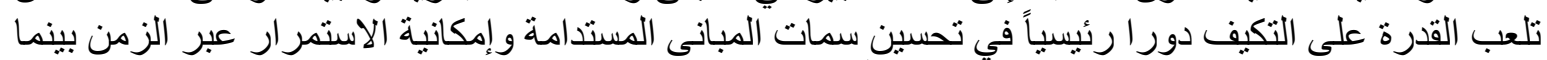

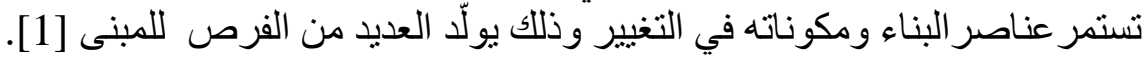

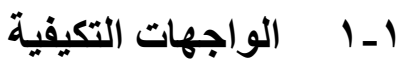
تتكون المباني التكيفية من أنظمة متعددة الوظائف و الفاصل المادي فيها بين البيئة الداخلية و الخارجية (أي غلاف

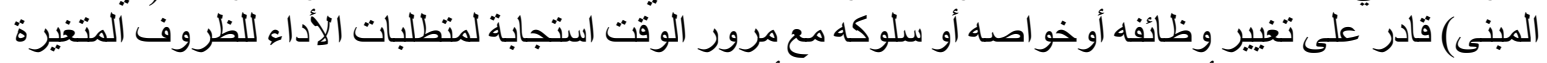

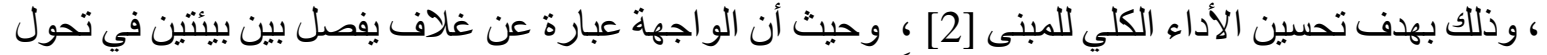

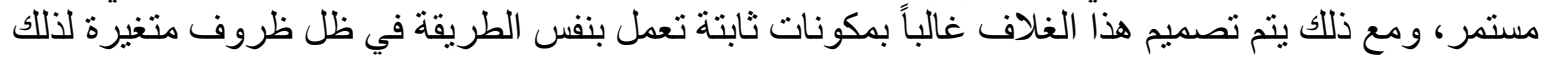

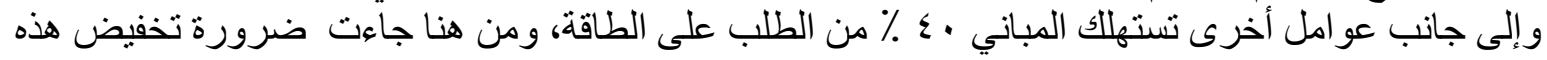

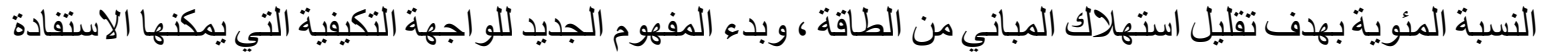

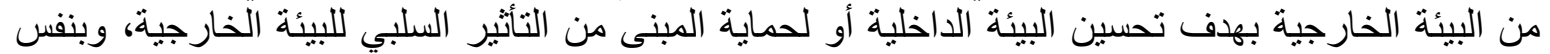

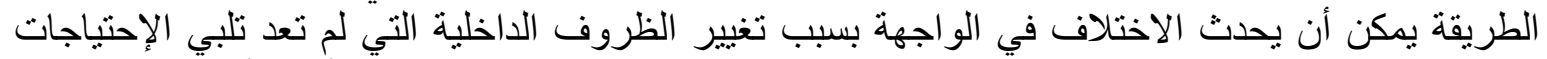

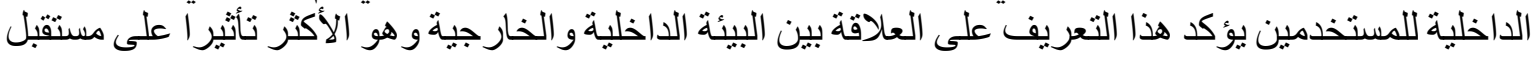

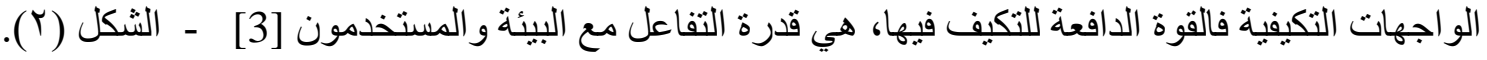

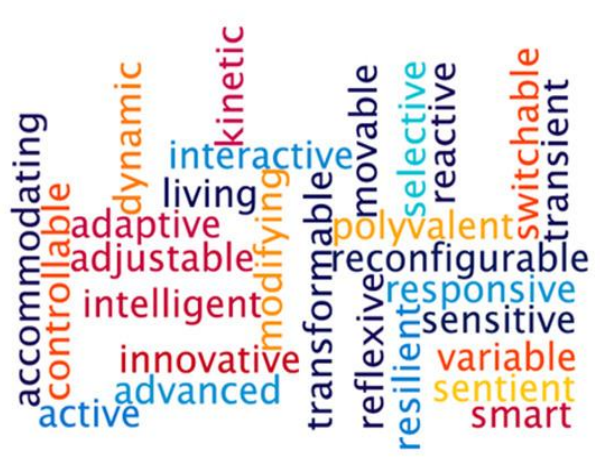

شكل (ّ) مصطلحات التكيف في الواجهات [4]

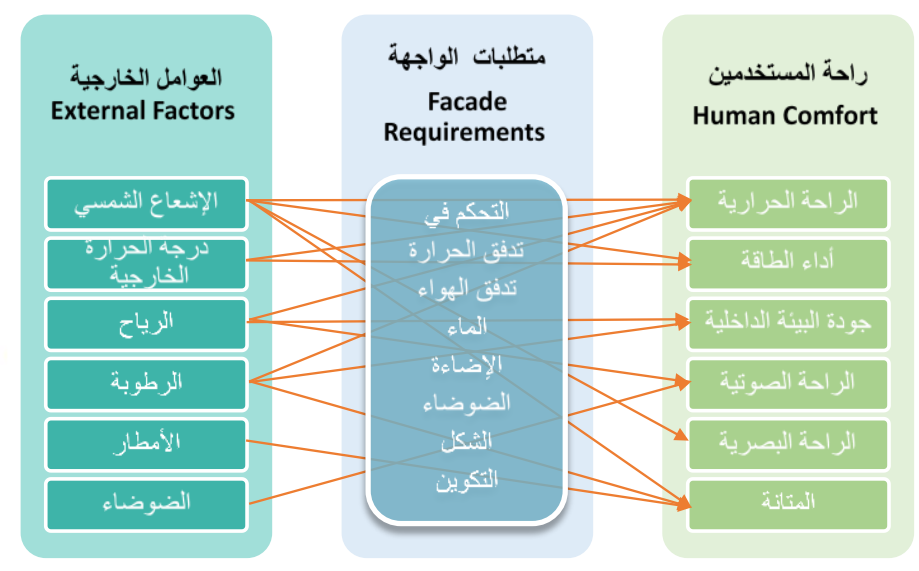

شكل(Y) وظائف الواجهات التكيفية ـ المصدر : الباحث من [4]

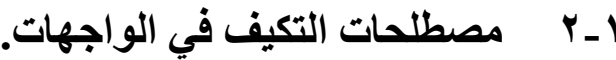

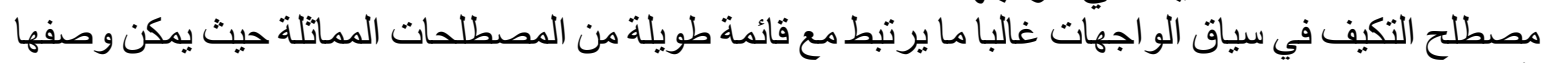

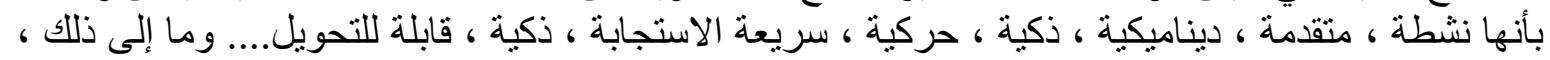

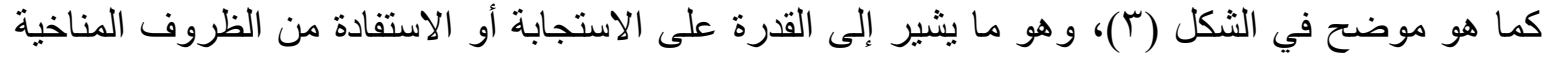

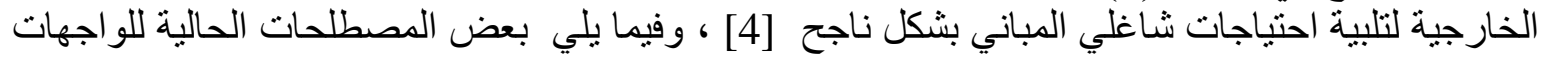

التكيفية [5].

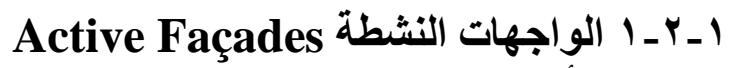

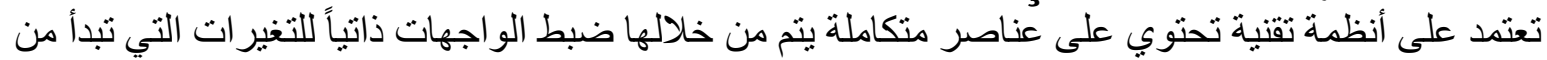

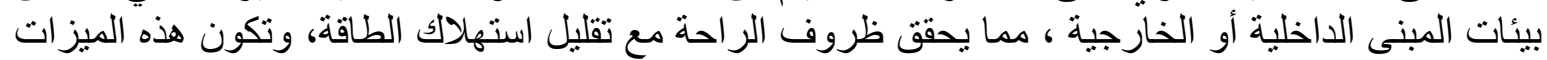

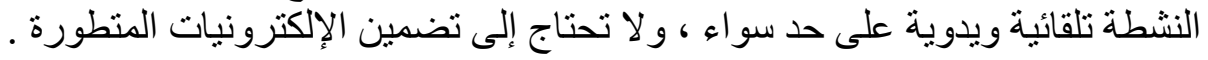




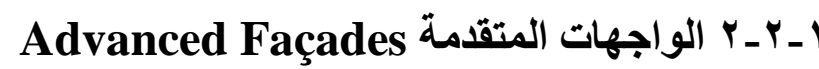

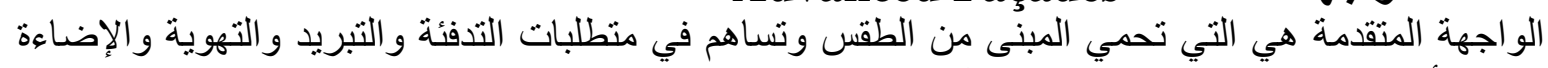

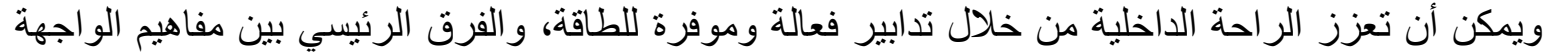

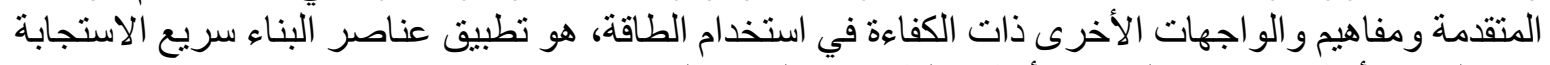

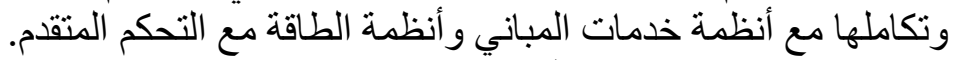

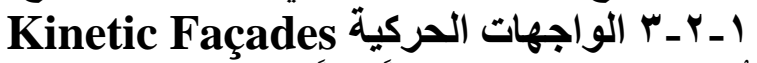

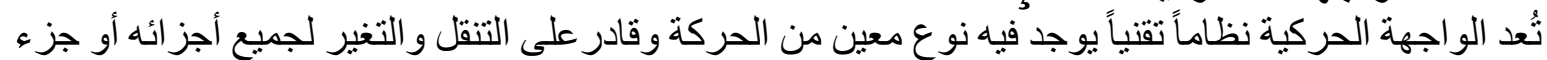

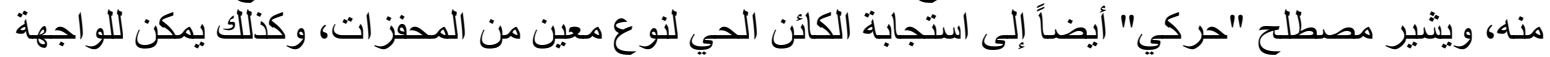

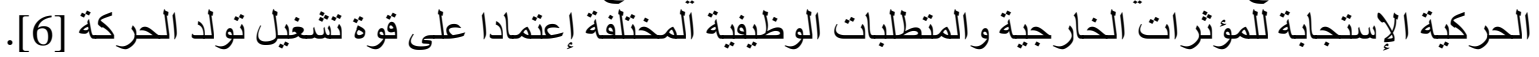

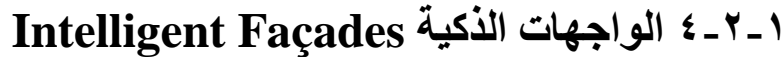

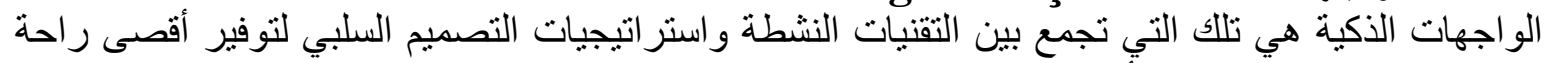

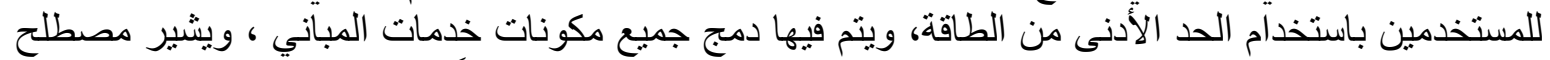

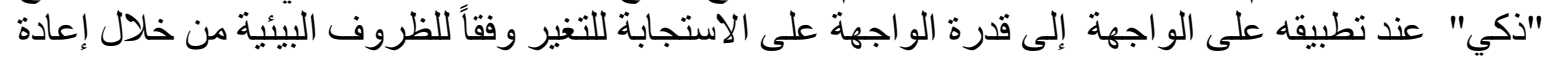

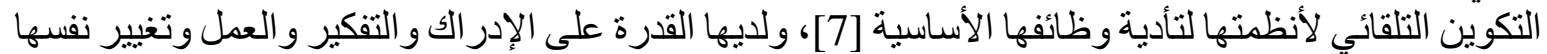

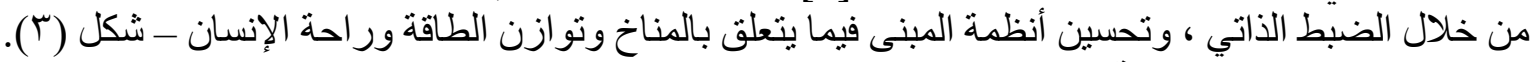

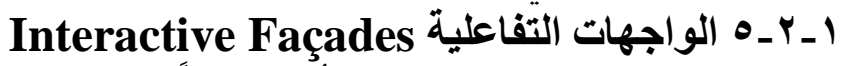

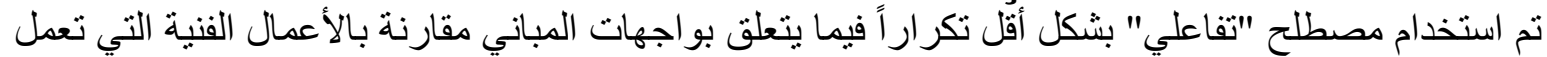

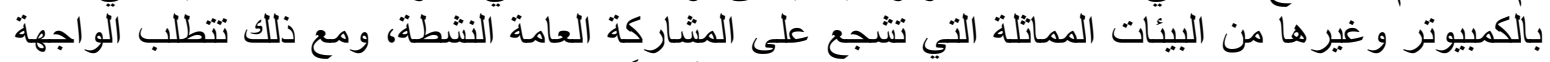

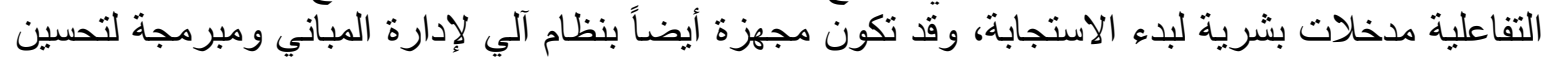

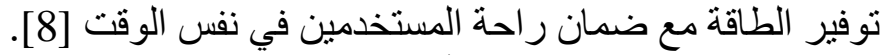

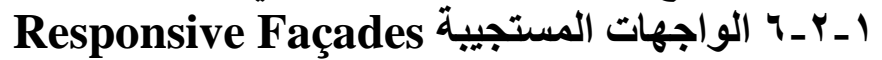

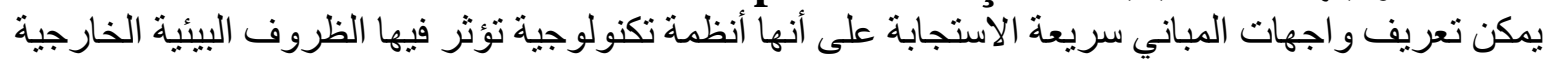

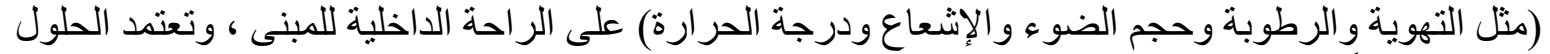

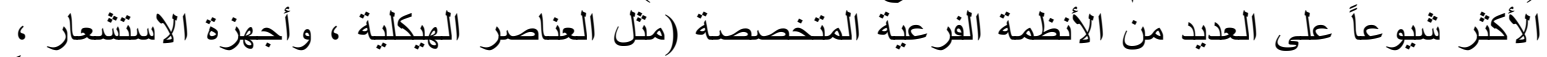

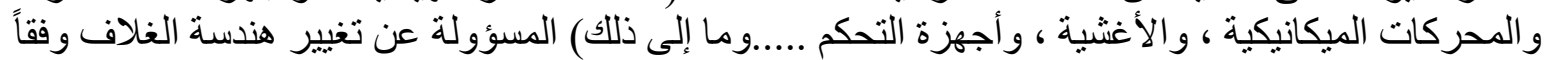

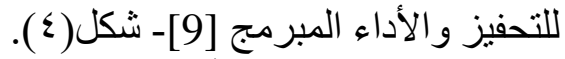

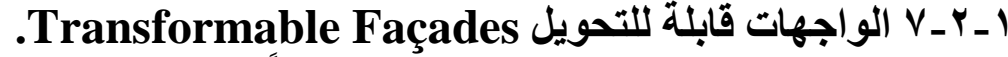

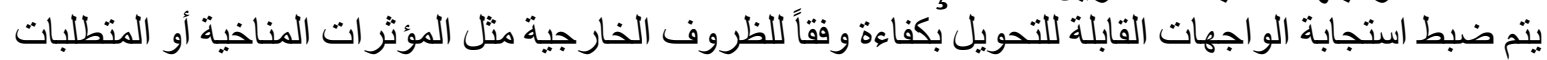

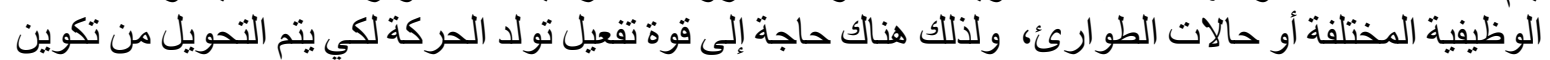

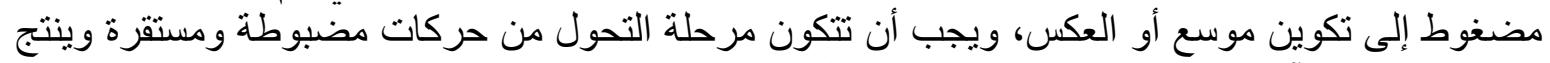

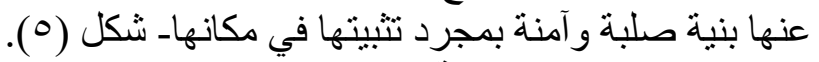

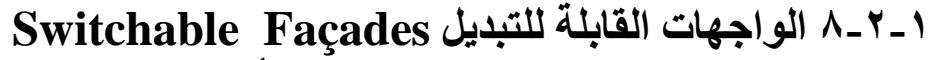
و هي واجهات شفافة يتم فيها دمج الزجاج الذكي أو المواد التكيفية الذكية لتنظيم الضوء وتدفئ الطاقة من خلال

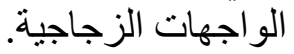

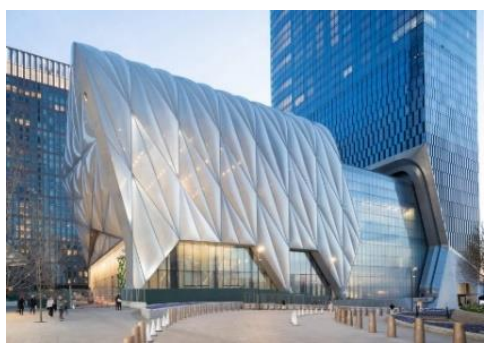

شكل(•) الواجهة القابلة للتحويل

Hudson Yards لمبنى (12)

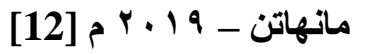

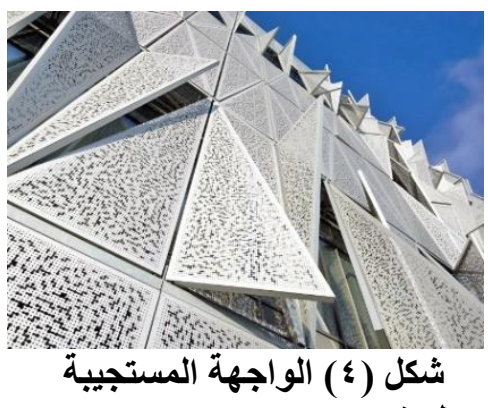

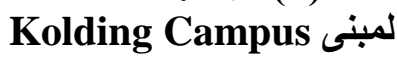

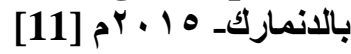

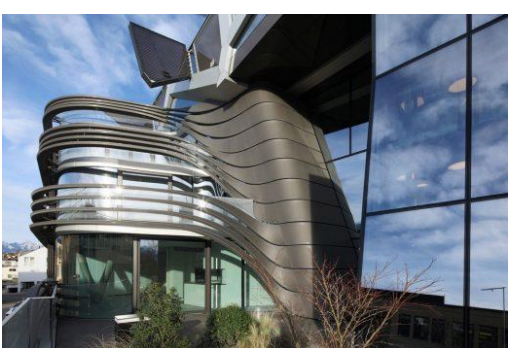

شكل (r) الواجهة الأكية لمبنى Active energy building

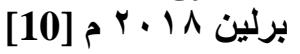




\section{ا \\ وتختلف طريقة تطبيق مفهوم القدرة على التكيف في الو اجهات وفقاً للخصائص النالية :}

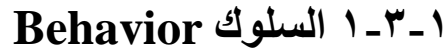

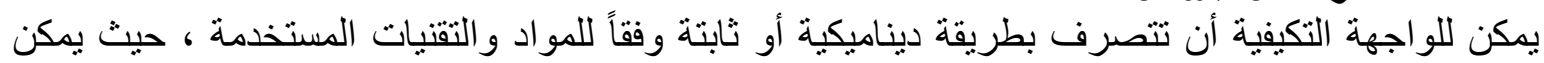
للواجهة أن تستجيب للحافز على نطاق جزئي أو كلي. لكاني.

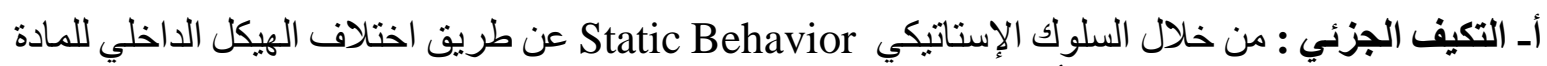

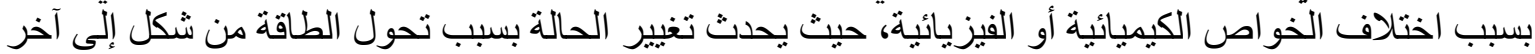

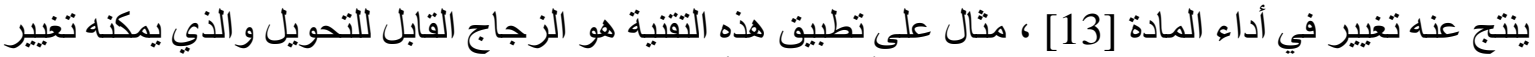

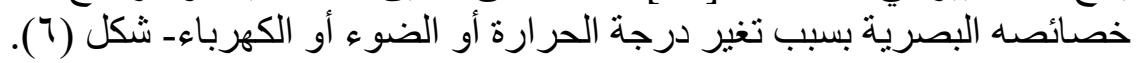

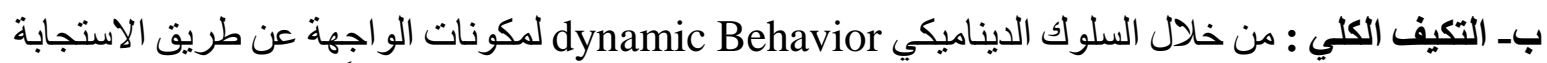

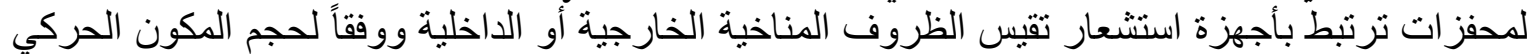

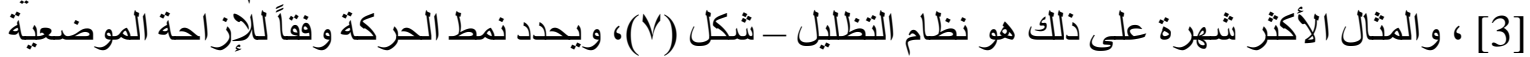

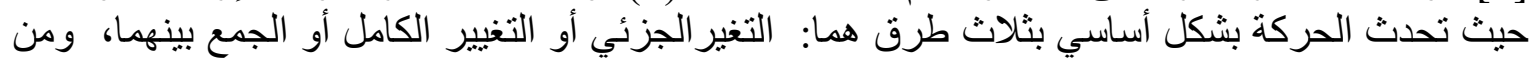

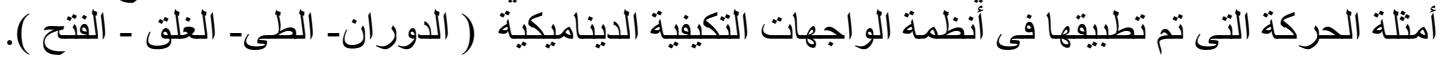

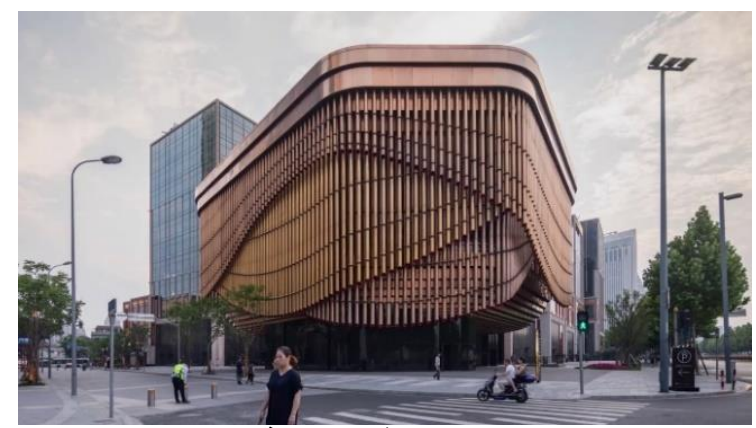

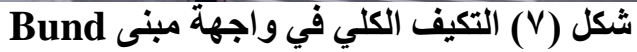
شنغهاي Finance Center

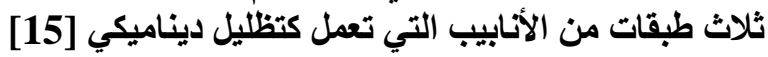

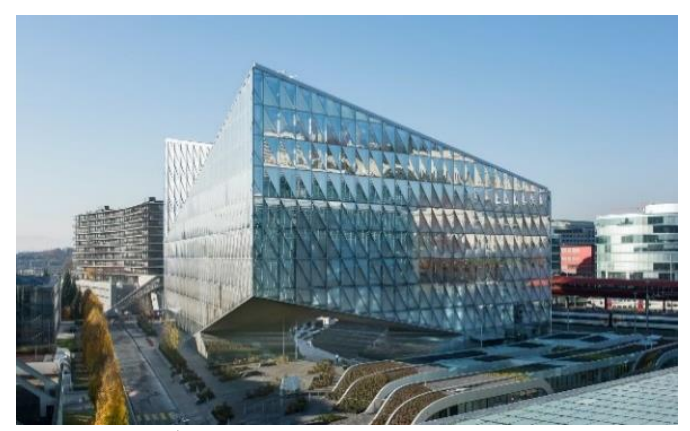

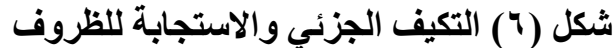

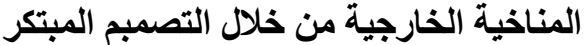

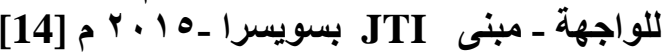

Agent of Adaptation عامل التكيف r r-r-1

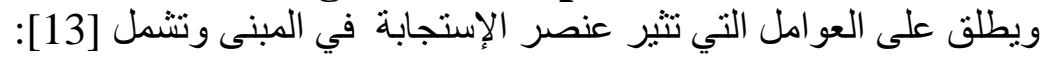
• العوامل الخارجية: مثل (الإشعاع الثمسي ـ درجة الحرارة ـ الرطوبة ـ الرياح ـ ـ هطول الأمطار-

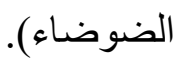

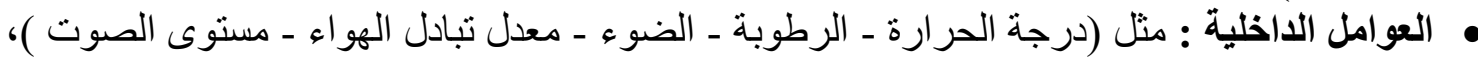

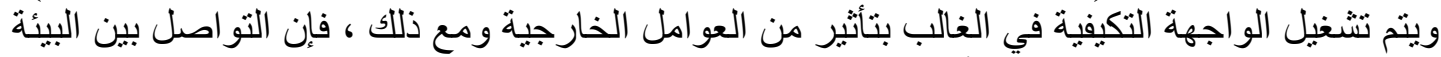
الداخلية والخارجية هو الطريقة الأكثر فعالية لتوفير الطاقة في الكئ المبنى.

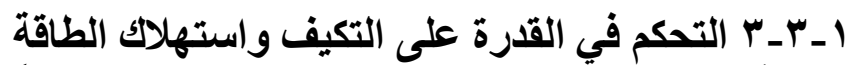

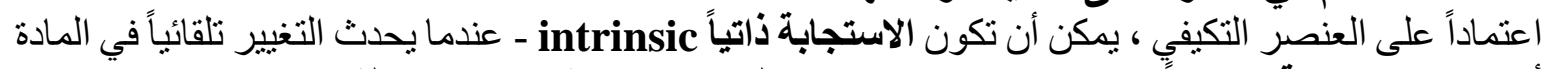

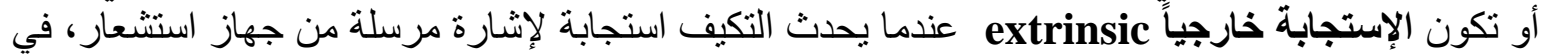

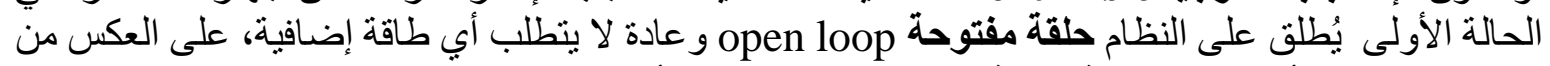

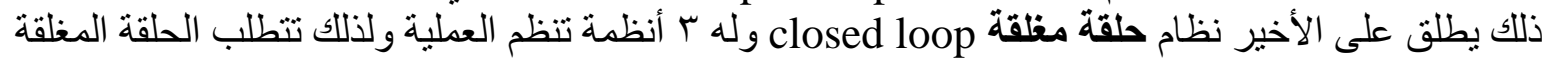

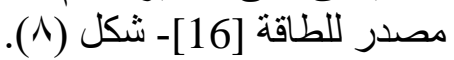

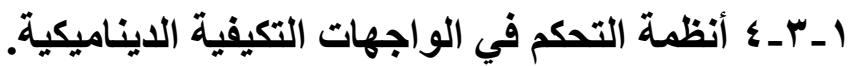

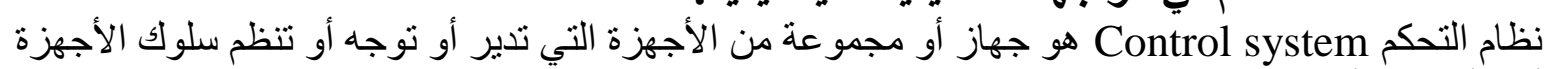
أو الأنظمة الأخرى ويتكون نظام التحكم من ب مستويات [17] : 
أـ أنظمة الإدخال Iput: يتم تمثيلها في أجهزة الاستشعار و أساليب الإدخال المختلفة ، و التي تعطي معلومات

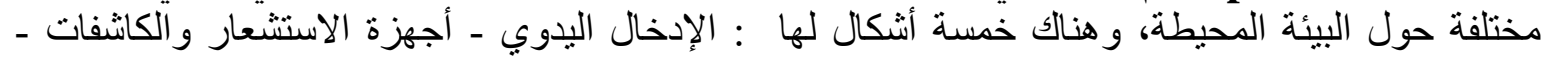

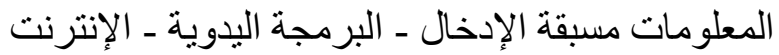

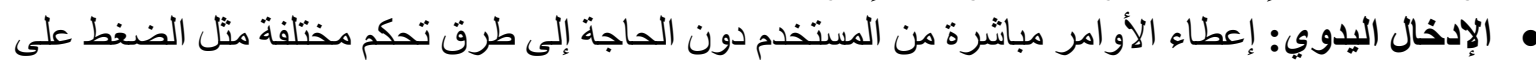

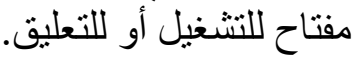

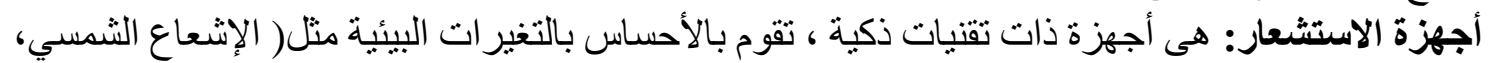

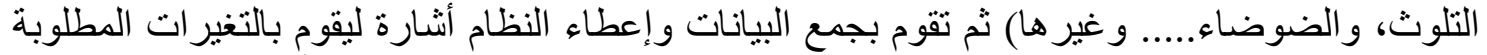

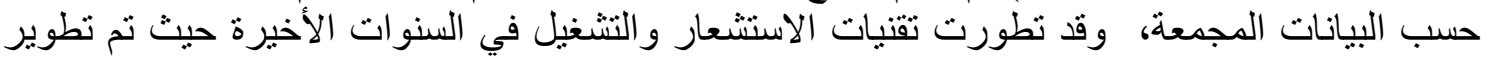

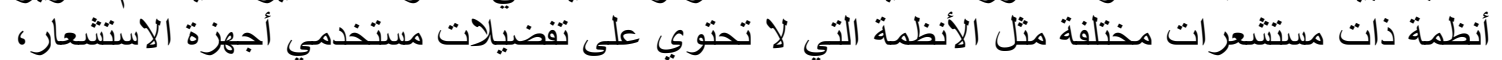

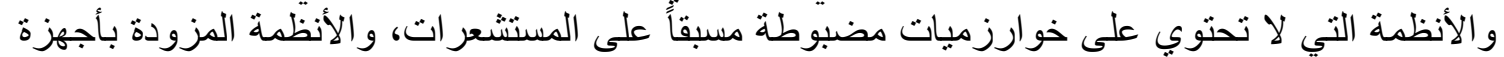

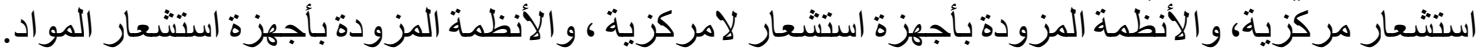

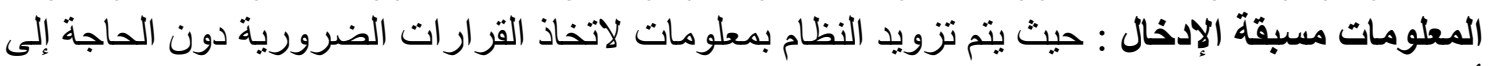

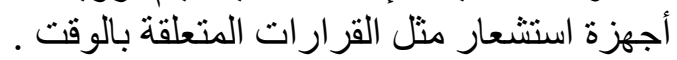
ه البرمجة اليدوية: والتي يمكن استخدامها اعتماداً على ظروف التهائ تشغيل المبنى وتعديل بر امج التشغيل وفقاً

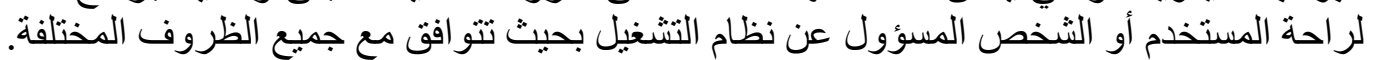

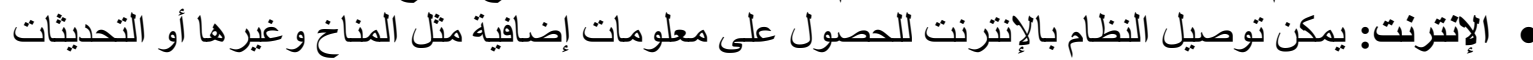

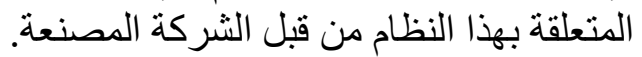

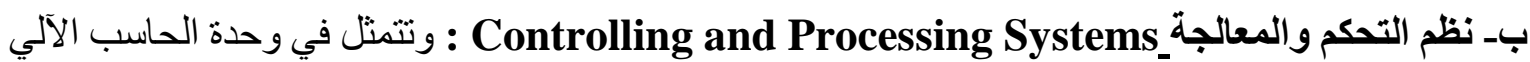

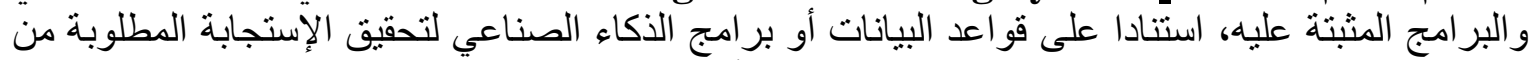

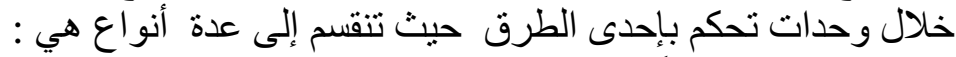

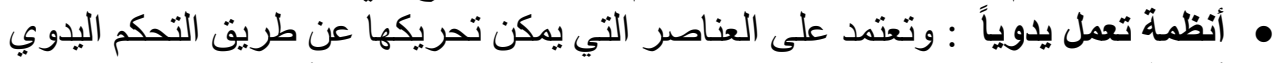

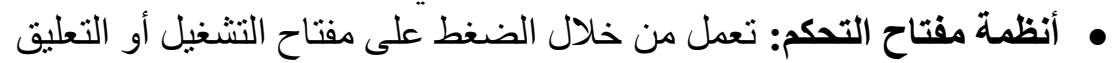

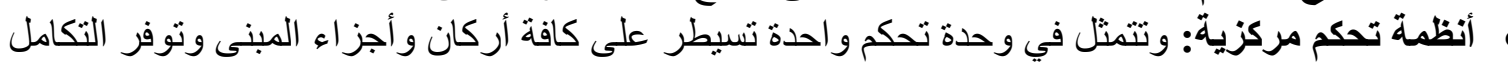

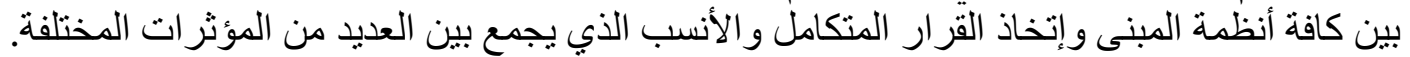

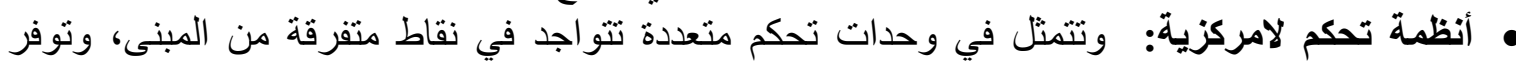

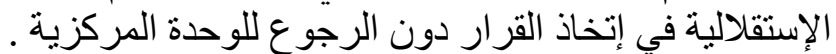

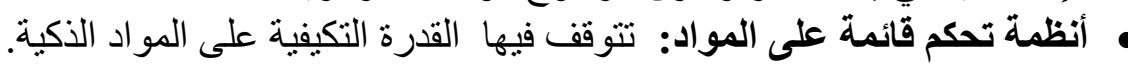

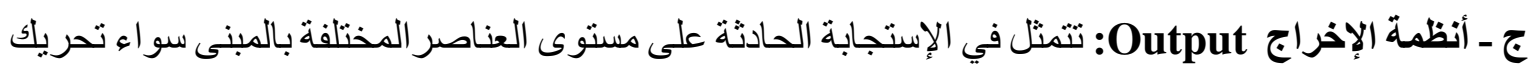

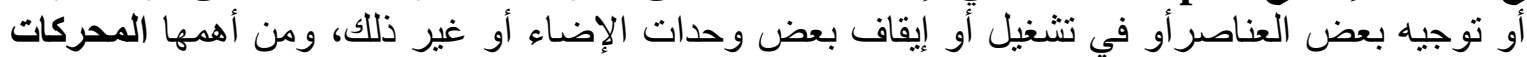

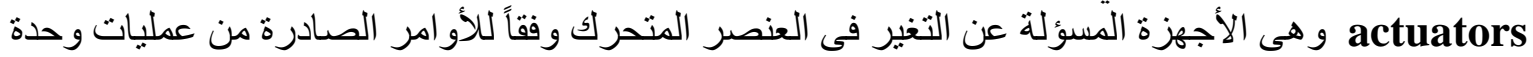

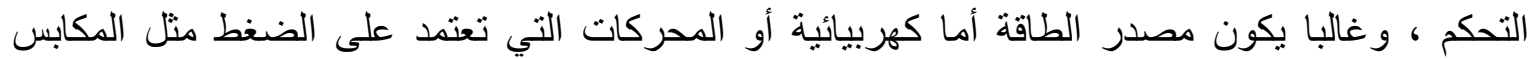

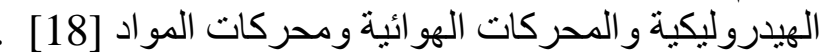

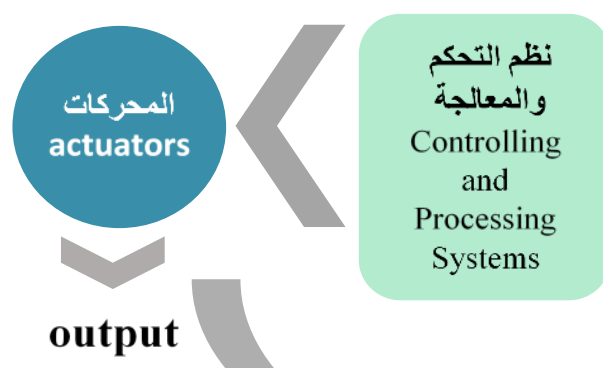

التثنية الراجعة

Feedback

شكل(^) الحلقة المغلقة closed loop للتحكم في الواجهات التكيفية ، المصدر: الباحث 
هذه المنظومات الثناثة تستمر في العمل و التغذية الر اجعة Feedback ، فبناء على نتائج نظم الإخر اج تتغيرحالة

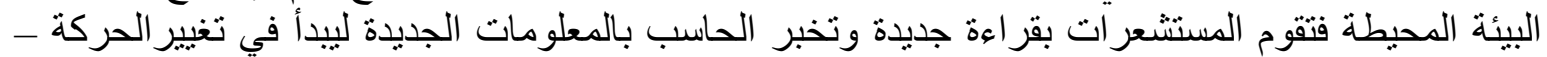

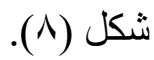

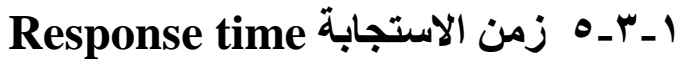

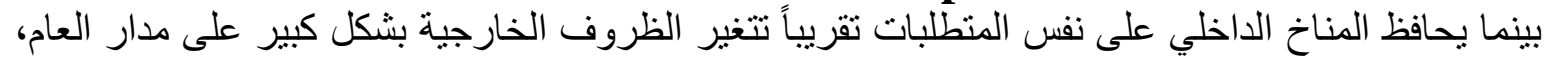

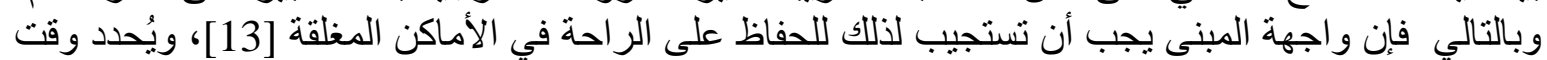

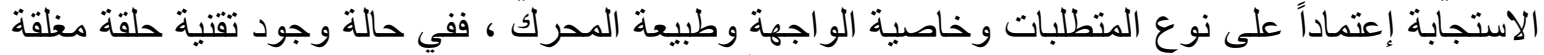
closed loop

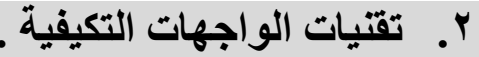

تتكون الواجهات التكيفية من أنظمة متعددة الوظائف عالية التكيف، حيث تكون الواجهة بمثابة الفاصل المادي

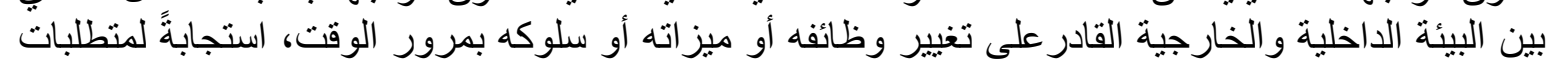

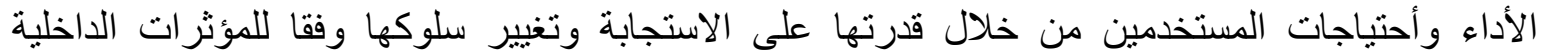

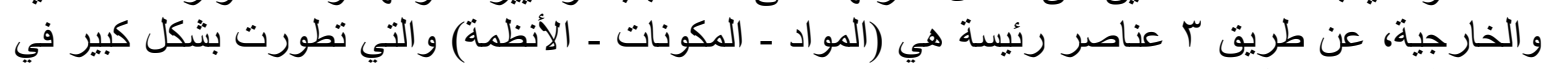

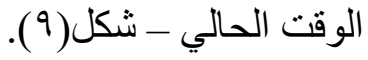

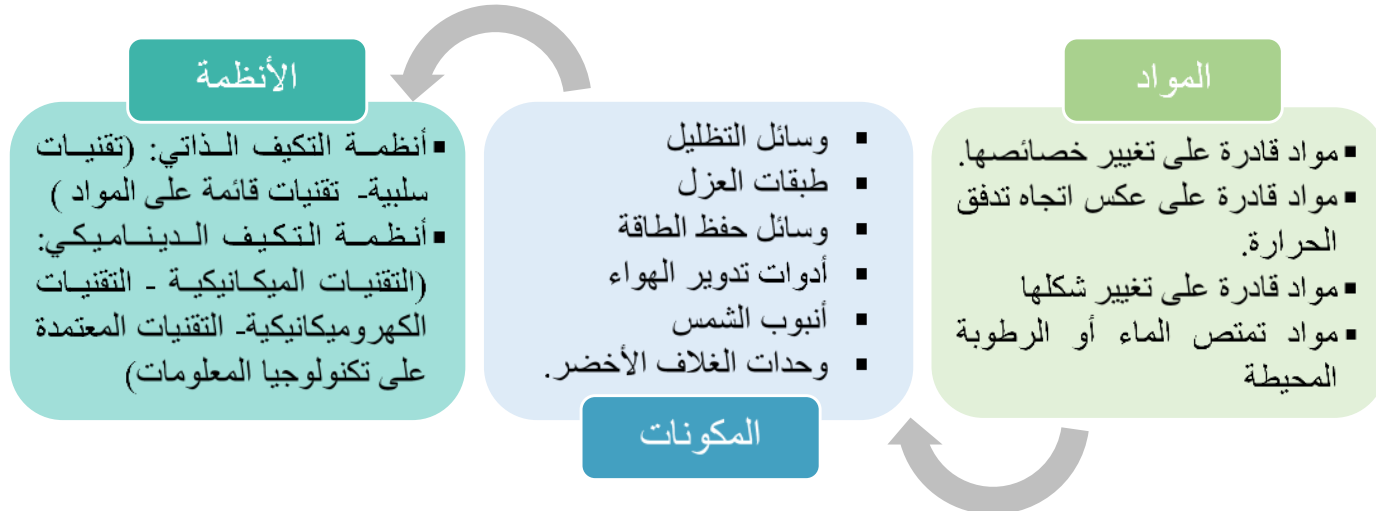

شكل(9) العناصر الرئيسية للواجهات التكيفية ، المصدر: الباحث من [19]

r ـ ا 1 مواد الواجهات التكيفية.

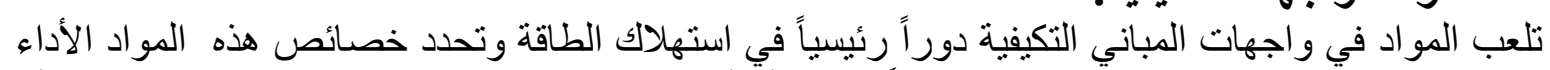

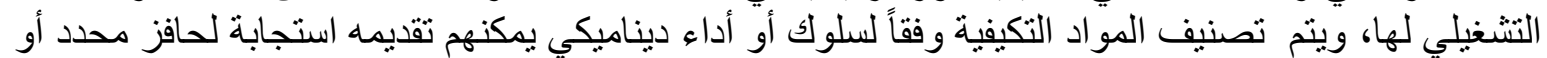

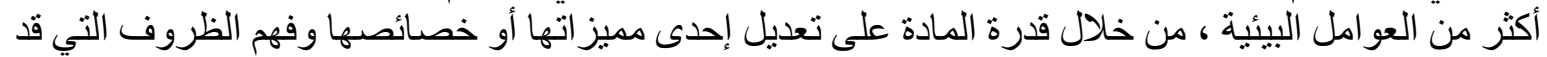

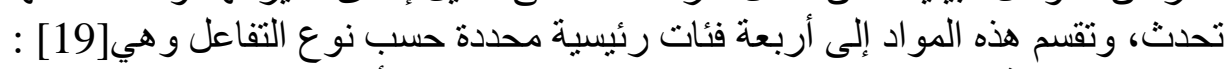

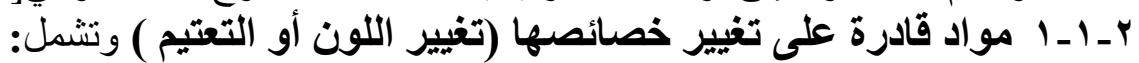

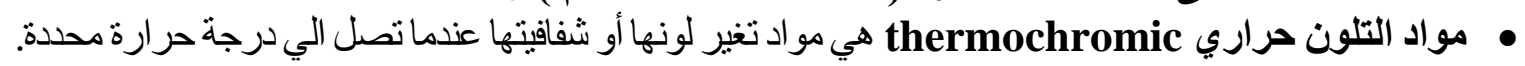

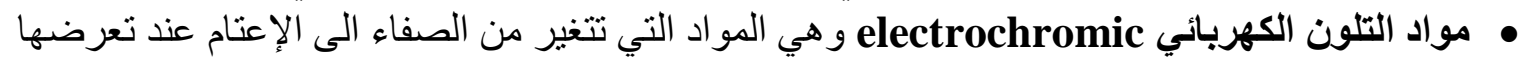

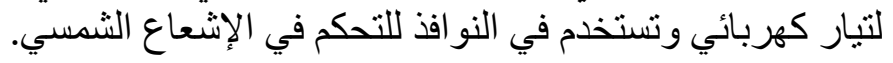
• مواد التلون الضوئي photochromic وهي المواد التي يتغير لونها أو درجة شئي التفافيتها عند تعرضها

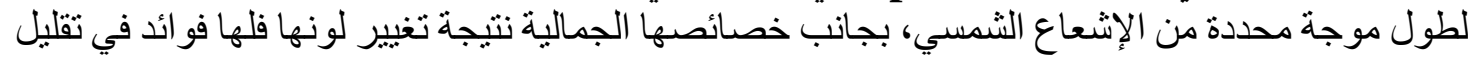
إستهلاك الطاقة و التحكم في الإشعاع الشعاع الشمسي.

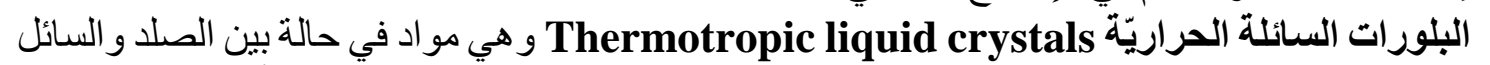

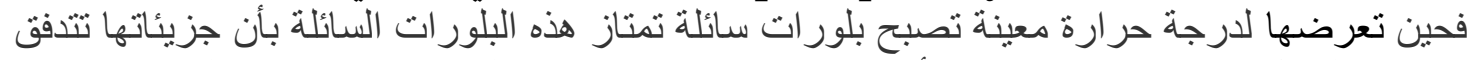

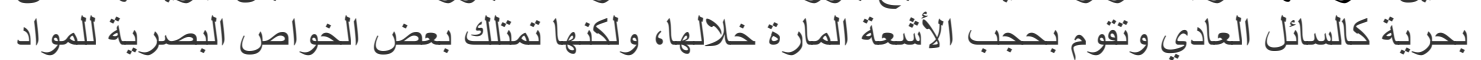

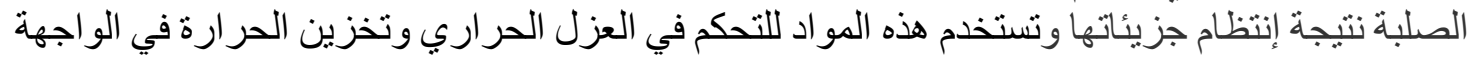

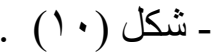



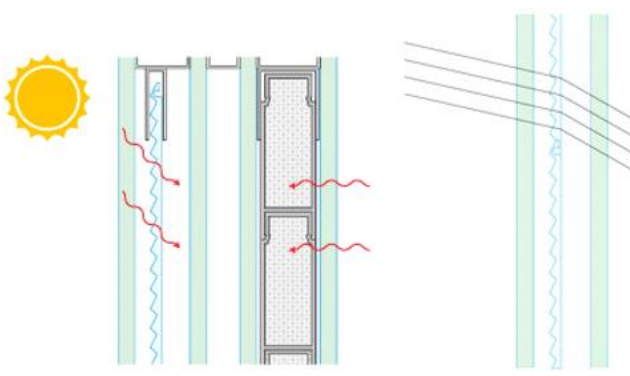

استخدامات المواد متغيرة الطور في الزجاج

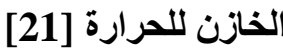
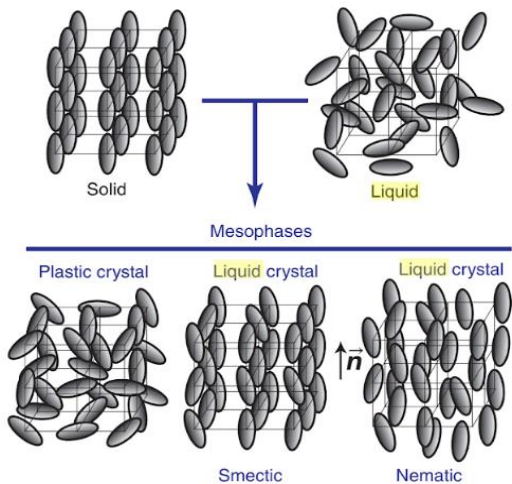

شكل(· ا م) البلورات السائلة الحراريّة [20]

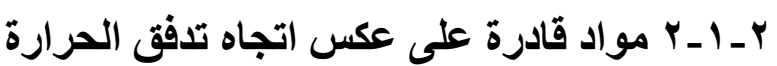

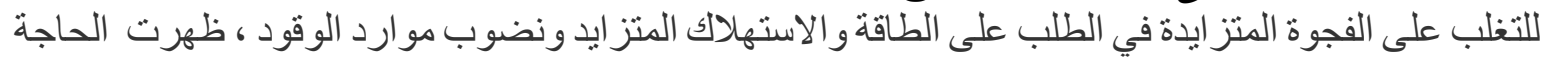

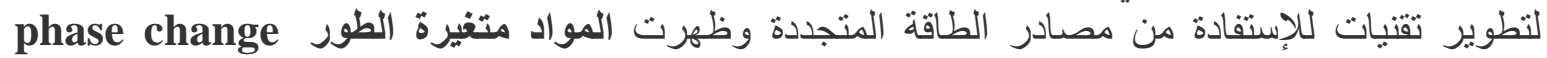
materials

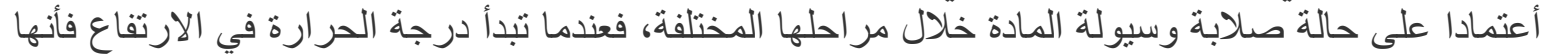

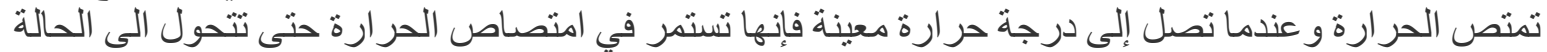

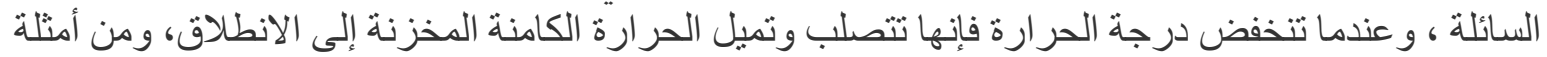

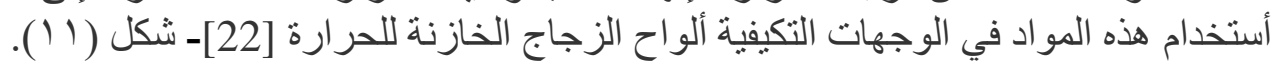

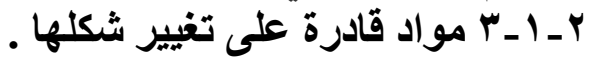

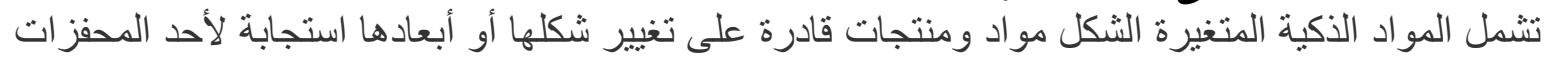

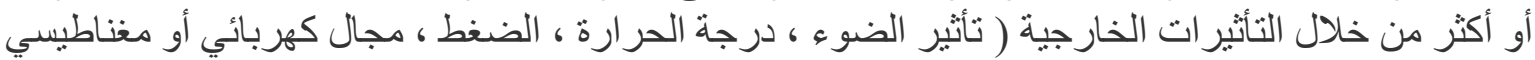

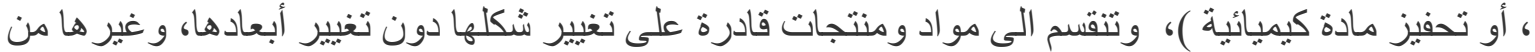

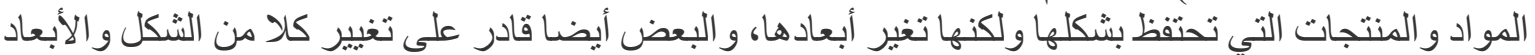

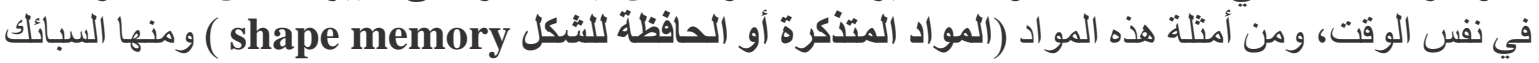

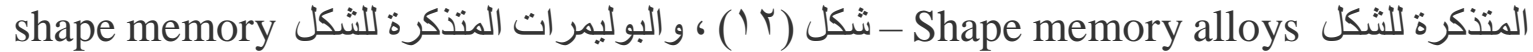
polymers

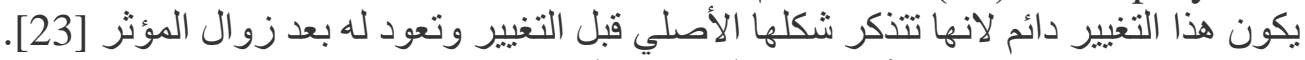

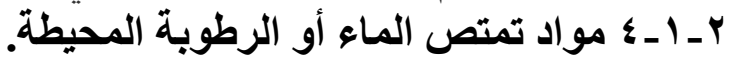
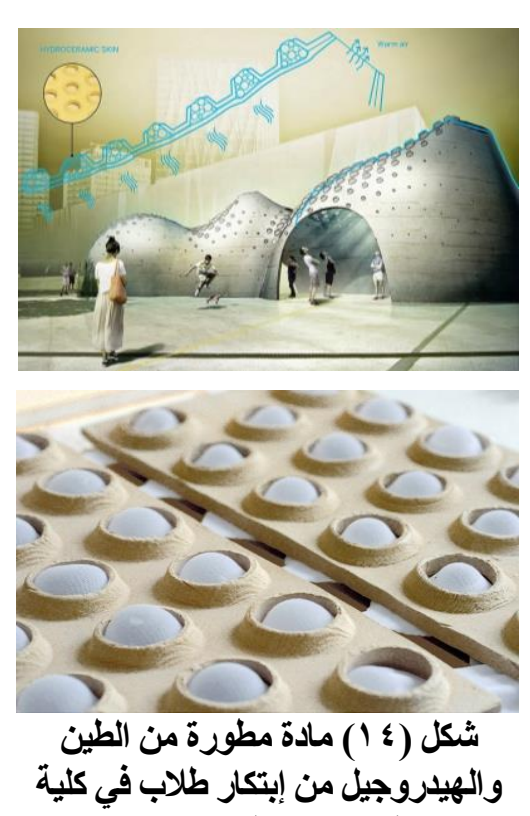

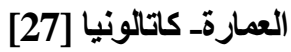

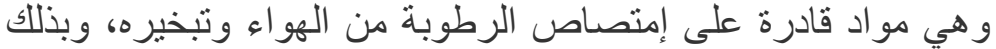

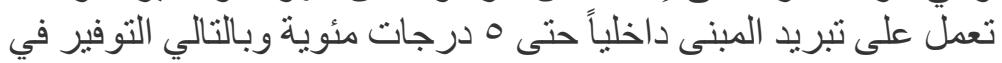
استهلاك الطاقة، مثل الهيدروجيل Hydrogel

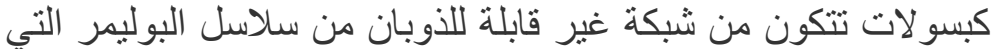

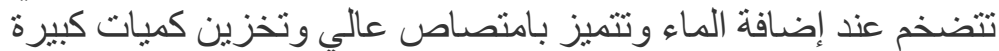

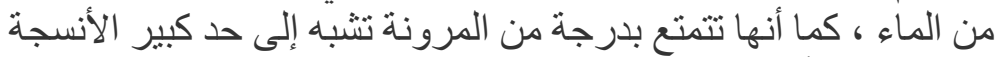
الطبيعية نظراً لمحتو اها المائي الكبير [24] - شكل (ع الن ).

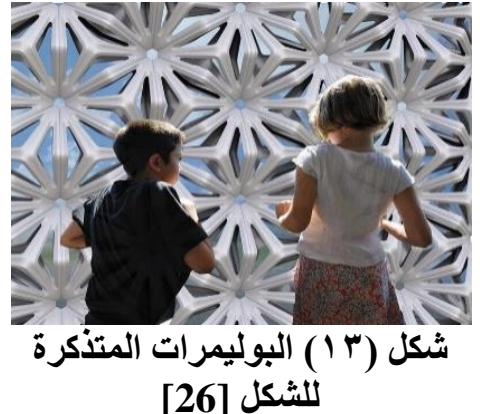

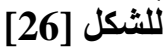

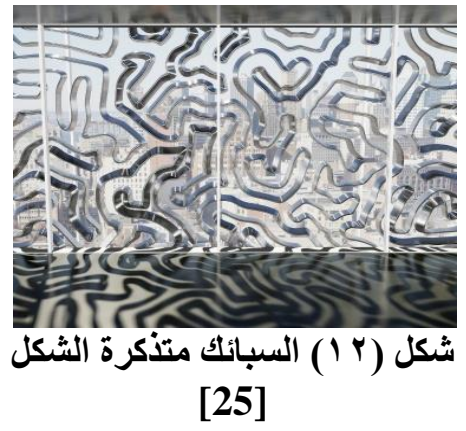




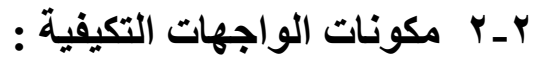

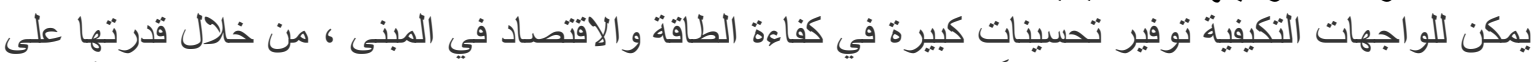

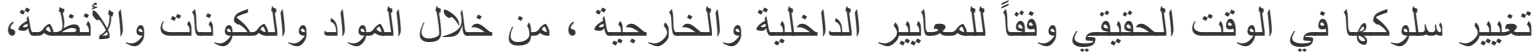

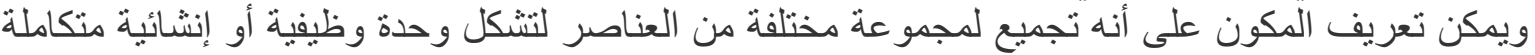

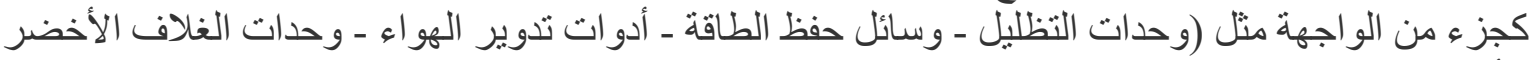

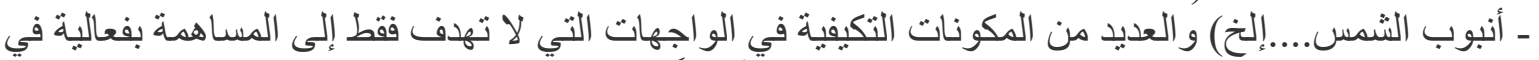

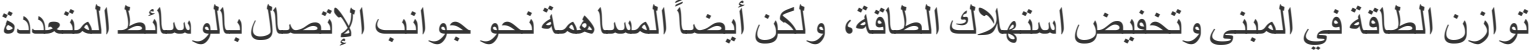

$$
\text { وفيم ما يلي عرض لبعض المكونات التكيفية الثائع إستخدامها بالو اجهات الماتيات : }
$$

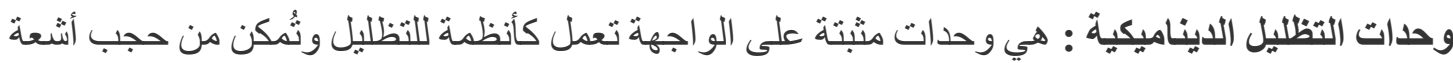

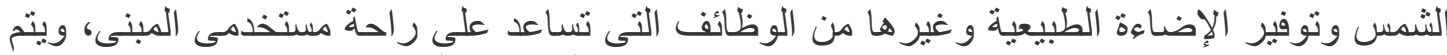

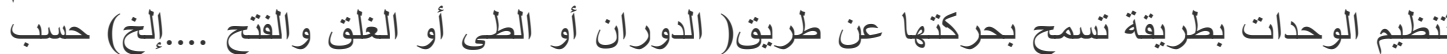

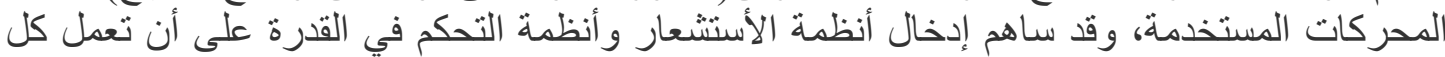
وحدة بشكل فردي بنظام مستقل وذلك عن طريق الأستجابة وفقاً للبيانات التي تتلقاها من أنظمة الأستشعار

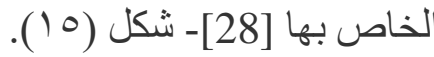

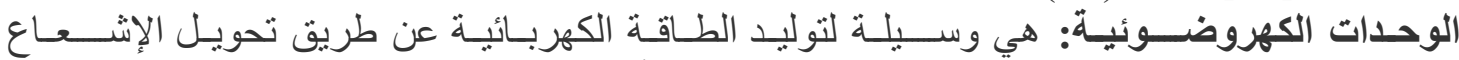

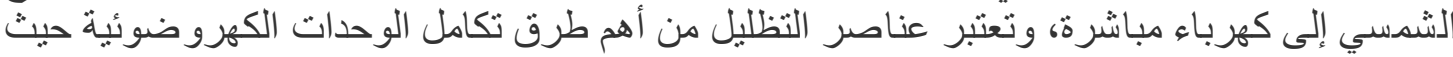

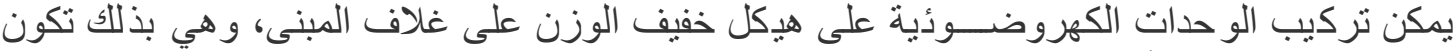

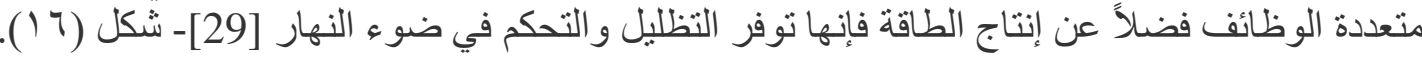

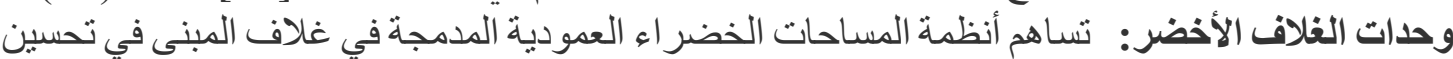

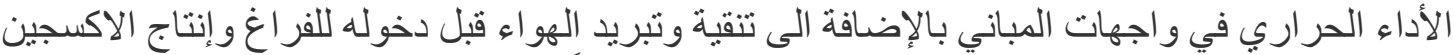

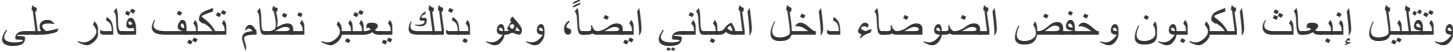

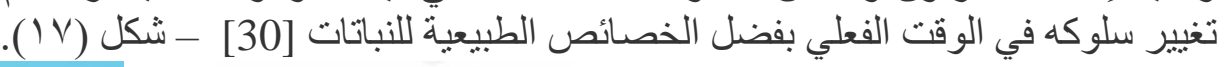

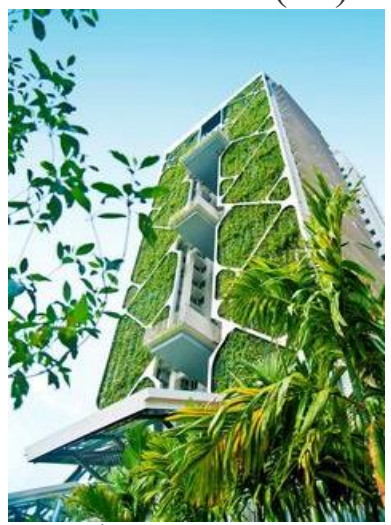

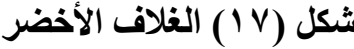

في مبنى فئن

في سنغافورة [32]
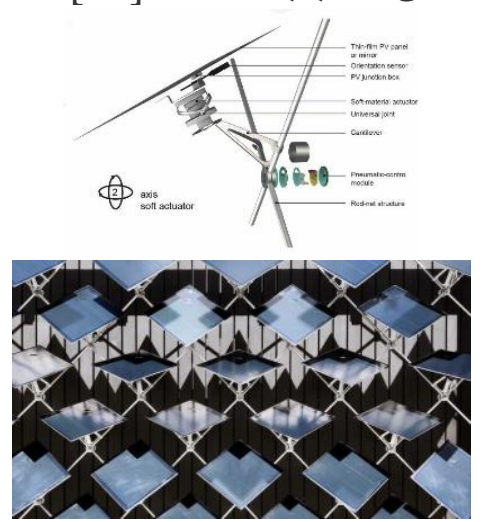

شكل (1 1 ) الواجهة التي تم تطويرها

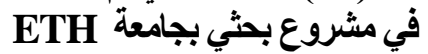
Zurich

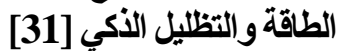

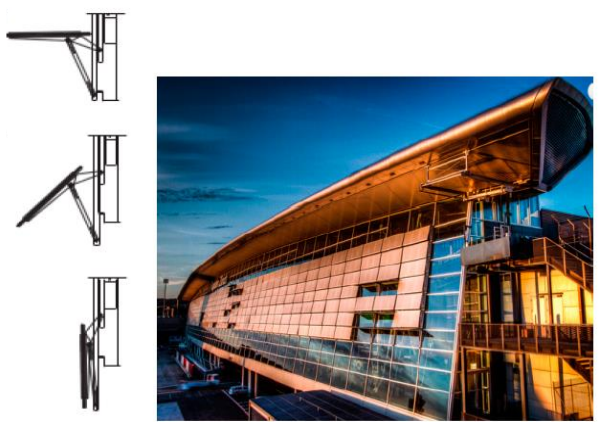

شكل (0 1 ) نظام التظليل مطار زيوريخ

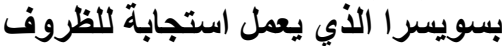
المناخية المتغيرة وضوع النهار [28].

ب_r r أنظمة الواجهات التكيفية

يمكن تصنيف الأنظمة المستخدمة في الواجهات التكيفية إلى مجموعتين بناء على المعايير الخاصة بتقنيات بالتحكم و الاستشعار و التشغيل و المو اد التكنولوجية و الهيكلية حيث يمكن أن يكون التحكم عبارة عن نظام حلقة التية

مغلقة أو حلقة مفتوحة كما ذكر سابقاً.

أـ المجموعة الأولى: أنظمة التكيف الذاتي التي تتوقف فيها القدرة التكيفية على الموارد الطبيعية أو المو اد الذكية ولا لتخية التضمن قابلية النظام للتكيف بالضرورة

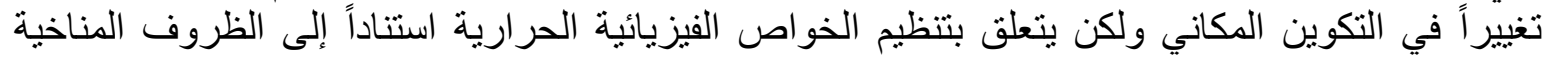

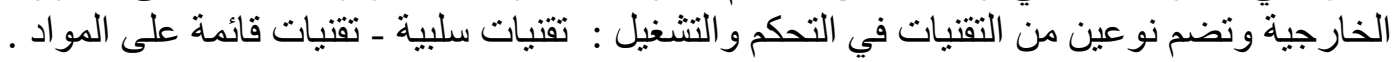




\section{ب- المجموعة الثانية : أنظمة التكيف الديناميكي}

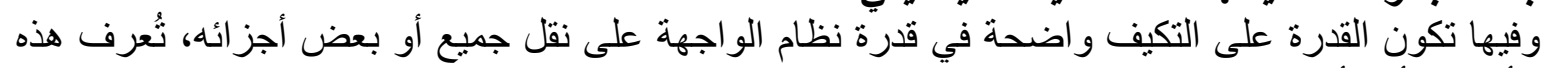

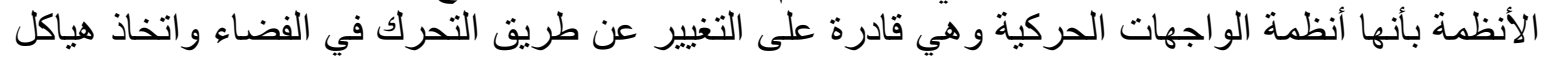

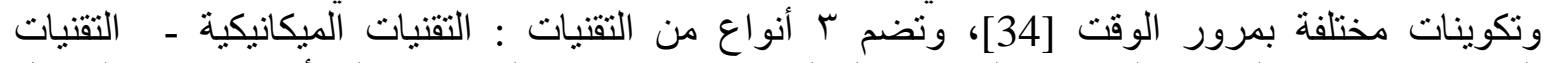

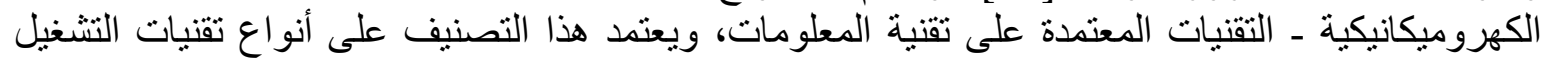

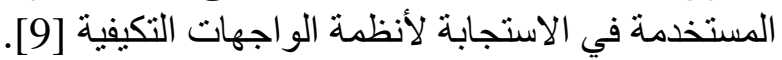
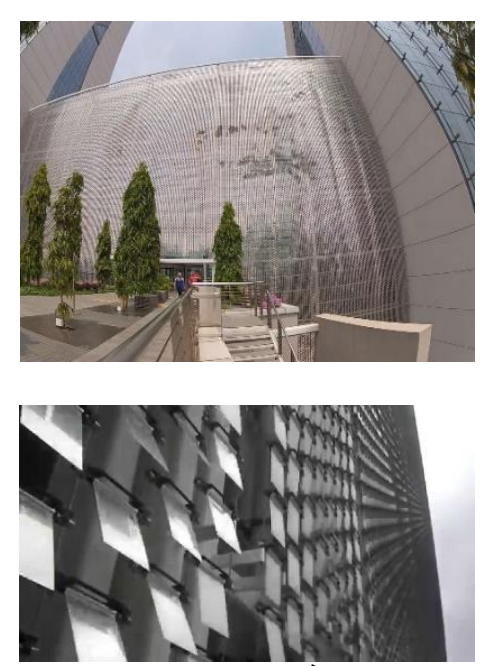

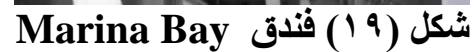
Sands Hotel [33]

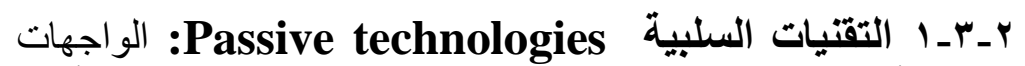

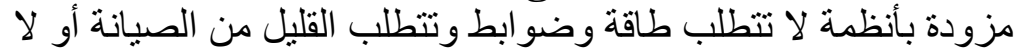

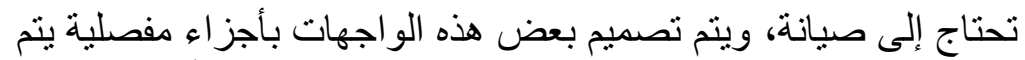

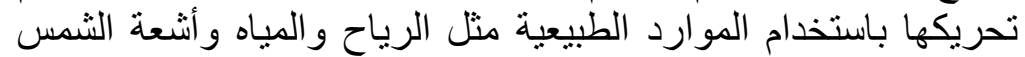

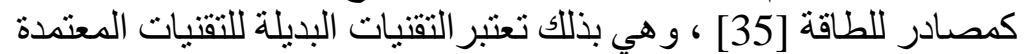

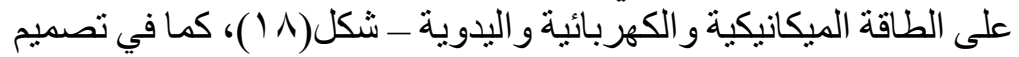

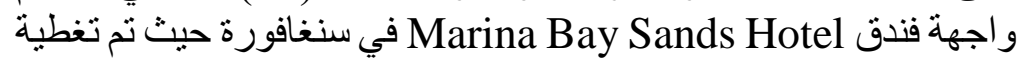
الإطار الزجاجي بلوحات من الراتنج المفصلي منصلة بهيكل شبكي

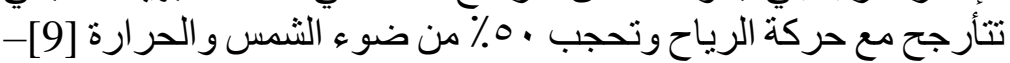

شكل (19). (1) (1).

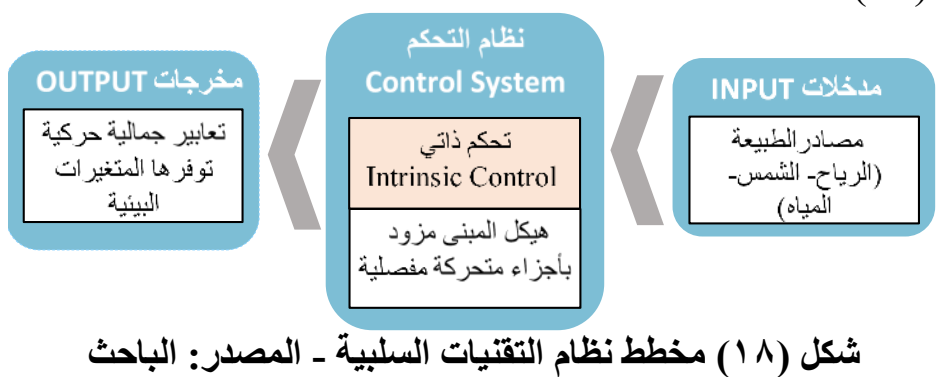

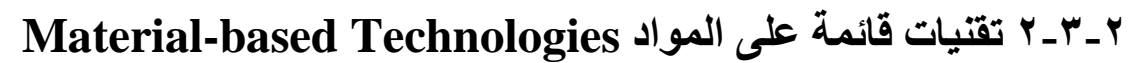

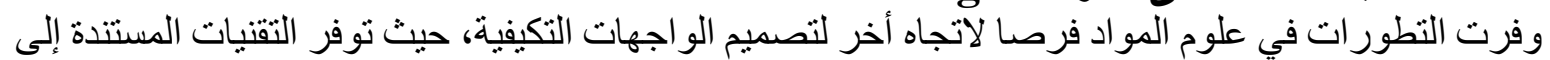

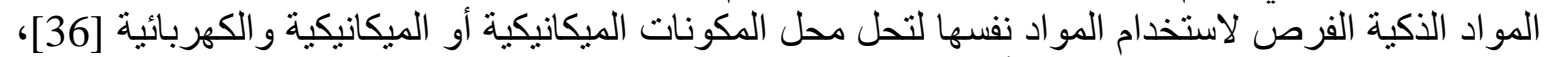

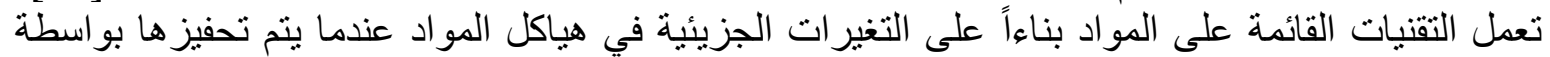

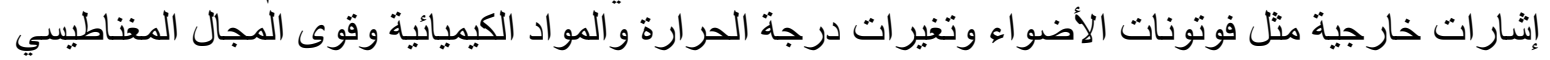

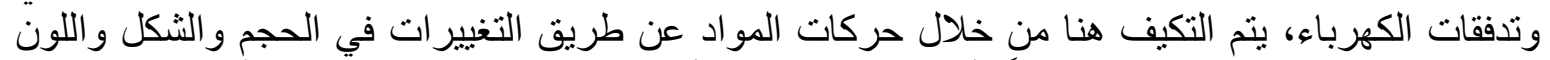

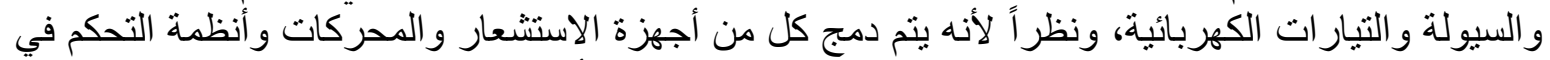

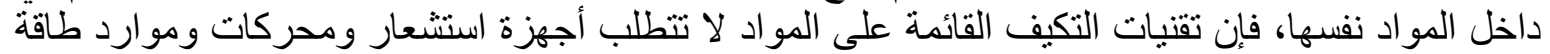

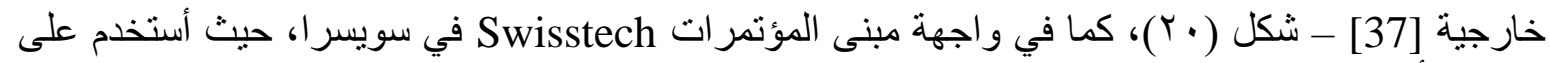

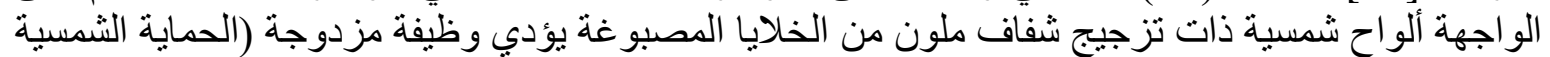

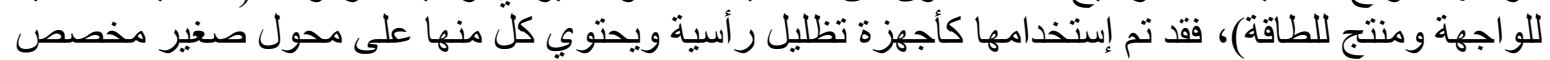
يتكيف باستمر ار مع ظروف الإضاءة المتغيرة مما يزيد من إنتاج الطاقة في التركيب بأكمله [19] - شكل (Y) (Y).

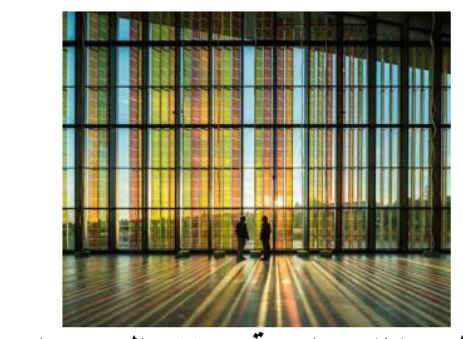

شكل (Yli ) واجهة مركز المؤتمرات

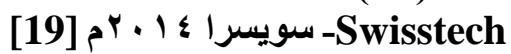

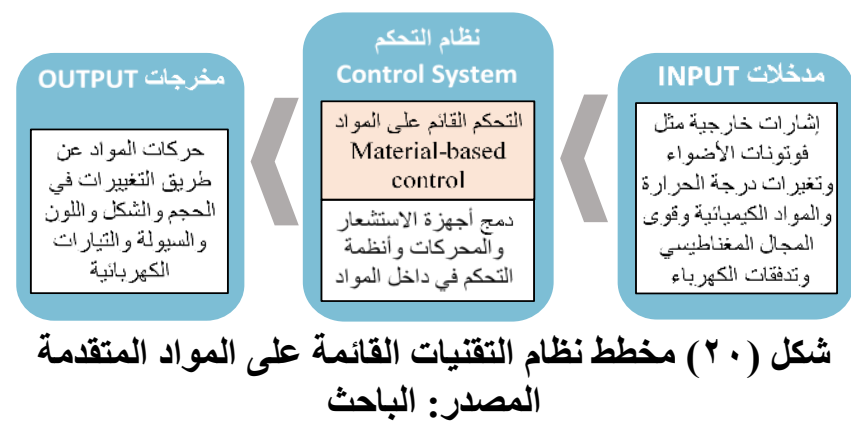




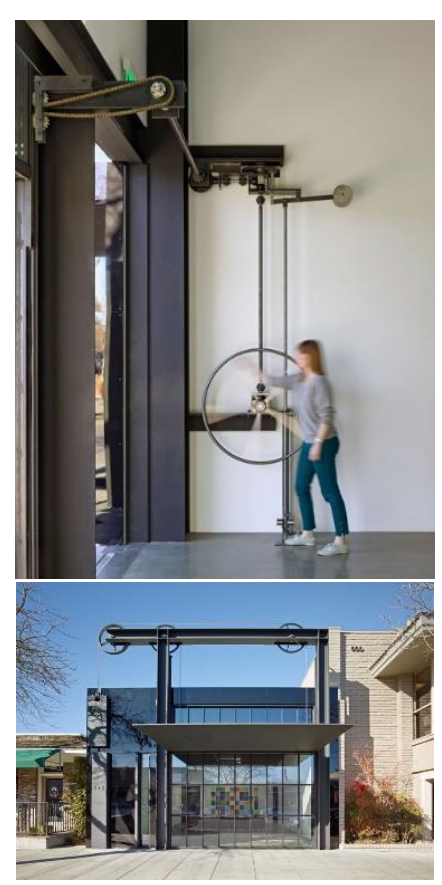

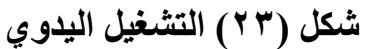
لواجهة معرض كاليفورنيا

[38]

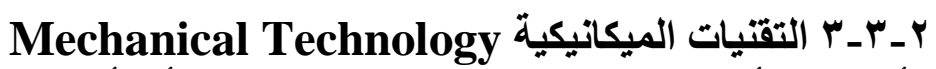
تتألف هذه الأنظمة من عناصر الميكانيكة ميكانيكية منر ابطة من شأنها أن تغير من حجم

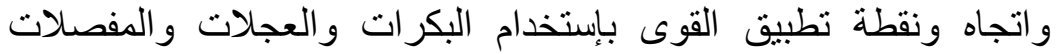

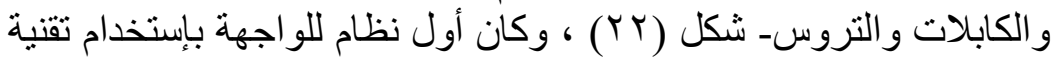

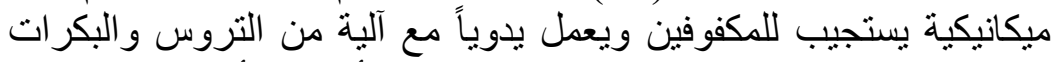

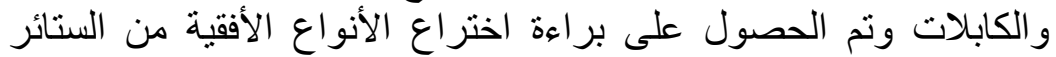

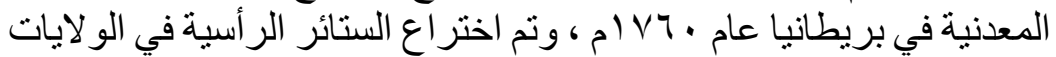

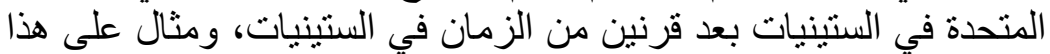

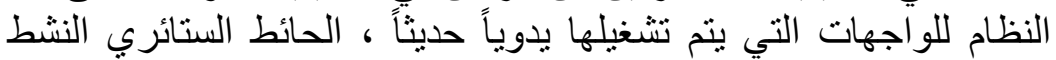

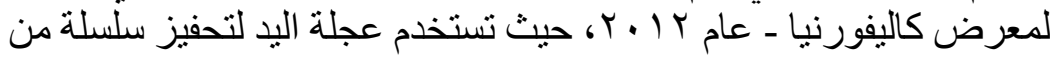

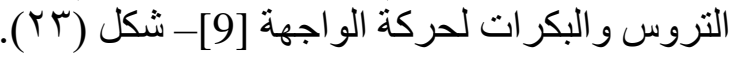

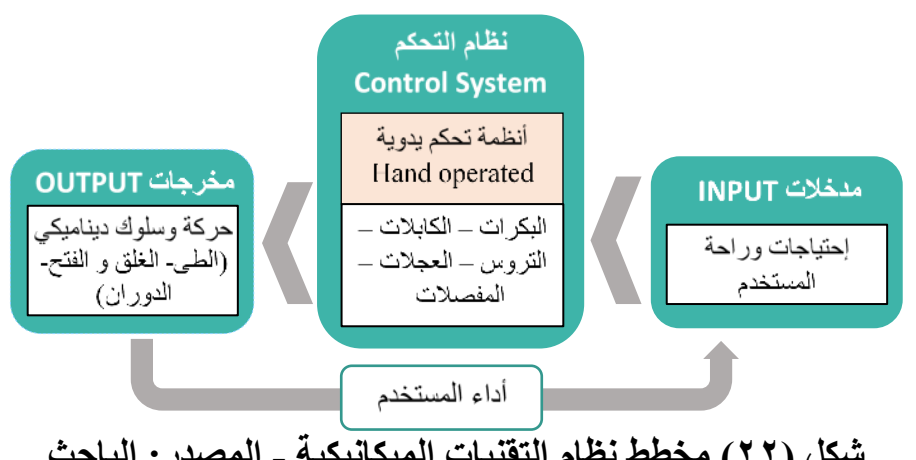

شكل (Y Y T ) مخطط نظام التقتيات الميكانيكية ـ المصدر: الباحث

ب _r

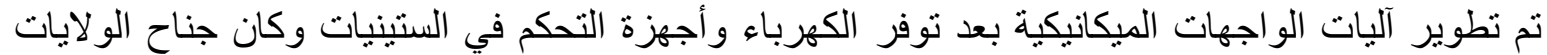

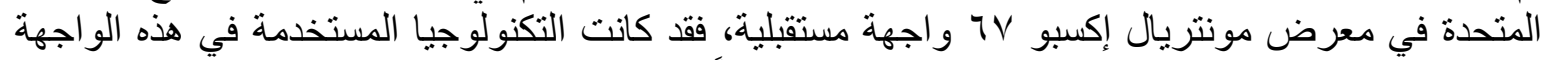

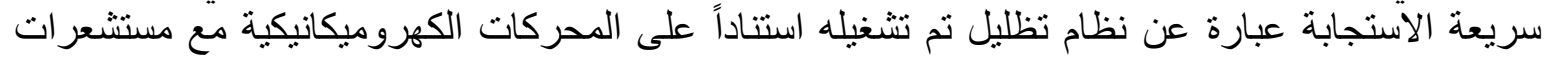
ضوئية للتحكم الحر اري في البيئة الداخلية للهيكل [39]، وتتمتع هذا النوع من التقنيات بمز ايا عديدة مثل التوحيد

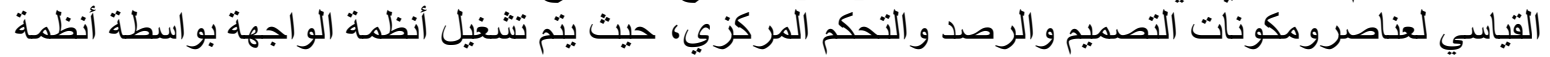

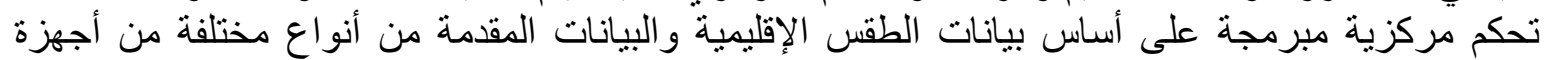

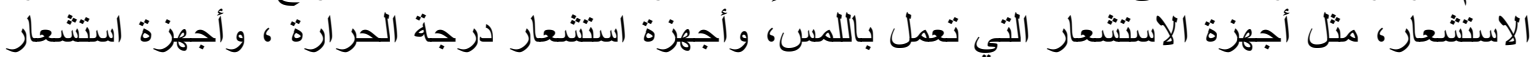

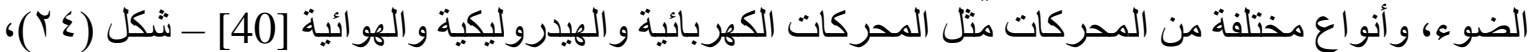

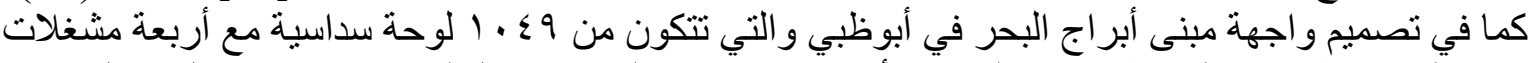

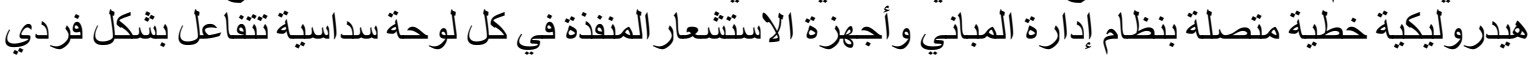

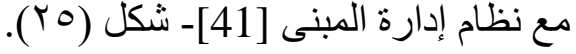
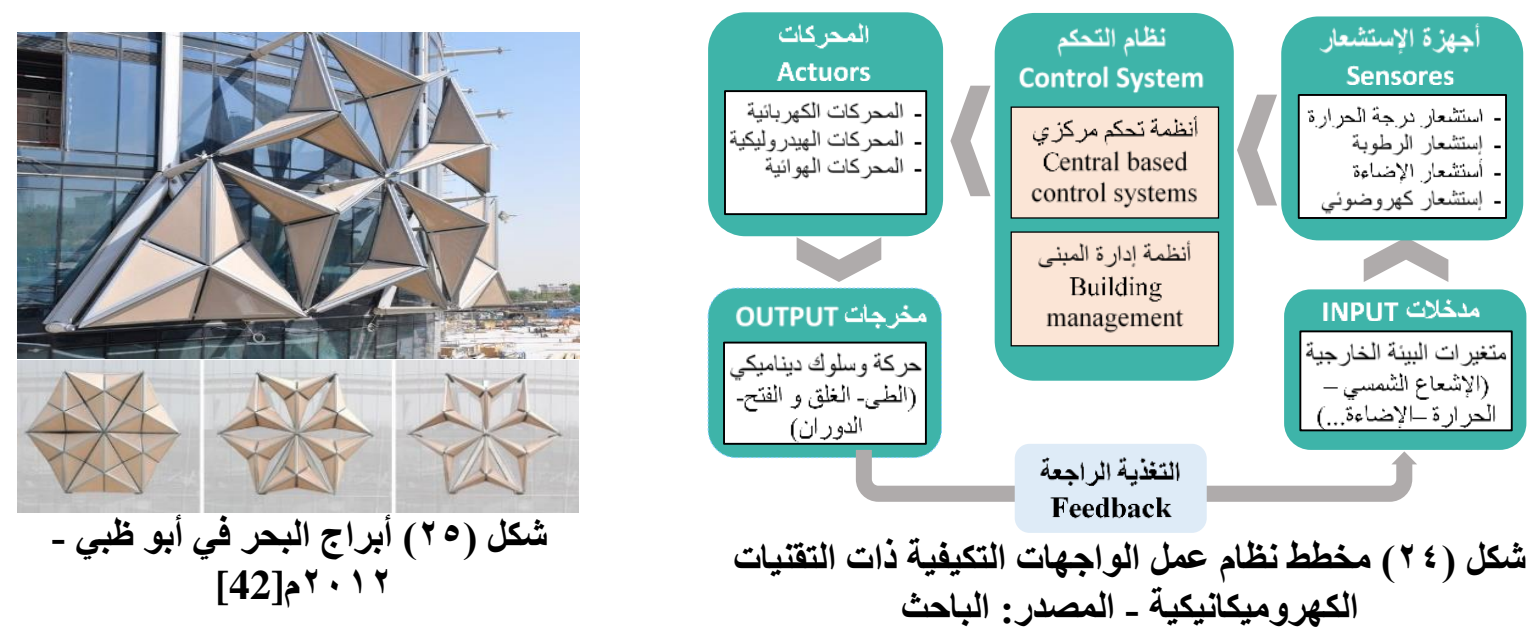


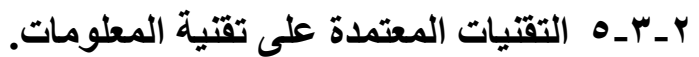
غيرت تقنية المعلو مات من طريقة تطبيق نظم التحكم في الأنظمة الكهروميكانيكية ، حيث تم استخدام فكرة نظام التحكم الموزع في الواجهات التكيفية للتحكم في الألواح المترابطة بواسطة فئة وحدات التهات تحكم دقيقة microcontrollers

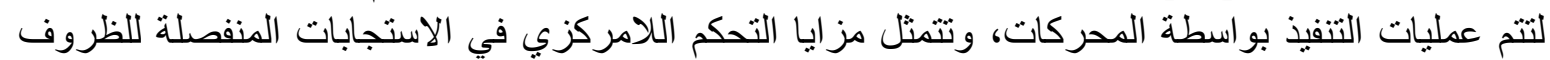

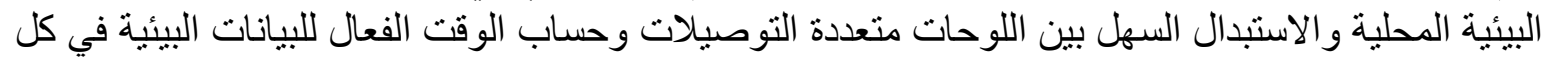

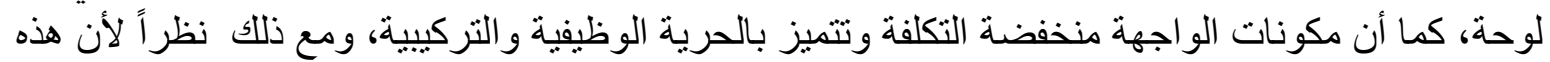

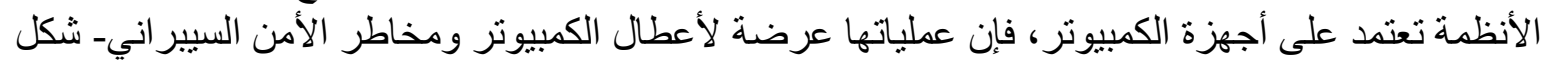

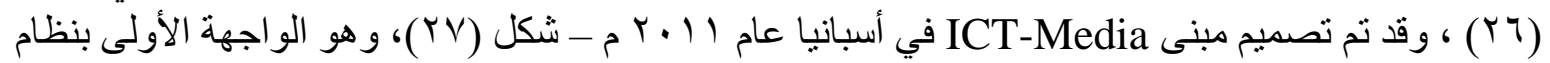

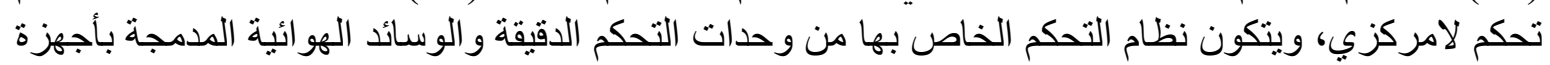

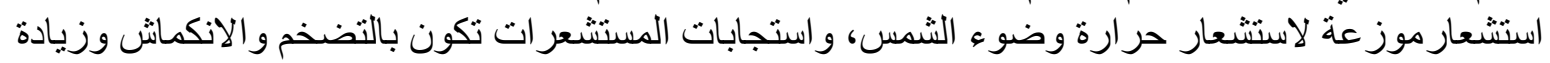

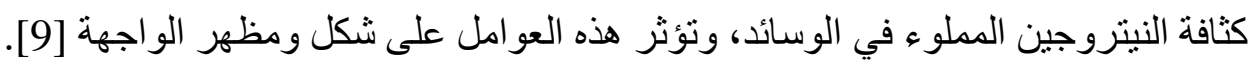
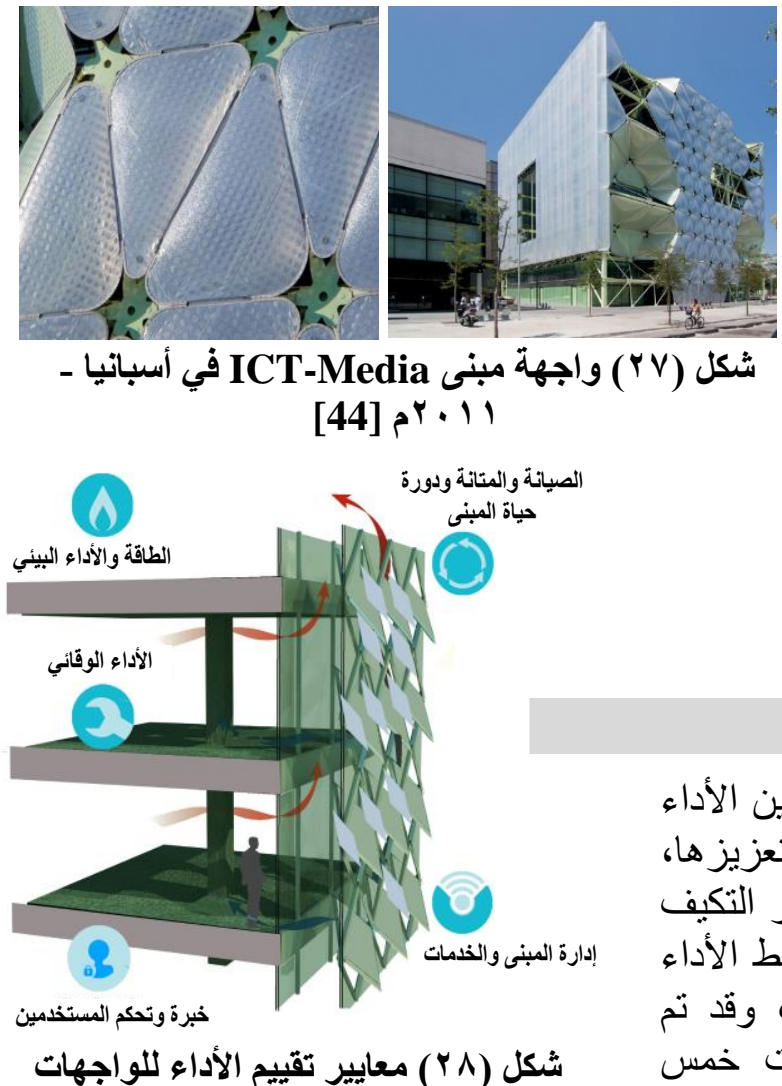

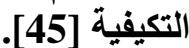

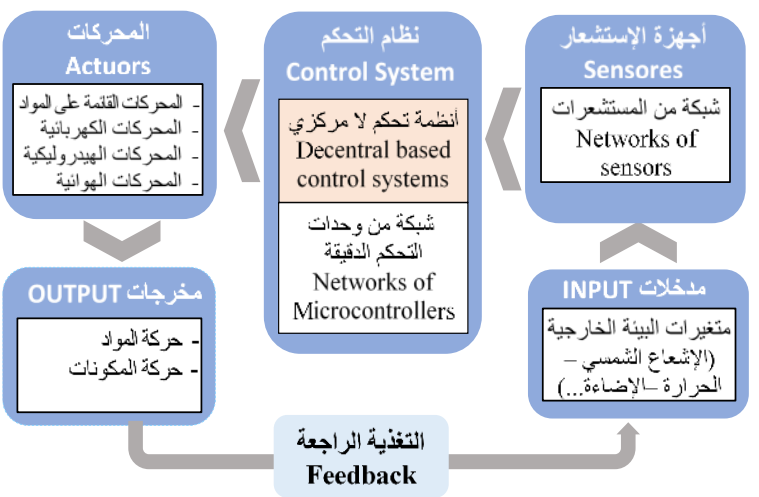

شكل (Y Y ) مخطط نظام عمل الواجهات التكيفية القائمة على تقنية المعلومات ـ المصدر : البطات البكات

\section{r. الأداء للواجهات التكيفية. .}

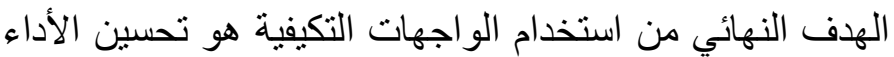

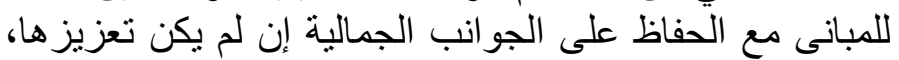

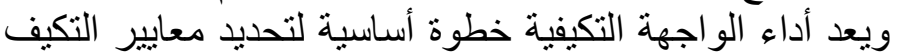

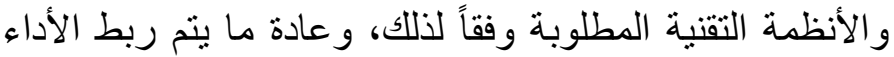

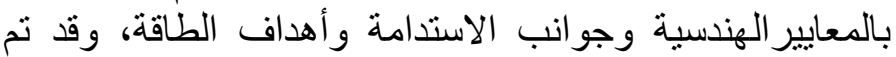

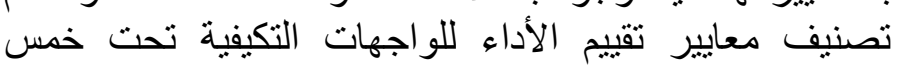

\section{rـ}

استهالك الطاقة والإنبعاثات الناتجة خلال عمليات دورة حياة المبنى من أهم التأثير ات السلبية للمباني على البياتئة

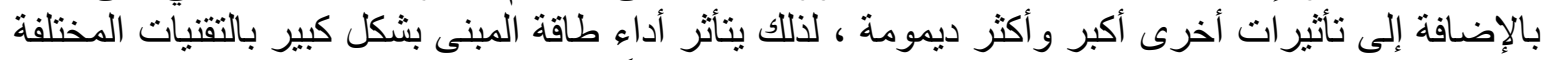

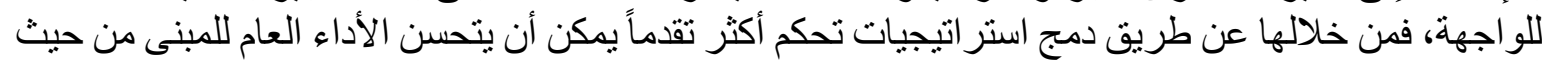

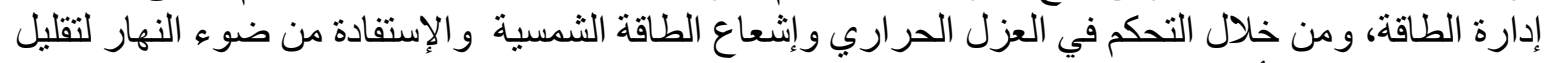

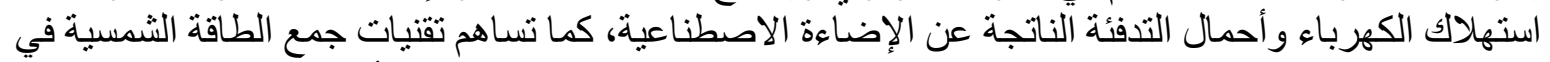

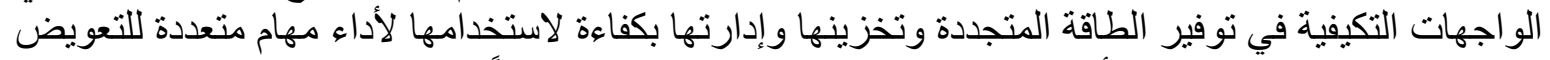

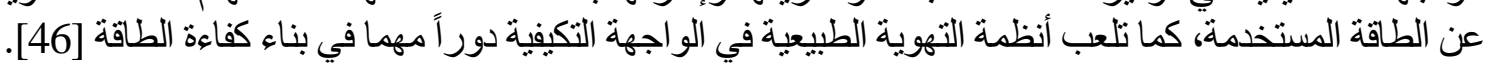




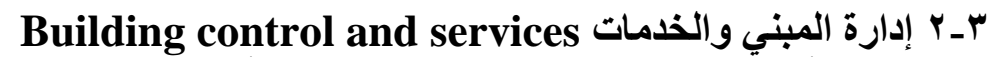

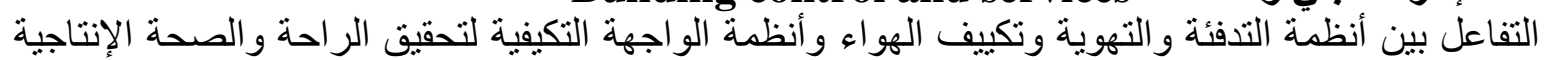

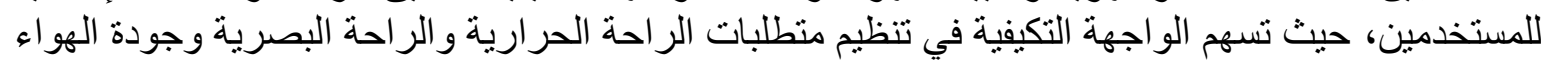

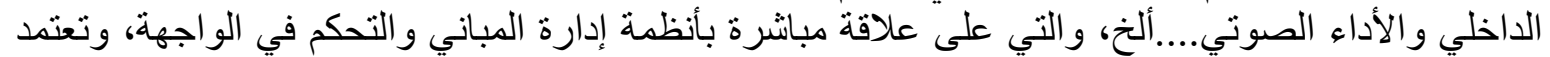

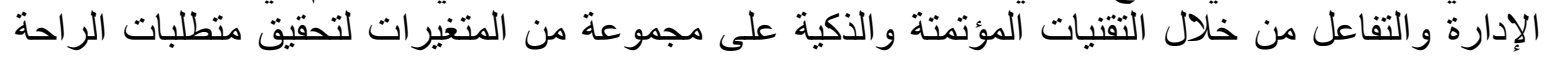
الاخلية، وفيما يلي الأربعة مجالات رئيسية للراحة الإنية الذاخلية:

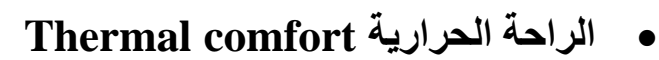

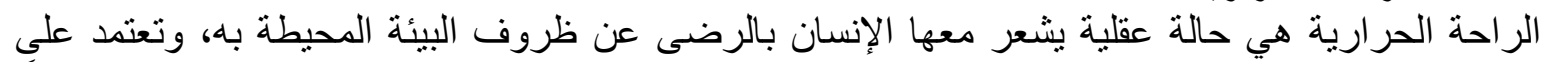

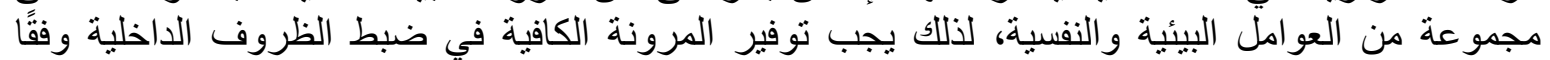

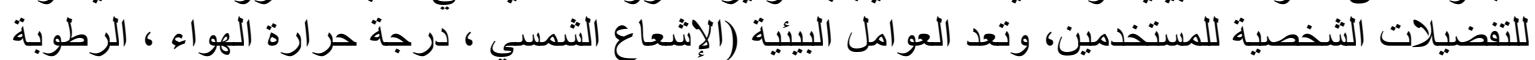

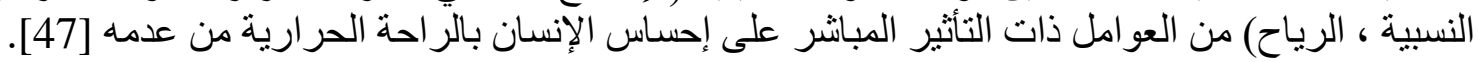

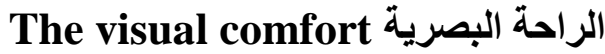

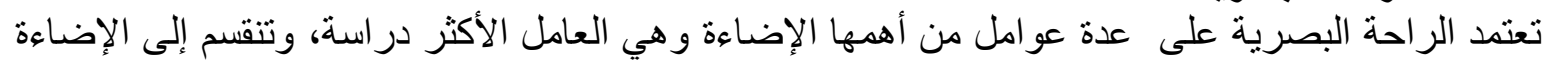

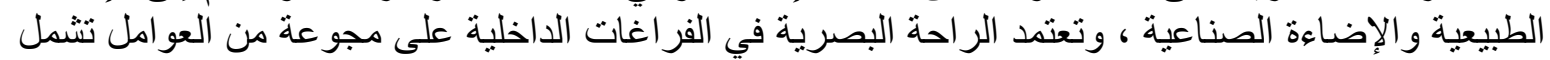

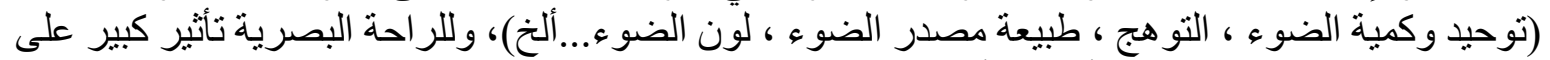

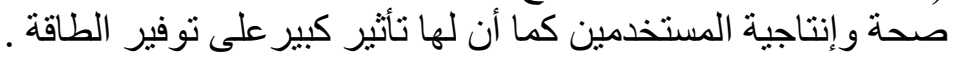

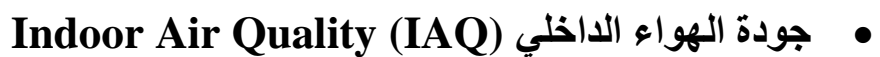

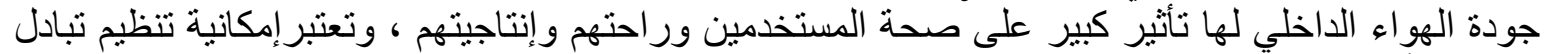

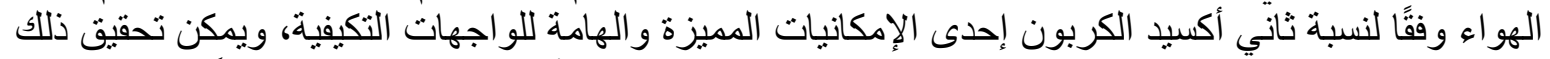

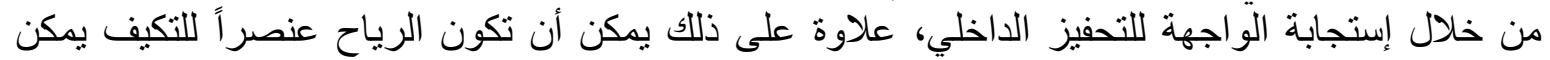

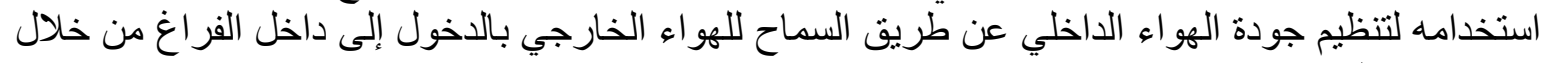

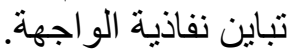

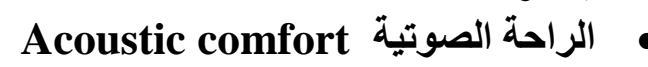

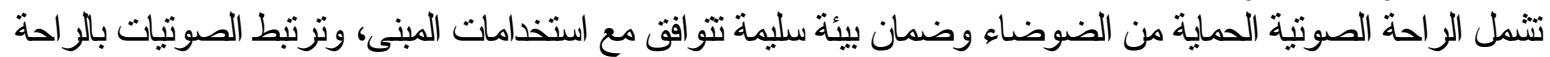

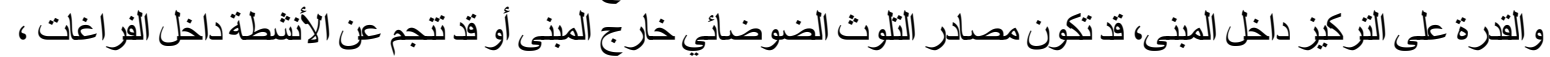

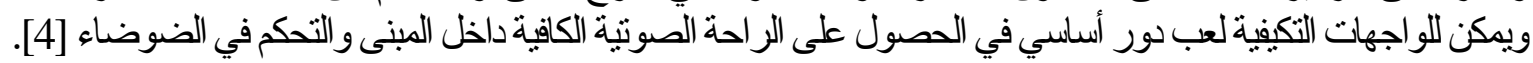

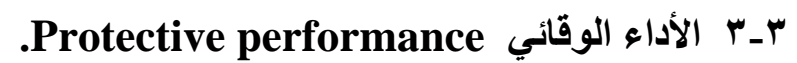

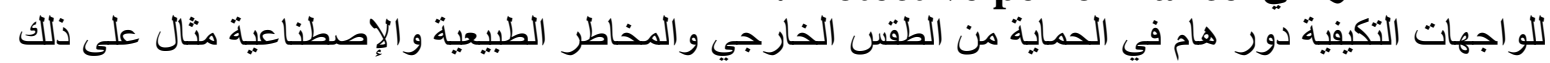

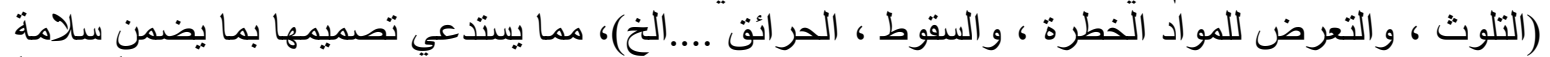

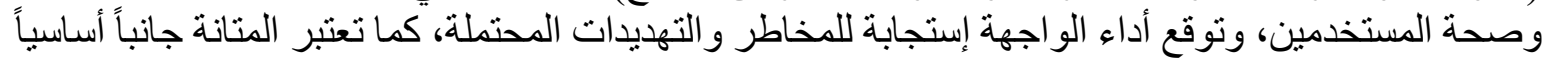

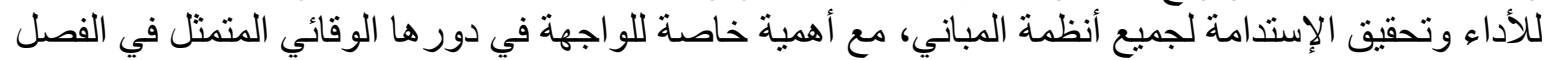

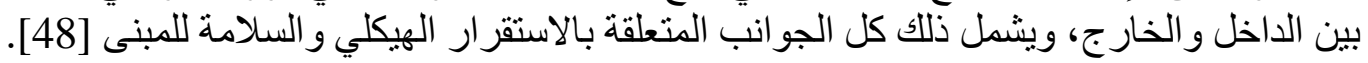

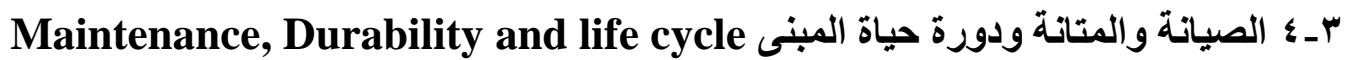

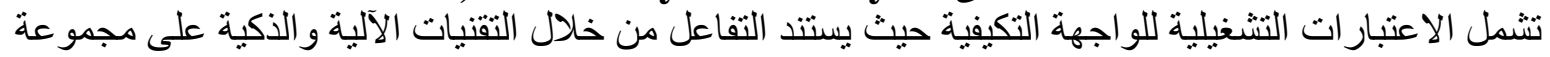

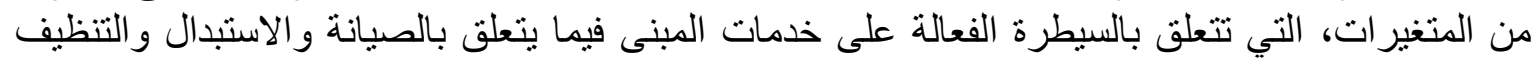

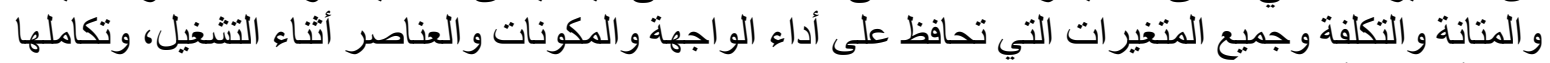

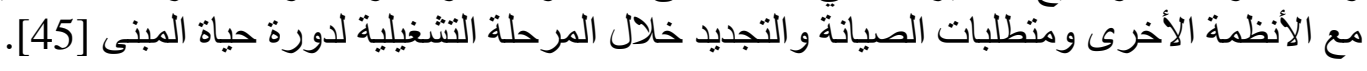

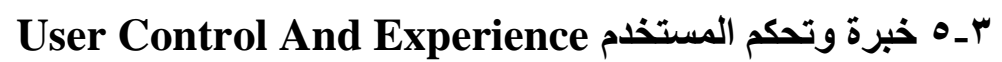
يشمل هذا المعيار التفاعل بين المستخدم وواجهة المبنى التكيفية لتحقيق مستويات الراحة المطلوبة لئنية يضم

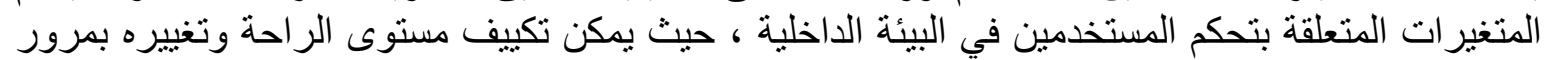

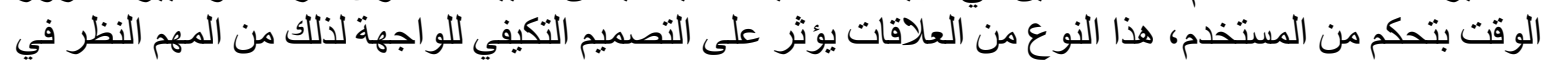

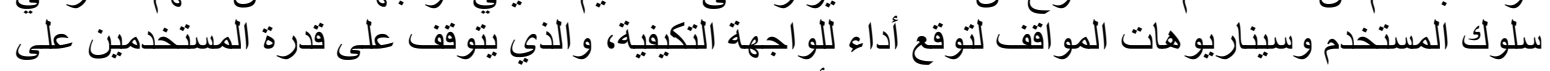

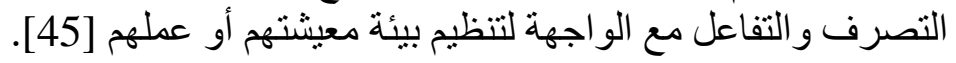




\section{ع. ـ دراسة تحليلية لنماذج واجهات تكيفية.}

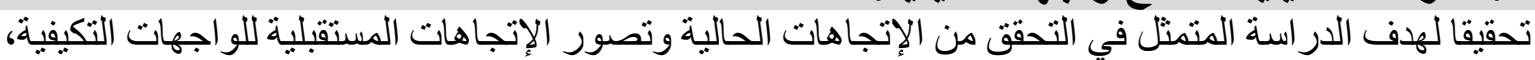

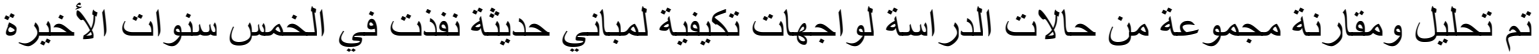

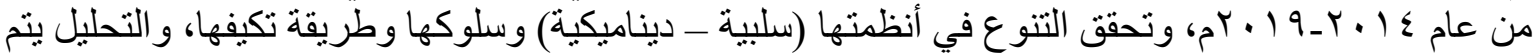

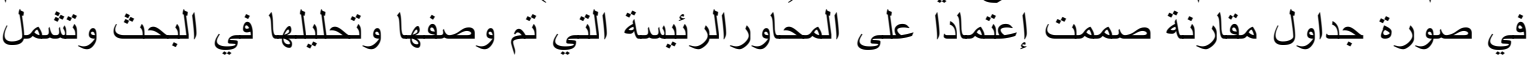
(خصائصها_سلوكها_ المواد ـ المكونات ـالأنظمة ـ تقنيات التشغيل - الأداء ) .

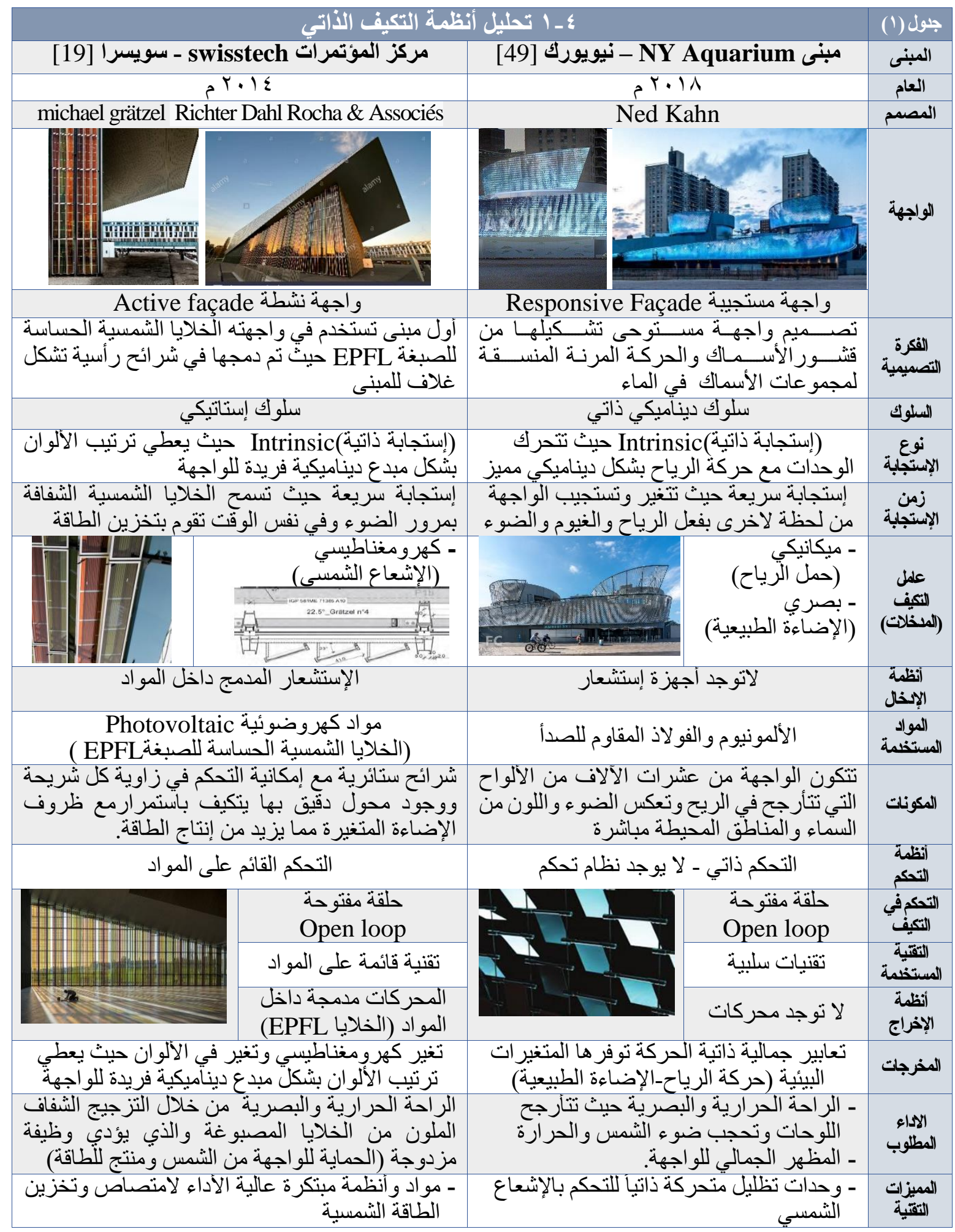




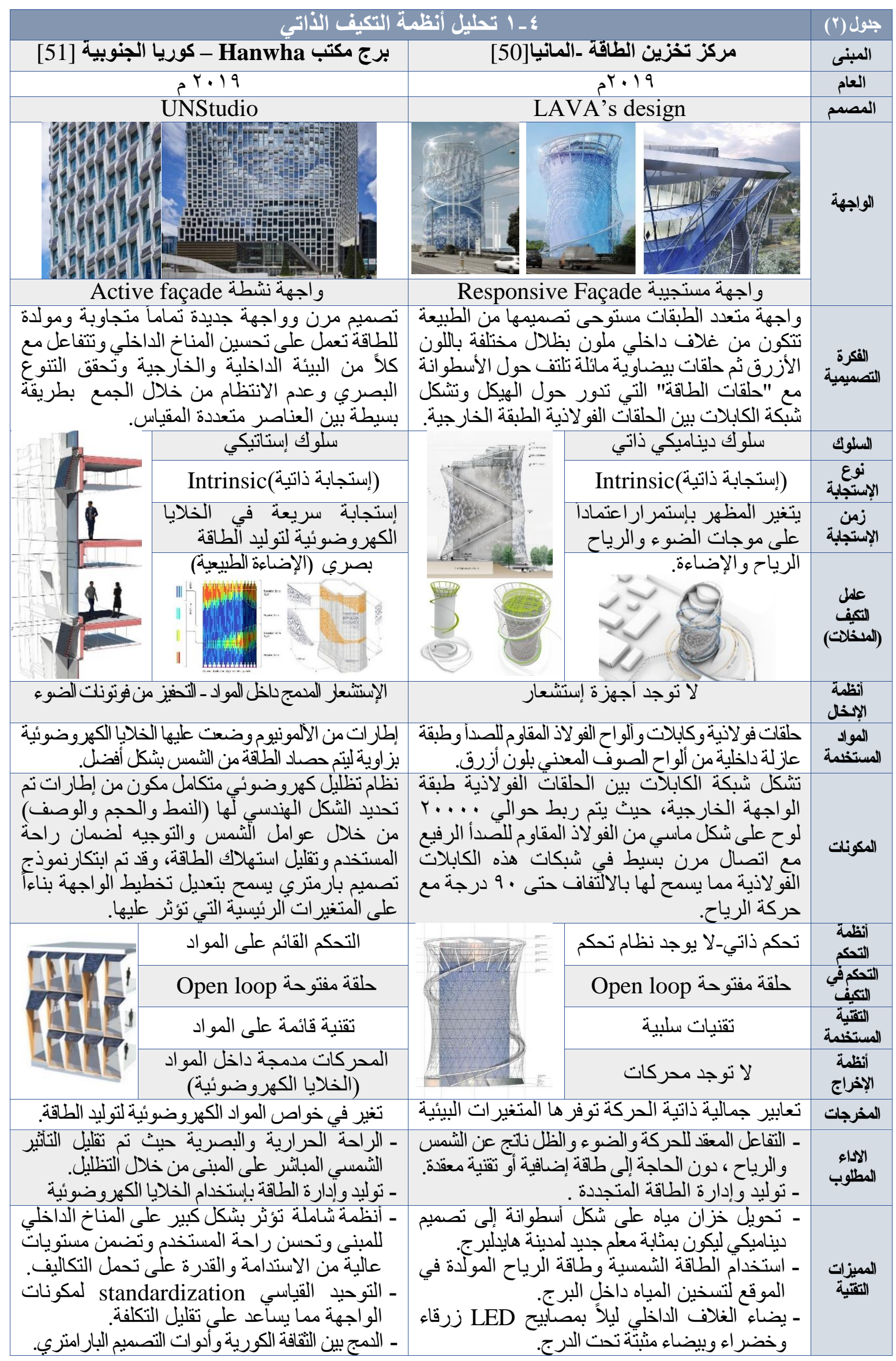




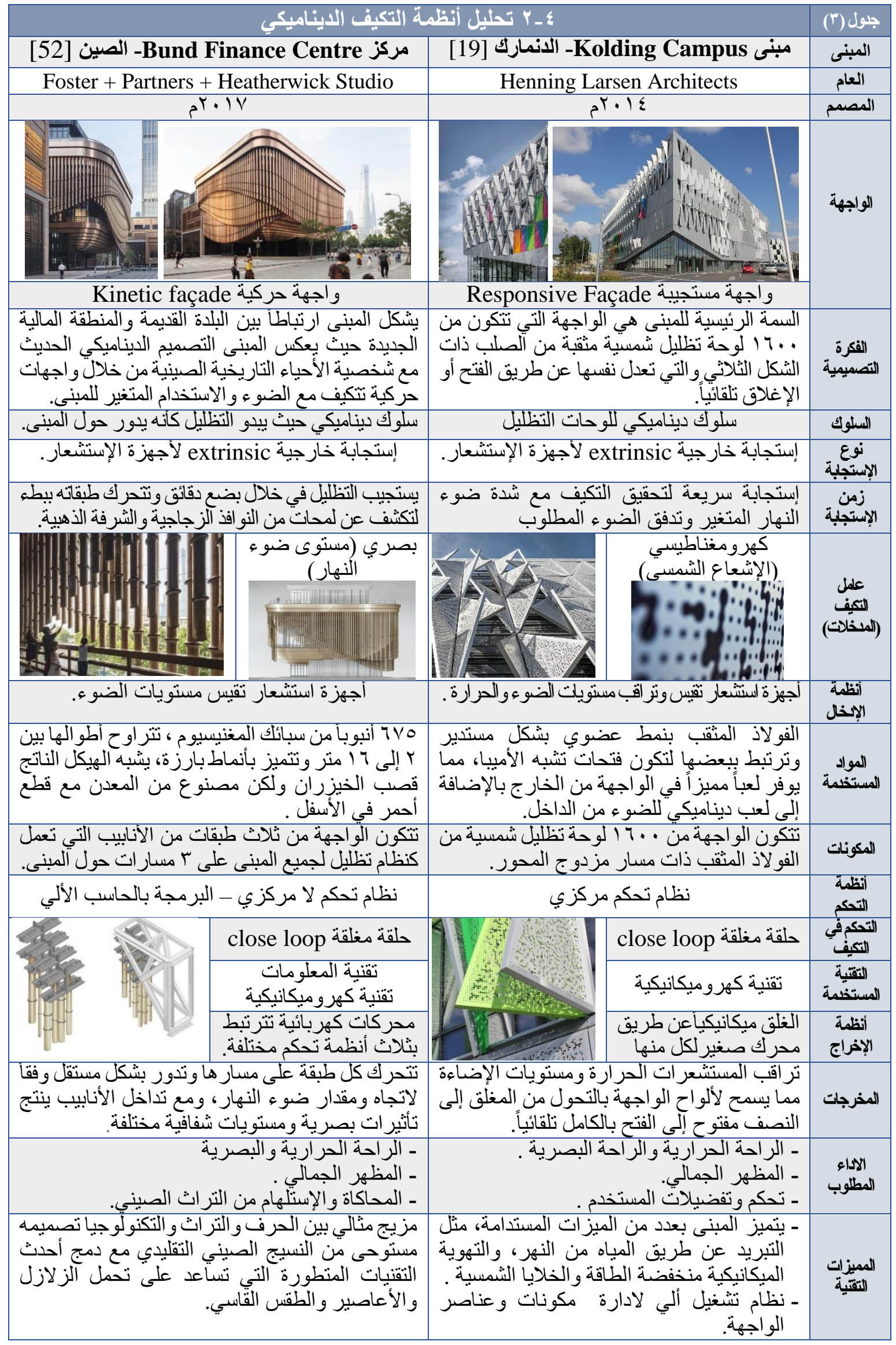




\section{مبنى The Shed Hudson- نيويورك[12 $3^{r \cdot 19}$} Diller Scofidio + Renfro
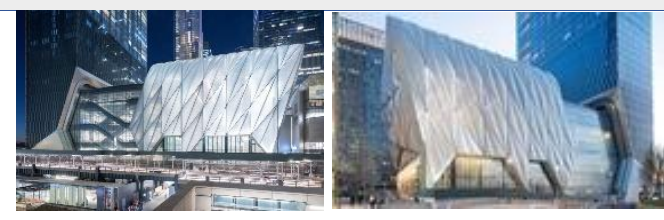

واجهة قابلة للتحول Transformable Façades المرونة في تمكين المبنى من التكيف مع التغييرات

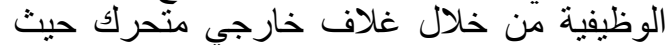

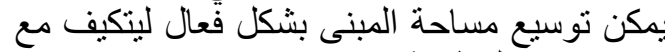

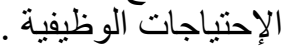
سلوك ديناميكي لهيكل و غلاف المبن المبنى الخارجي إستجابة خارجية extrinsic تبعا لإحتياجات النيات المستخدمين خلال خمس دقائق يمكن نقل الهيكل و الغلاف حيث تم تصميم المبنى كآلة ديناميكية تكيفية وتفاعلية لونية

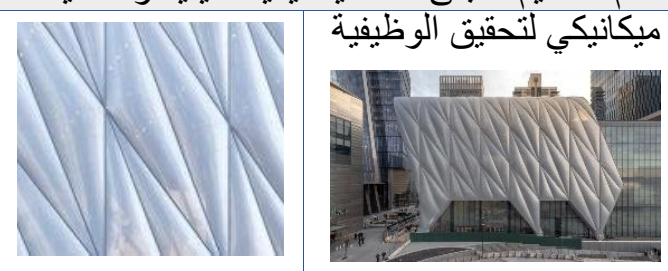
البرمجة البدوية اعتمادا على ظروف تشغيل المبنى

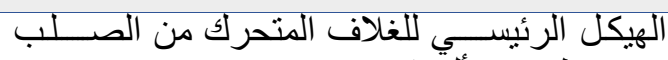

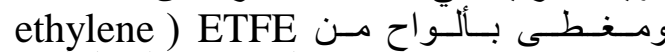
تم tetrafluoroethylene

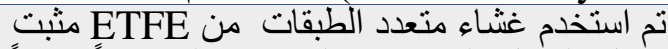
داخل الهيكل الفولاذي والذي يتحرك ذهاباً وإياباً

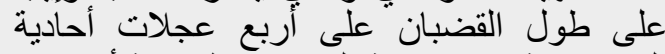

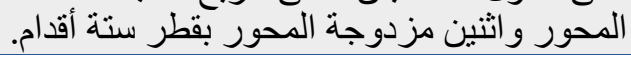
التحكم المركزي- تحكم المستخدمين ـ البرمجة ولنه

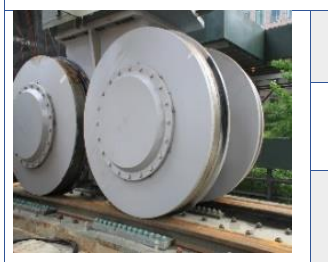

حلقة مغلقة close loop

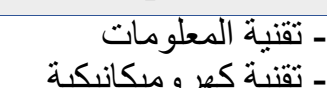

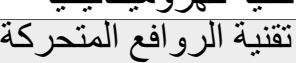
و المحركات الكهربائية هيكل الغلاف يتحرك ذهاباو إيابا بإنتخدام العجلات كما

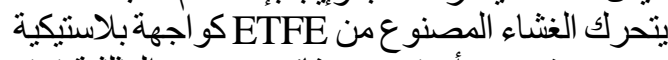

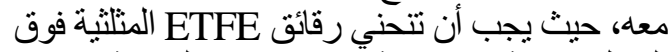

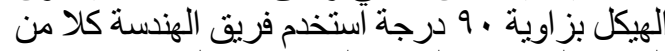

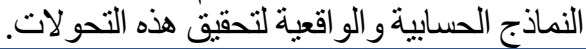
- المرونة التصميمية لتحقيق الوظائف المتعددة للفز اغات.

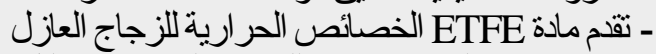
مع خفة في الوزن وتسمح للضوء بالمرور مع تقائليل

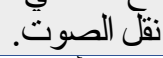

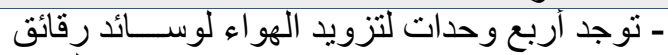

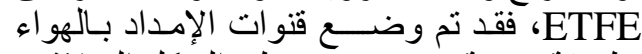
بطريقة مخفية في مستوى سطح الهيكل الفو لاذي

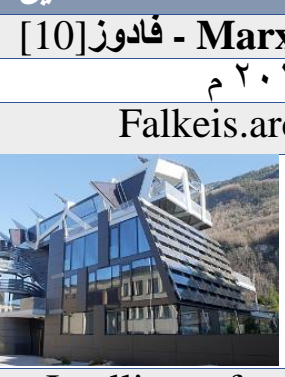

واجهة ذكية Intelligent façade

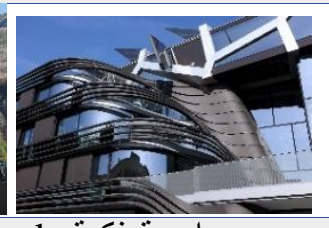

مبنى سكني مستدام مستوحى تصميمه من الطبية الطيعة

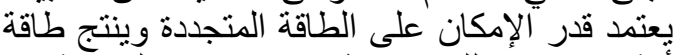

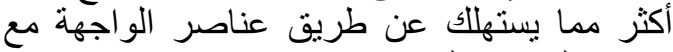

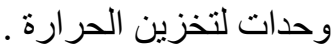
- سلوك ديناميكي للاجنحة المتحركة والخان الخايا الثمسية

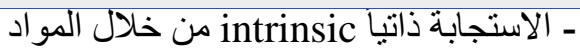

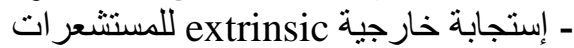
إستجابة سريعة حيث تتبع الخلايا الثمسية مسار

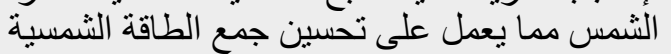

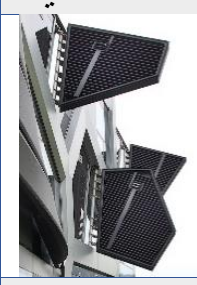
كهرومغناطيسي (الإشعاع الثمسي)

شبكة من المستشعرات

(2)

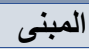

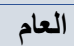

المصمم

الواجهة

الفكرة

التصميمية السلوك نوع العنوية

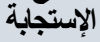
زمن الإستجابة

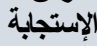

أستخدمت مادة RUBITHERM PCM داخل أنابيب من الألمونيوم وهي مواد مبتكرة لتغيير الطور تعتئد

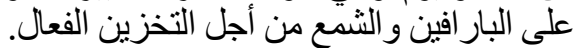

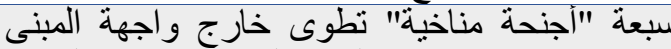

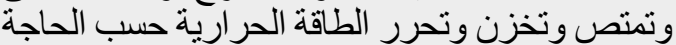

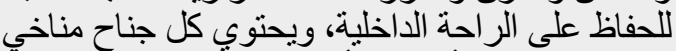

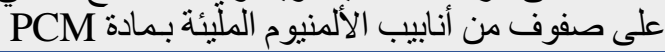
نظام تحكم لامركزي ويتم التحكم في حركة الإجنحة و الخلايا الثُمسية بيرمجة من الحاسب الألي

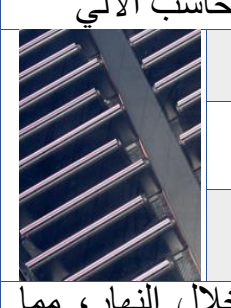

حلقة مغلقة close loop - تقنية المعلومات ـ ت تقنية المو اد المتطورة المحركات الكهربائية

علمل

النكفيف

(لالنغلات)

أنظمة

الإنخل

المواد

المستخمة الموال

المكونات

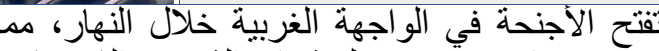

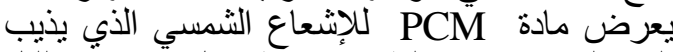

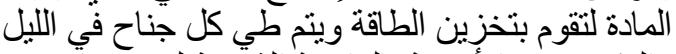

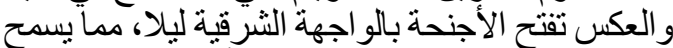
للإهو اء البارد بتصلد PCM و الإنقل الأجنحة بالنهار.

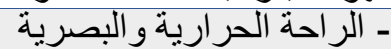

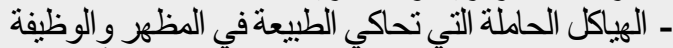
ـ توليد الطاقة من خلال ألخلايا الثمسية ولية الأجنحة السبعة - توليد - وحدات تظليل متحركة للتحكم بالإشعاع الثمسي التهي - إدارة التهوية الطبيعية - نظام تشغيل ألي لادارة مكونات وليعة وعناصر الواجهة الاداء المطلوب

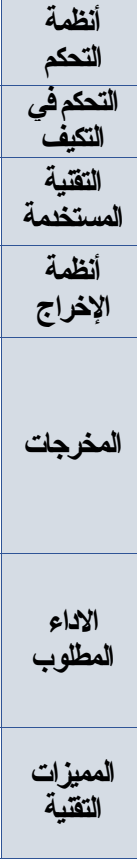


حققت حالات الدر اسة مفاهيم وخصائص تكيفية متنو عة من خلال إستخدام المو اد و المكونات التكيفية المبتكرة وكلا

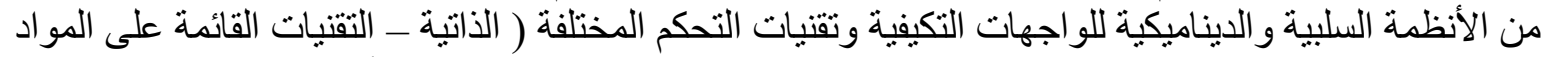

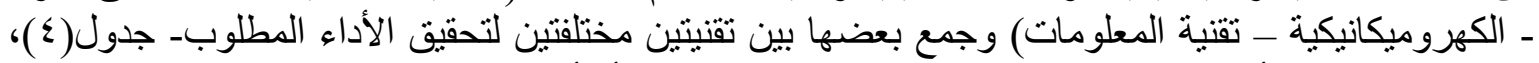
وبشكل عام تميزت أنظمة الواجهات المتكيفة التي تم تحليلها بو احدة أو أكثر من المميز ات التئنة التقنية التالية:

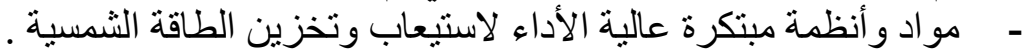

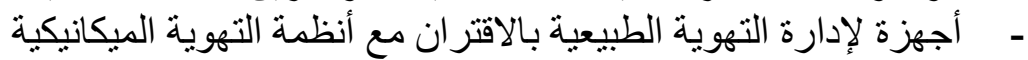

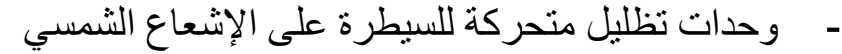

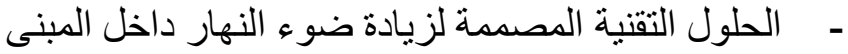

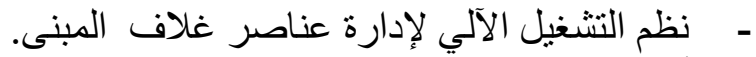

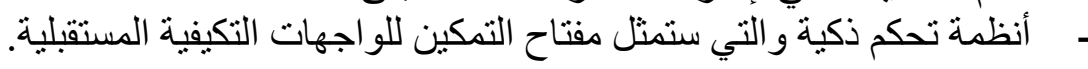

\section{•. صياغة الإطار المستقبلي للواجهات التكيفية.}

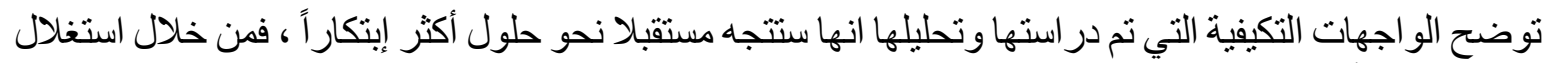

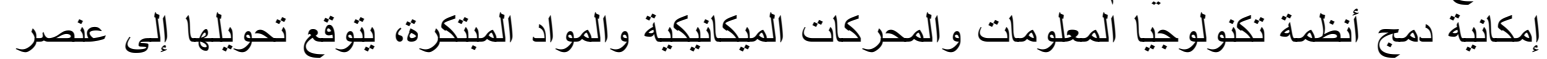

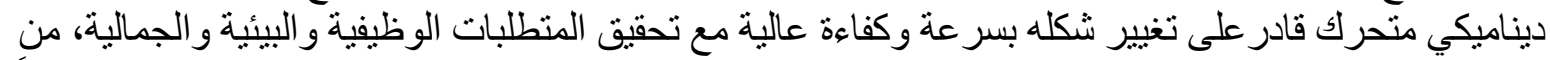

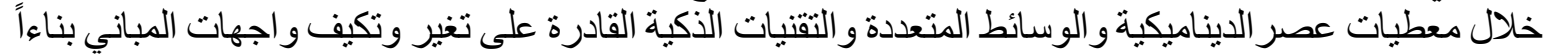

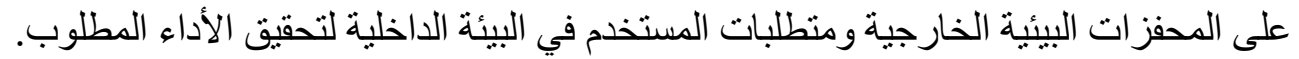

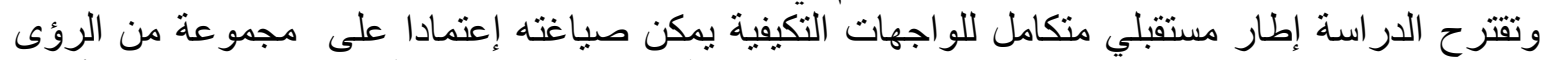

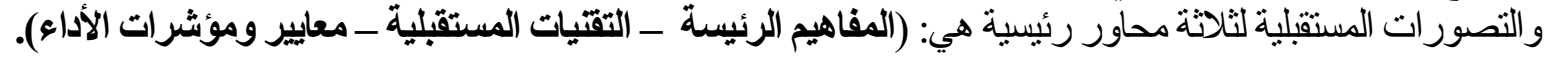

\section{هـ ا مفاهيم رئيسية للواجهات التكيفية في المستقبل.}

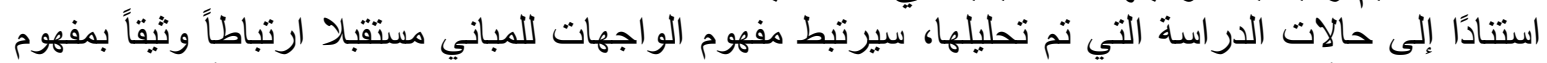

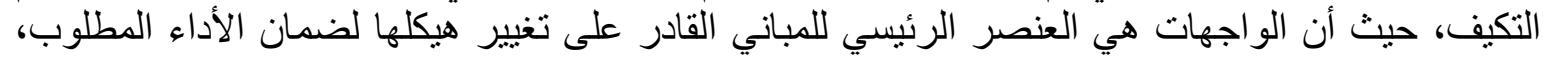

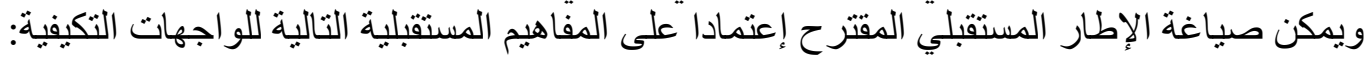

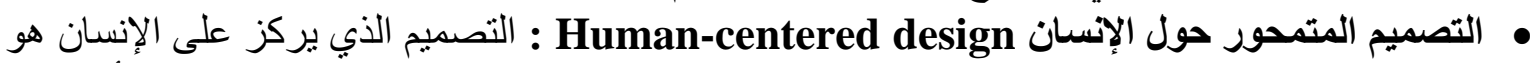

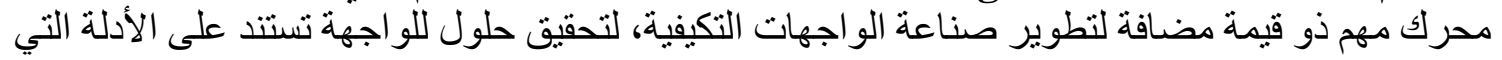

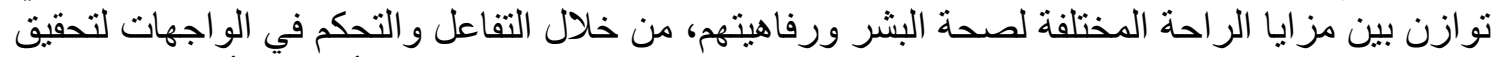

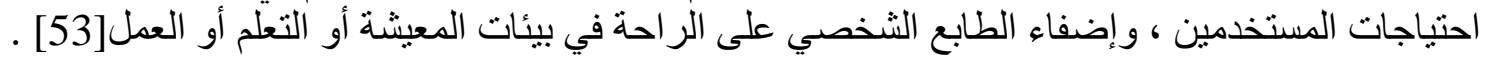

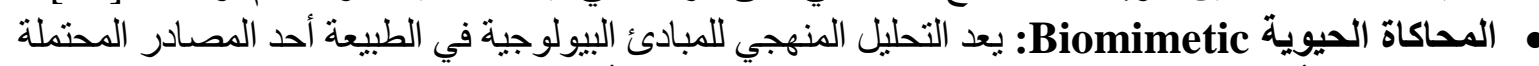

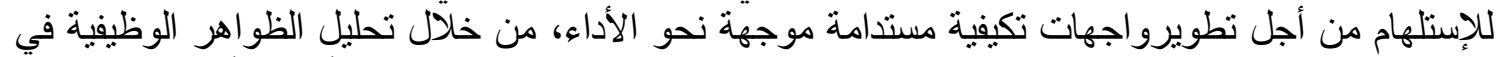

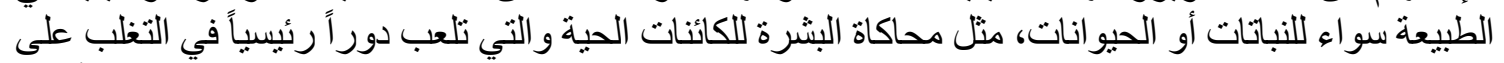

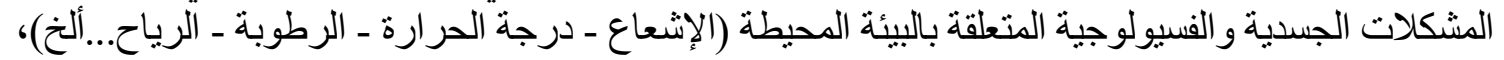

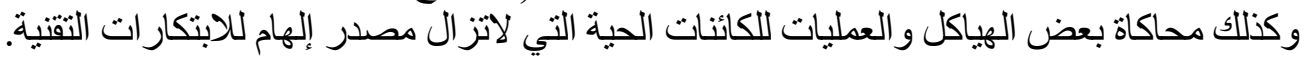

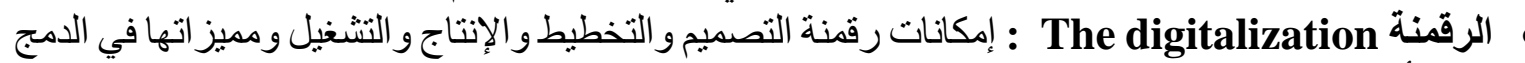

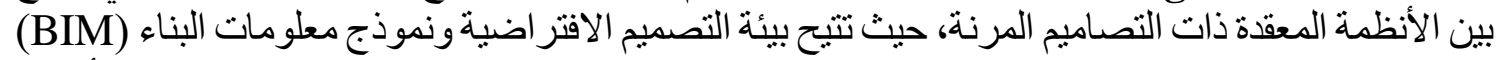

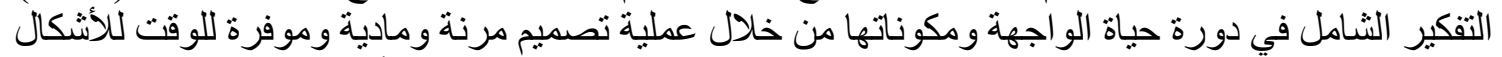

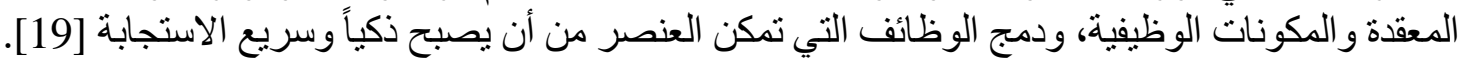

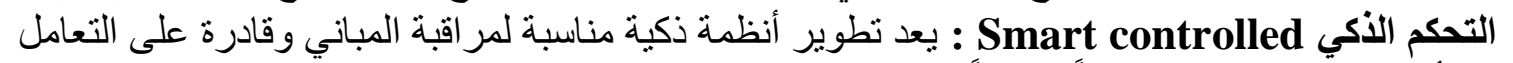

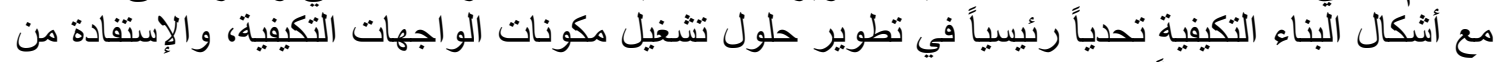

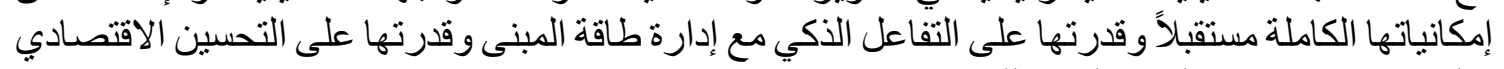
و المساهمة في توفير الحياة الذكية للمستخدمين .

r_o

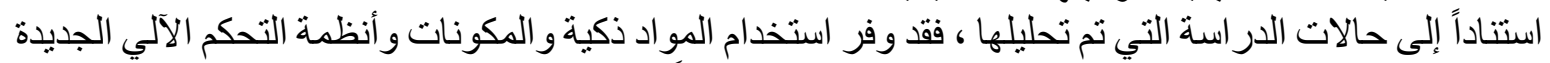

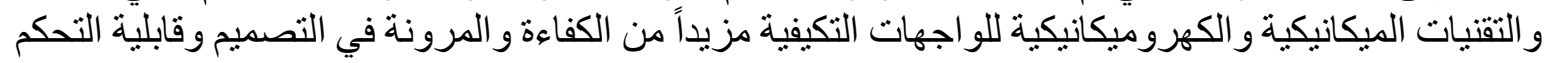


و الاستجابة و التتوع ، ليصبح المبنى نظاماً ديناميكياً نشطاً مستداماً، ومع ذلك في بعض در اسات الحالات نم

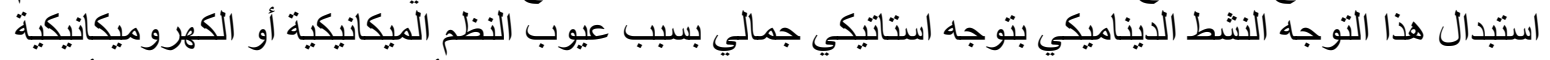

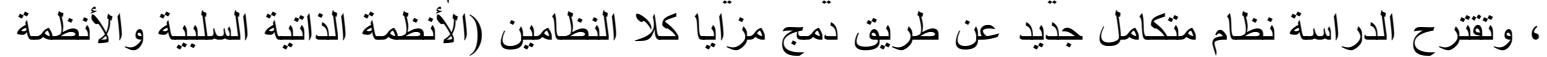

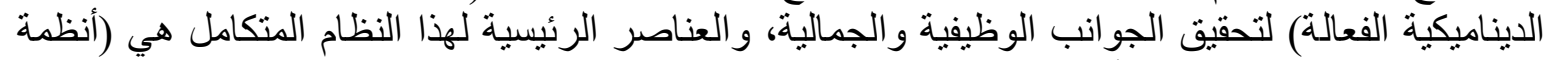

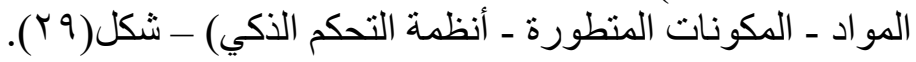

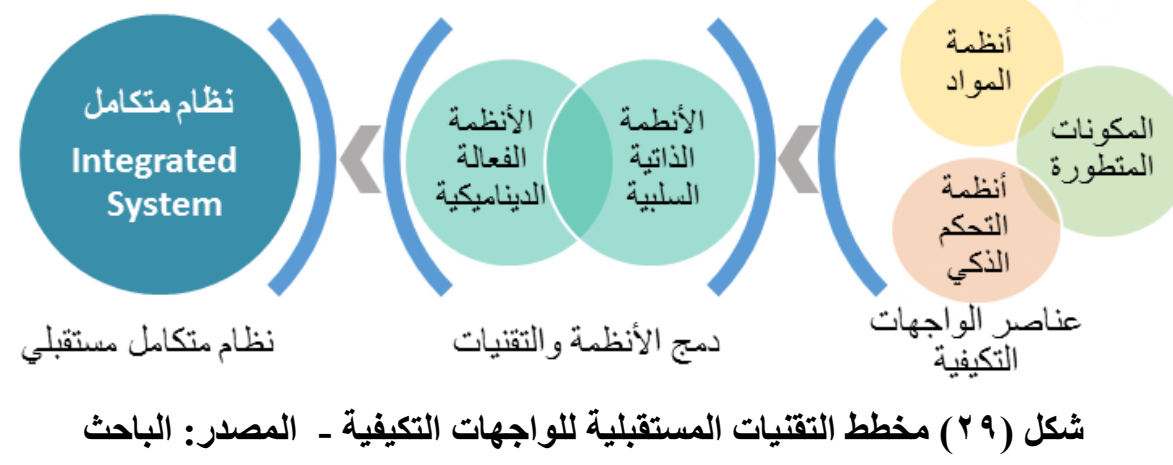

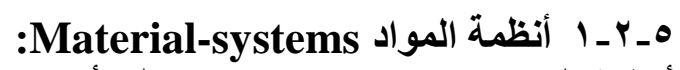

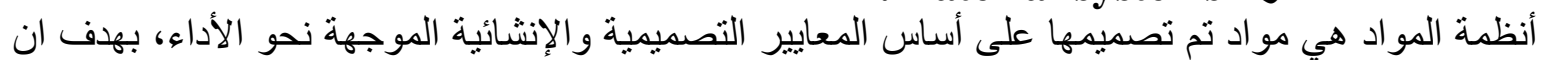

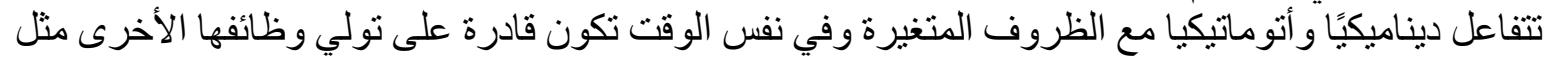

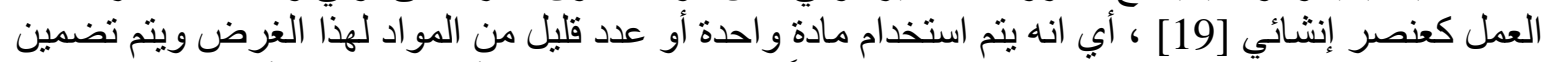

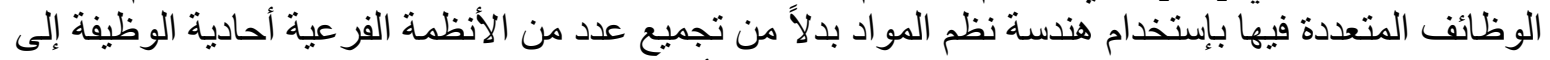

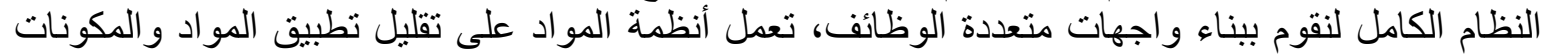

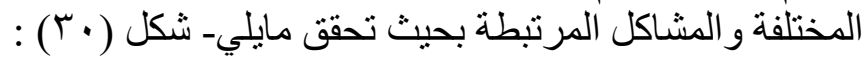

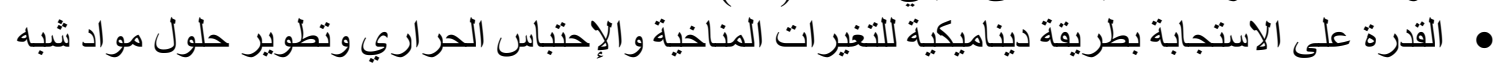

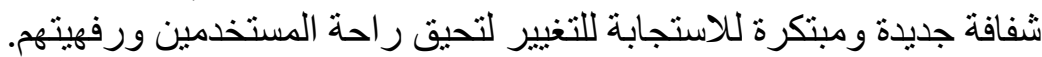

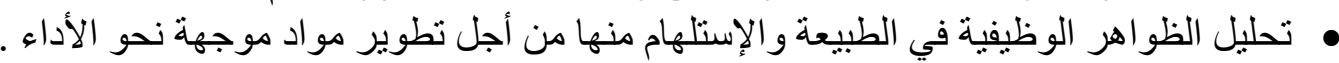

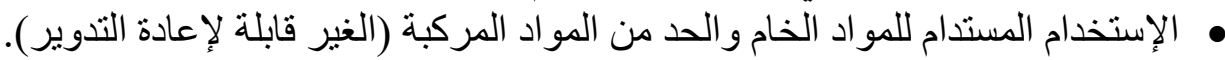

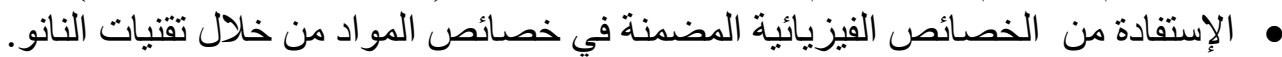

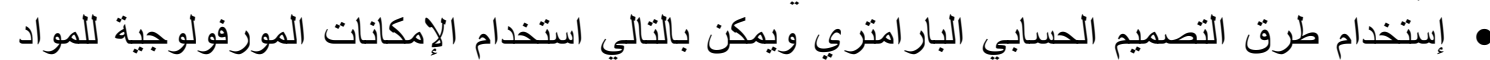

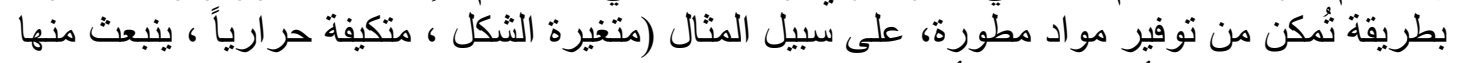

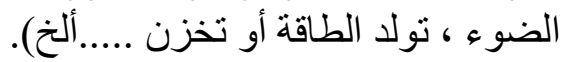
هـ التطور المستقبلي لأنظمة المو اد المصممة بذكاء يوفر الفرصة للجمع بشكل مبتكر بين التقنية الفائقة والاستدامة.

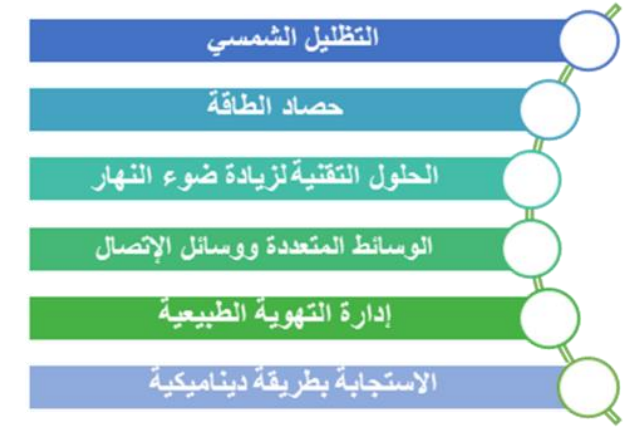

شكل ( ا M) وظائف المكونات المتطورة للواجهات

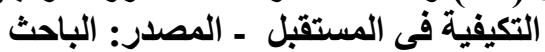

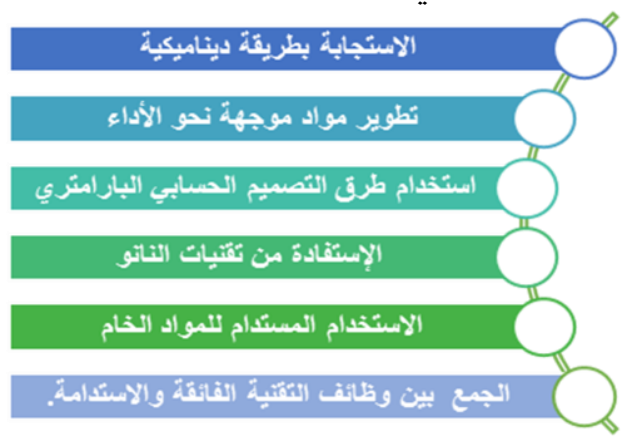

شكل (· • م) خصائص أنظمة المواد للواجهات التكيفية

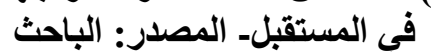

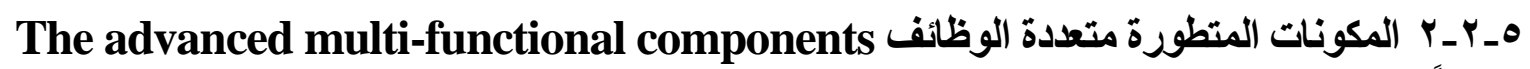

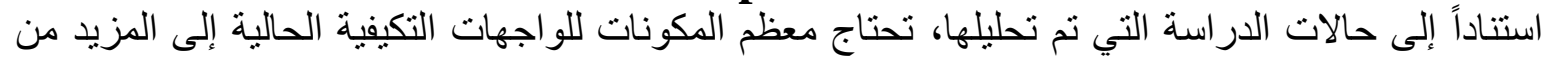

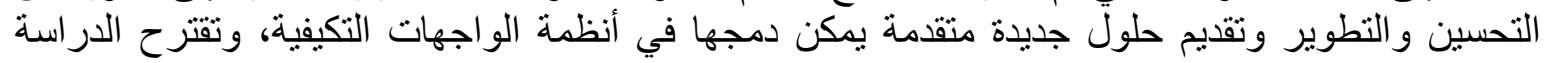


التطوير للمكونات بالو اجهات التكيفية من خلال الدمج بين المكونات التابتة و المكونات الديناميكية بطريقة تكاملية

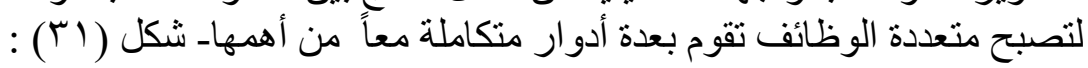

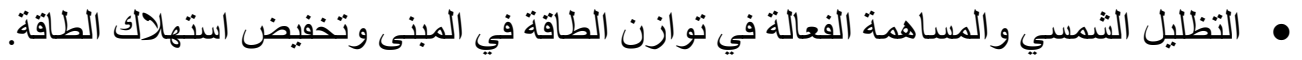

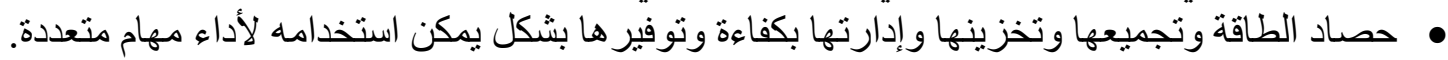

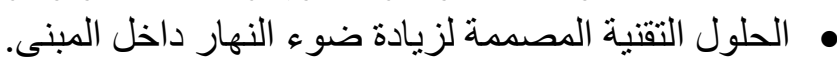

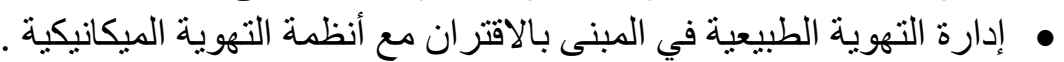

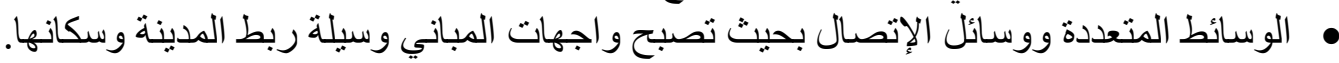

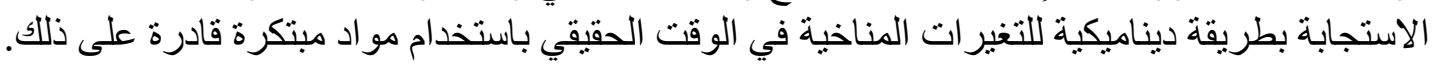

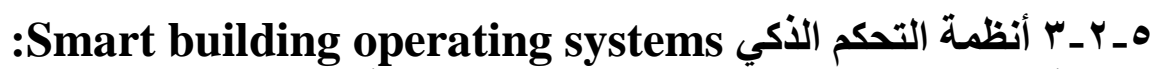
تطوير أنظمة التحكم الذكية للوأجهات التكيفية والاستخدام الأمثل لعناصر الواجهات التهات التكيفية في نظام التحكم في المبنى

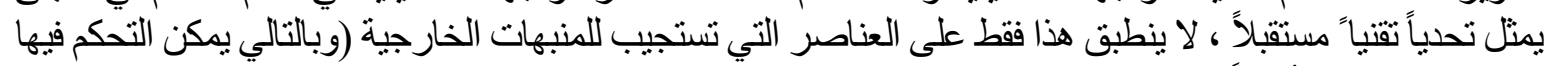

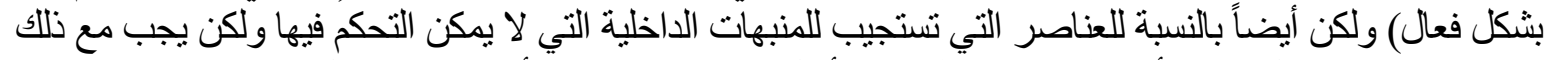

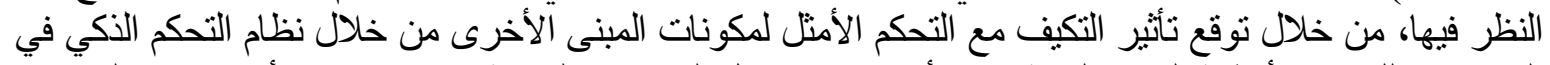

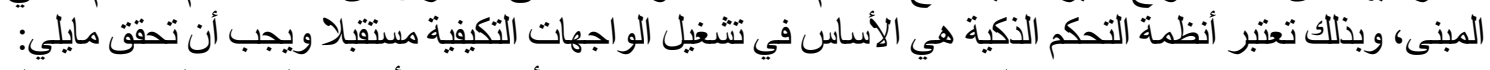

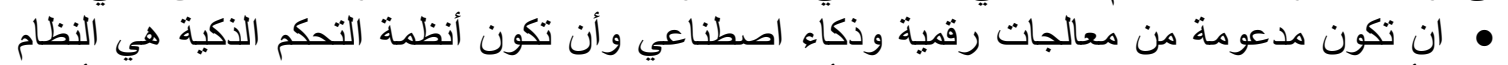

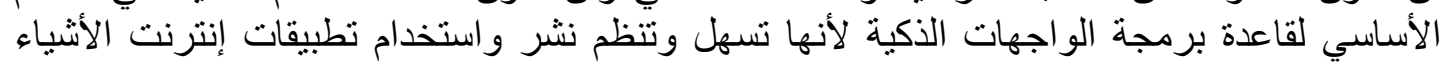

Internet of the things

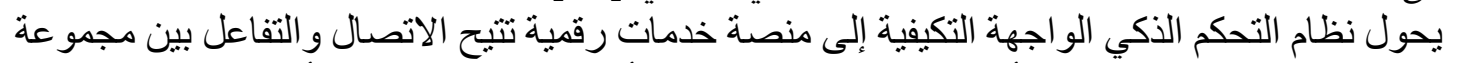

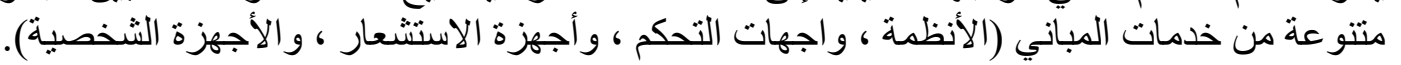

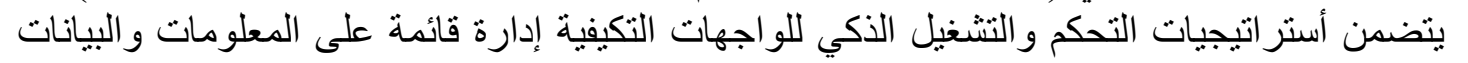

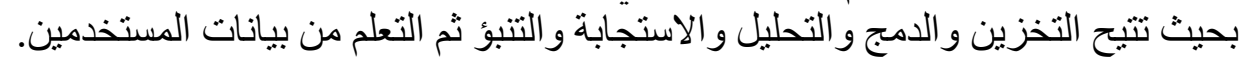

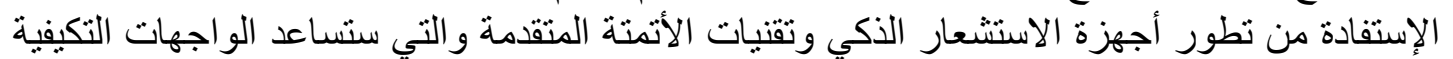

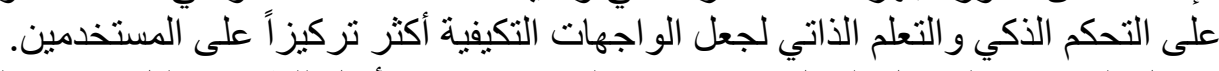

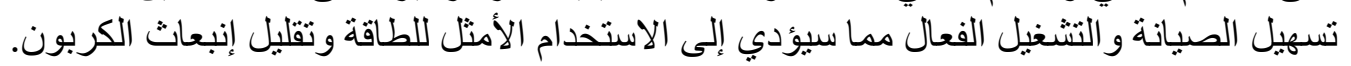

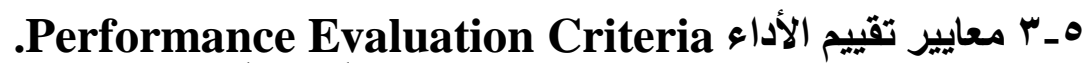

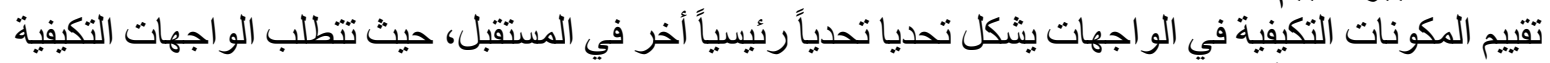

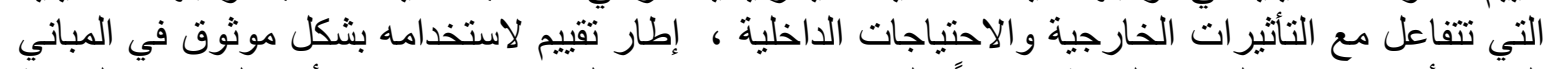

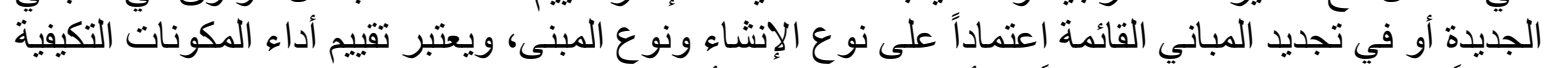

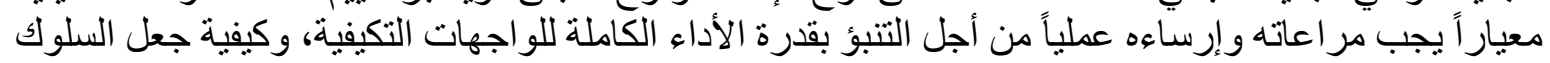

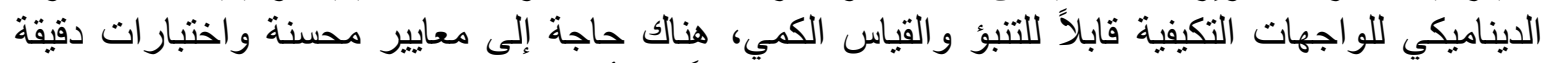

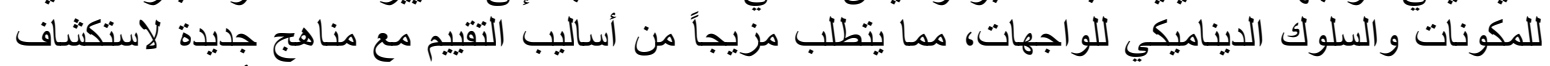

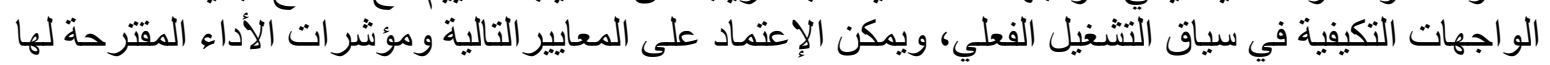

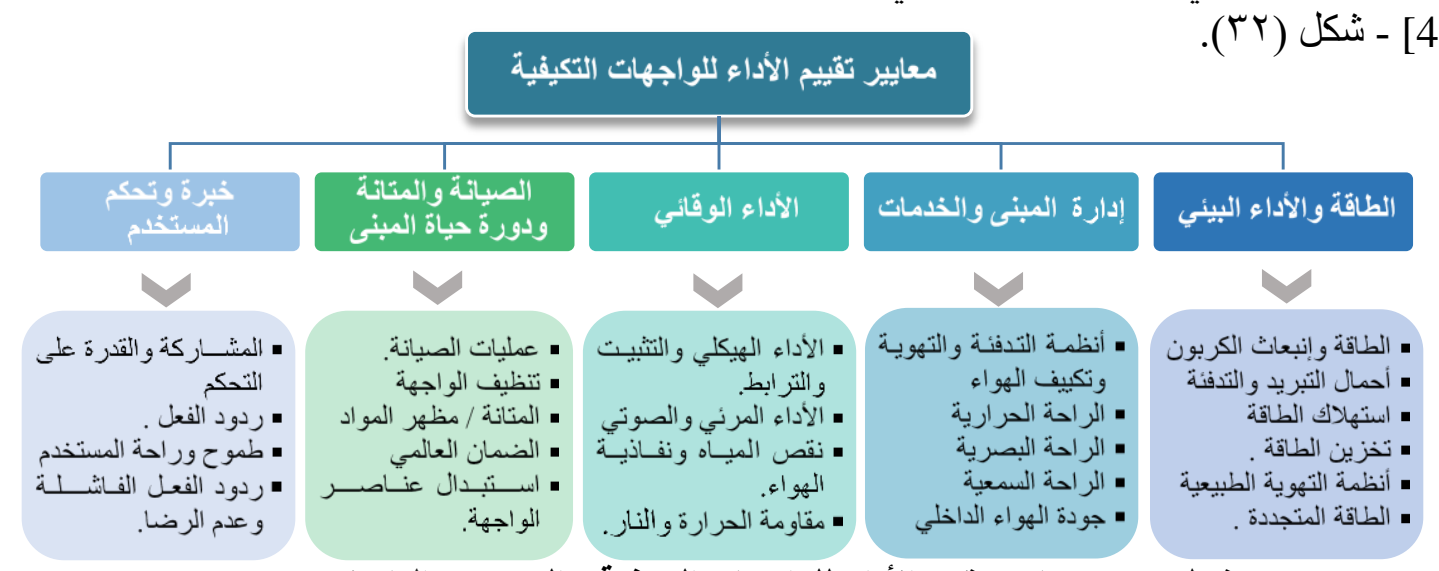

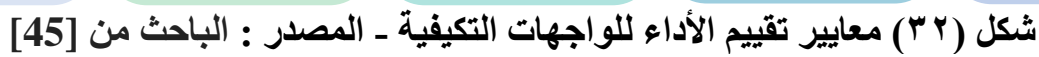




\section{0ــ الإطار المستقبلي للواجهات التكيفية.}

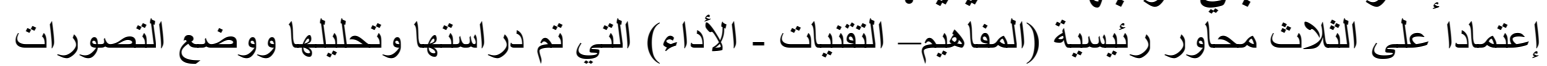
المستقبلية عنها يمكن صباغة الإطار المستقبلي المقترح و الذي يقوم على دمج التقاءئيات والأنظمة السلبية

و الديناميكية للوصول لنظام متكامل للواجهات التكيفية ـ شكل (سTr).

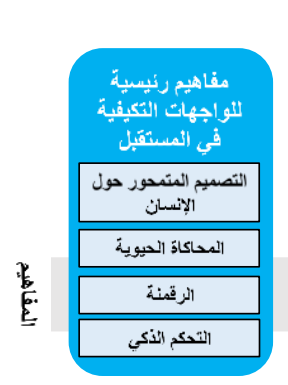

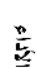

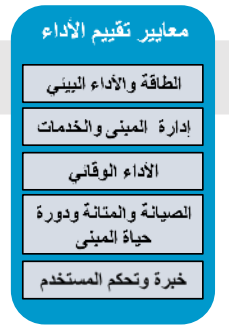

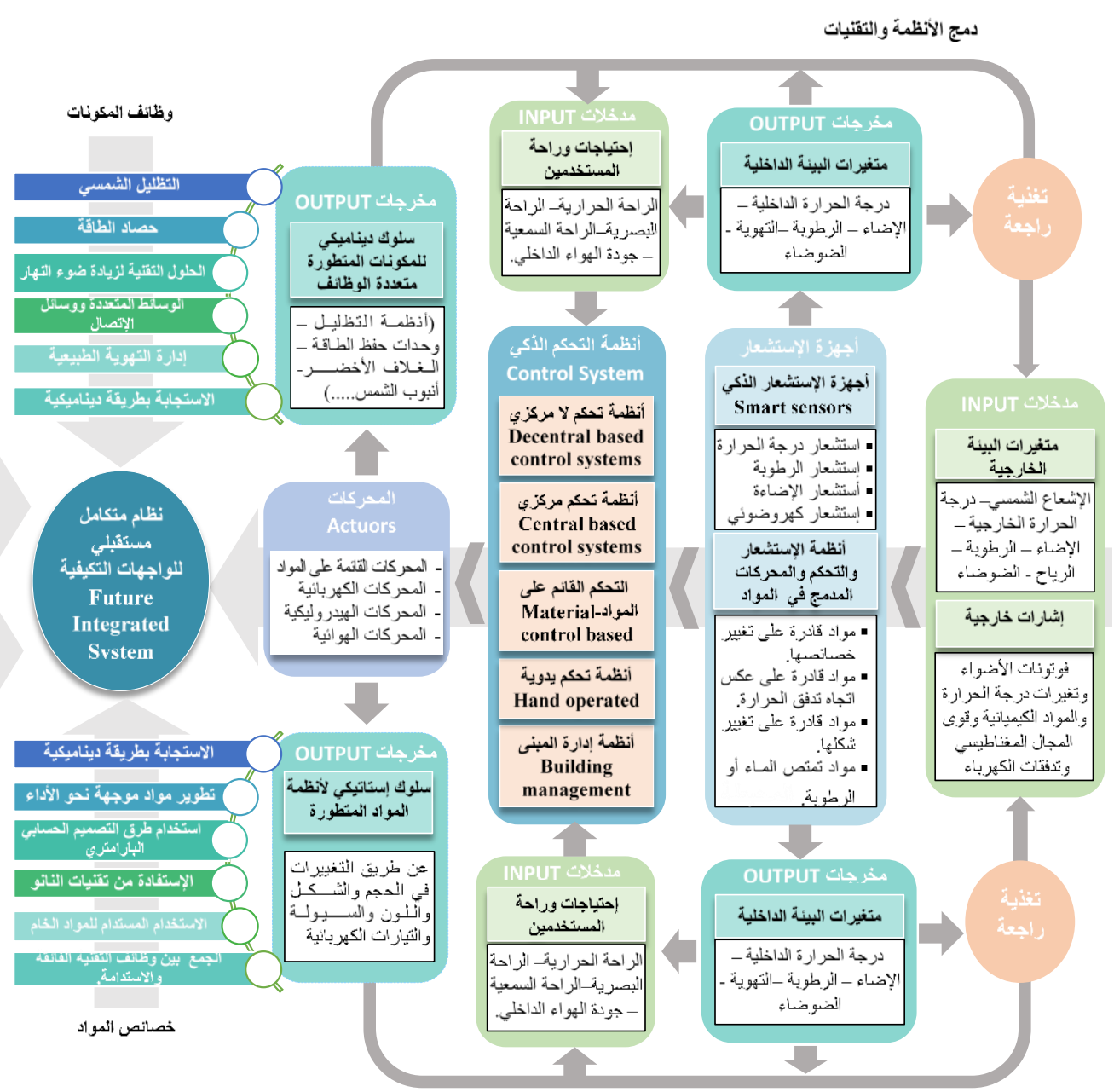

شكل (rr) إطار مستقبلي متكامل للواجهات التكيفية يقترح دمج التقنيات

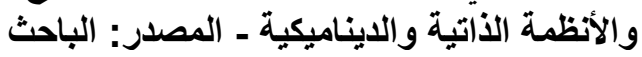

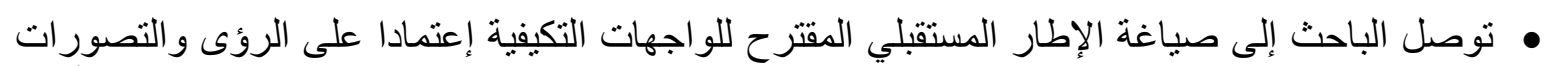

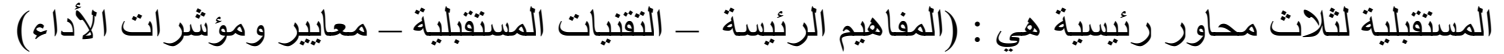

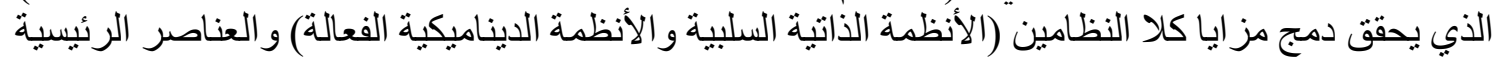

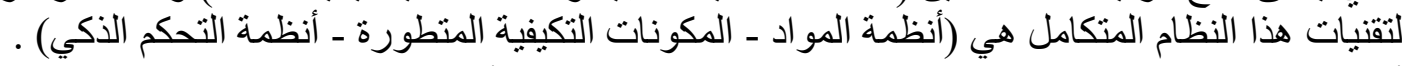

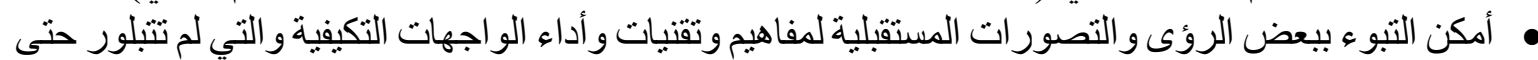

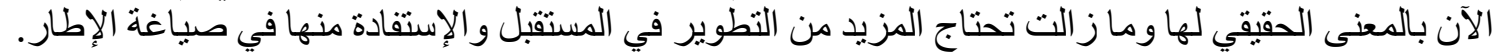

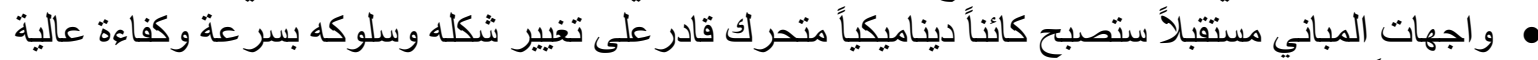
ومرتبطاً بأنظمة تحكم مركزية و لامركزية في المبنى ويتكيف بفاعلية مع المؤثرات الخارجية فئية والداخلية لتحقيق المنطلبات الوظيفية و البيئية والجمالية ور احة المستخدية فئنين ورفاهيتهم ـ 


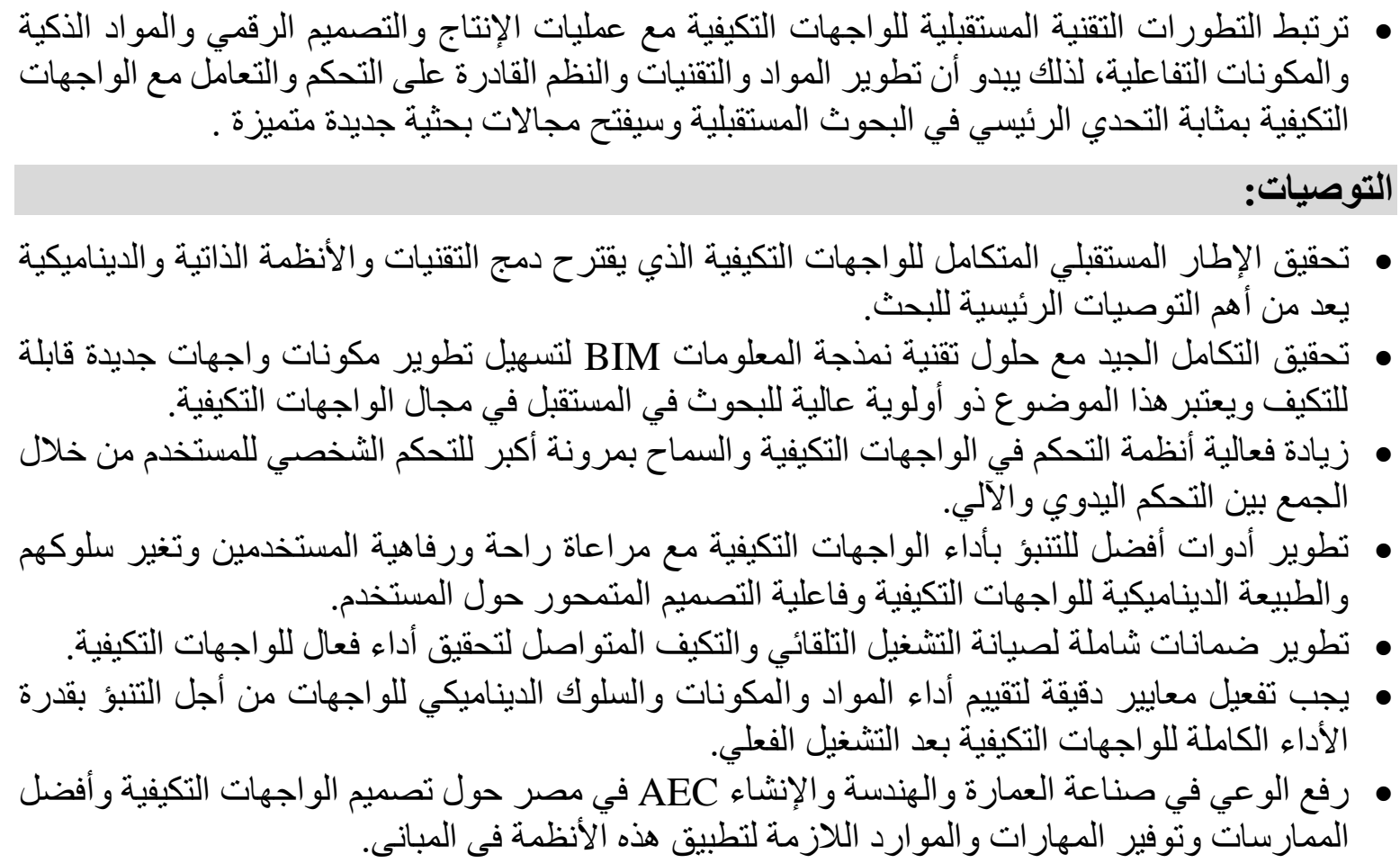

[1] Nakib, F.(2010). Toward an adaptable architecture guidelines to integrate adaptability in building. In Building a Better World: CIB World Congress,Pp276-286.

[2] Loonen, R. C., Trčka, M., Cóstola, D., \& Hensen, J. L. (2013). Climate adaptive building shells: State-of-the-art and future challenges. Renewable and sustainable energy reviews, 25, 483-493.

[3] Masoudi, S. (2018). Adaptive Façade Design for the Regulation of Visual Comfort. Delft University of Technology ,MSc. Architecture, Urbanism \& Building Sciences.

[4] Aelenei, D., Aelenei, L., \& Vieira, C. P. (2016). Adaptive Façade: concept, applications, research questions. Energy Procedia, 91, Pp 269-275.

[5] Romano, R., Aelenei, L., Aelenei, D., \& Mazzucchelli, E. S. (2018). What is an adaptive façade? Analysis of Recent Terms and definitions from an international perspective. Journal of Facade Design and Engineering, 6(3), Pp 65-76.

[6] Fortmeyer, R., \& Linn, C. D. (2014). Kinetic Architecture: design for Active Envelope. Australia: The Images Publishing Group Pty Ltd.

[7] Masri, Y. (2015). Intelligent Building Envelopes: Design and Applications. Proceedings of the International Conference on Building Envelope Design and Technology, Graz Advanced Building Skins 2015, Pp.37-46.

[8] Velikov, K., \& Thün, G. (2013). Responsive Building Envelopes: Characteristics and evolving paradigms. In: Trubiano, F., Design and Construction of High Performance Homes. pp. 75-92. London and New York: Routledge.

[9] Matin, N. H., Eydgahi, A., \& Shyu, S. (2017, June). Comparative analysis of technologies used in responsive building facades. In Proceedings of the 2017 ASEE Annual Conference Exposition, Washington, DC, USA Pp. 1-28.

[10] [Online]. Available: http://www.puretemp.com/pcmatters/tag/solar/page/11/. [Accessed 26 6 2020]. 
[11] [Online]. Available: https://www.e-architect.co.uk/denmark/kolding-campus-universitysouthern-denmark. [Accessed 236 2020].

[12] [Online]. Available: https://archello.com/project/the-shed-3. [Accessed 276 2020].

[13] Loonen, R. C., Trčka, M., Cóstola, D., \& Hensen, J. L. (2013). Climate adaptive building shells: State-of-the-art and future challenges. Renewable and sustainable energy reviews, 25, Pp 483-493.

[14] [Online]. Available: https://architizer.com/projects/closed-cavity-facade/. [Accessed 166 2020].

[15] [Online]. Available: https://www.archdaily.com/881511/bund-finance-centre-foster-pluspartners-plus-heatherwick-studio. [Accessed 166 2020].

[16] Loonen, R. C. G. M. (2010). Climate Adaptive Building Shells - What can we simulate? Architecture, Building \& Planning Faculty. Eindhoven, The Netherlands, TU Eindhoven. MSc: 230., [Online].

[17] Elkhayat, Y. O. (2014). Interactive movement in kinetic architecture. Journal of Engineering Sciences, 42(3),Pp 816-845.

[18] Fiorito, F., Sauchelli, M., Arroyo, D., Pesenti, M., Imperadori, M., Masera, G., \& Ranzi, G. (2016). Shape morphing solar shadings: A review. Renewable and Sustainable Energy Reviews, 55, Pp 863-884.

[19] Aelenei, L., Aelenei, D., Romano, R., Mazzucchelli, E. S., Brzezicki, M., \& Rico-Martinez, J. M. (2018). Case studies: adaptive facade network. Case studies: adaptive facade network.

[20] Castellón, E., \& Levy, D. (2018). Smart Windows Based on Liquid Crystal Dispersions. Transparent Conductive Materials: Materials, Synthesis, Characterization, Applications, Pp337-365.

[21] Fokaides, P. A., Kylili, A., \& Kalogirou, S. A. (2015). Phase change materials (PCMs) integrated into transparent building elements: a review. Materials for renewable and sustainable energy, 4(2), 6.

[22] Nazir, H., Batool, M., Osorio, F. J. B., Isaza-Ruiz, M., Xu, X., Vignarooban, K., ... \& Kannan, A. M. (2019). Recent developments in phase change materials for energy storage applications: A review. International Journal of Heat and Mass Transfer, 129, Pp 491-523.

[23] Decker, M., \& Zarzycki, A. (2014). Designing Resilient Buildings with Emergent Materials. Fusion - 32nd ECAADe Conference. Conference Proceedings 2014, Northumbria University, Newcastle upon Tyne, England, 10-12 September 2014, 2, Pp 179-184.

[24] Lopez, M., Rubio, R., Martín, S., Croxford, B., \& Jackson, R. (2015). Active materials for adaptive architectural envelopes based on plant adaptation principles. Journal of Facade Design and Engineering, 3(1), Pp27-38.

[25] [Online]. Available: https://www.archdaily.com/tag/shape-memory-alloys. [Accessed 86 2020].

[26] [Online]. Available: http://studiokimiis.com/envira/shape-memory-polymer-responsivearchitecture. [Accessed 86 2020].

[27] [Online]. Available: https://www.archdaily.com/590348/iaac-students-develop-a-passivecooling-system-from-hydrogel-and-ceramic . [Accessed 186 2020].

[28] Al Dakheel, J., \& Tabet Aoul, K. (2017). Building Applications, opportunities and challenges of active shading systems: A state-of-the-art review. Energies, 10(10), Pp 1-32.

[29] Svetozarevic, B., Begle, M., Jayathissa, P., Caranovic, S., Shepherd, R. F., Nagy, Z., ... \& Schlueter, A. (2019). Dynamic photovoltaic building envelopes for adaptive energy and comfort management. Nature Energy, 4(8), Pp 671-682.

[30] Santi, G., Bertolazzi, A., Croatto, G., \& Turrini, U. (2019). Vertical Turf For Green Façades: A Vertical Greenery Modular System Integrated To The Building Envelope. Journal Of Green Building, 14(4), Pp 111-132. 
[31] [Online]. Available: https://ethz.ch/en/news-and-events/eth-news/news/2019/08/kraftwerkvor-dem-fenster.html. [Accessed 206 2020].

[32] [Online]. Available: https://stateofbuildings.sg/places/tree-house. [Accessed 216 2020].

[33] [Online]. Available: http://skisoo.com/blog/en/2012/wind-arbor-on-the-facade-of-themarina-bay-sands-hotel/. [Accessed 216 2020].

[34] Elkhayat, Y. O. (2014). Interactive movement in kinetic architecture. Journal of Engineering Sciences, 42(3),Pp 816-45.

[35] Mazzucchelli, E. S., Aelenei, L., Gomes, M. D. G., Karlessi, T., Alston, M., \& Aelenei, D. (2018). Passive adaptive façades: examples from COST TU1403 working group 1. In Facade 2018-Adaptive: Adaptive Facades Network Final Conference Pp 63-72.

[36] Kolarevic, B., \& Parlac, V. (2015). Building Dynamics: Exploring Architecture of Change. New York: Routledge Press.

[37] Perino, M., \& Serra, V. (2015). Switching from static to adaptable and dynamic building envelopes: a paradigm shifts for the energy efficiency in buildings. Journal of Facade Design and Engineering, (3), Pp 143-163.

[38] [Online]. Available: https://www.dezeen.com/2014/03/20/tom-kundig-242-state-streetgallery-california/. [Accessed 216 2020].

[39] Sharaidin, K. (2014). Kinetic facades: towards design for environmental performance, Doctor of Philosophy (PhD), Architecture and Design, RMIT University.

[40] Harry, S. (2016). Dynamic Adaptive Building Envelopes-an Innovative and State-of-TheArt Technology. CS Volume 3 Number 2 (January - 2016).

[41] Attia, S. (2018). Evaluation of adaptive facades: The case study of Al Bahr Towers in the UAE. QScience Connect, 2017(2, Special Issue on Shaping Qatar's Sustainable Built Environment-Part I).

[42] [Online]. Available: https://www.designboom.com/architecture/aedas-al-bahar-towers/. [Accessed 216 2020].

[43] Grobman, Y. J., \& Yekutiel, T. P. (2013). Autonomous Movement of Kinetic Cladding Components in Building Facades. In ICoRD'13, Springer, India, Pp 1051-1061.

[44] [Online]. Available: https://solarfacades4architects.wordpress.com/. [Accessed 226 2020].

[45] Attia, S., Bilir, S., Safy, T., Struck, C., Loonen, R., \& Goia, F. (2018). Current trends and future challenges in the performance assessment of adaptive façade systems. Energy and Buildings, 179, Pp165-182.

[46] Taveres-Cachat, E., Grynning, S., Thomsen, J., \& Selkowitz, S. (2019). Responsive building envelope concepts in zero emission neighborhoods and smart cities-A roadmap to implementation. Building and Environment, 149, Pp 446-457.

[47] Lechner, N. (2015). Heating, cooling, lighting : sustainable design methods for architects. Hoboken, New Jersey :, John Wiley \& Sons, Inc.

[48] Bedon, C., Honfi, D., Machalická, K. V., Eliášová, M., Vokáč, M., Kozłowski, M., ... \& Portal, N. W. (2019). Structural characterisation of adaptive facades in Europe-Part I: Insight on classification rules, performance metrics and design methods. Journal.

[49] [Online]. Available: http://nedkahn.com/portfolio/ny-aquarium. [Accessed 246 2020].

[50] [Online]. Available: https://www.archdaily.com/877158/lava-breaks-ground-on-sculpturalenergy-tower-in-germany. [Accessed 306 2020].

[51] [Online]. Available: https://www.unstudio.com/en/page/11994. [Accessed 306 2020].

[52] [Online]. Available: https://www.archdaily.com/881511/bund-finance-centre-foster-pluspartners-plus-heatherwick-studio?ad_medium=gallery. [Accessed 166 2020].

[53] Attia, S., Lioure, R., \& Declaude, Q. (2020). Future trends and main concepts of adaptive facade systems. Energy Science \& Engineering ,Energy Sci Eng.,Pp1-18. 


\title{
The Future Of Adaptive Façades: Concepts, Technologies And Performance.
}

\begin{abstract}
:
Over the past decades, innovations and technological developments have contributed to improving the efficiency of many building elements such as envelopes, ceilings, windows, walls, etc. by translating dynamic term into functions, behaviour and response to building components, changing over time to adapt to dynamic internal user requirements on the one hand And with the effects and changing external climatic conditions on the other hand and The terms such as adaptive, responsive and dynamic buildings have emerged. Adaptive building facades provide significant improvements in energy efficiency and user's comfort through their ability to respond and change their behaviour according to internal and external influences through materials, components, and systems, which have evolved significantly at the present time and there is an increased interest in studying and developing its components and technologies, to achieve its multiple functions, adapt to its surrounding environment and the requirements of comfort and well-being of users, and it is expected to increase their innovative solutions in the near future, However With this development, there is a knowledge gap and a lack of research studies on the perception of its future trends, which requires a more comprehensive study on the future of adaptive facades.

The study investigates the current main concepts and trends of adaptive facades and studying the materials, components, systems and technologies for them, with a special focus on understanding how they perform through analyzing a set of study cases, to achieve the formulation of an integrated framework of concepts, systems and future technologies of adaptive facades that contribute to improving their performance and to achieve their full potential in adapting to the effects of the surrounding environment, energy conservation and improving user's satisfaction.
\end{abstract}

\section{Keywords:}

Adaptation, Adaptive Facades, Components, Performance, Control Systems. 